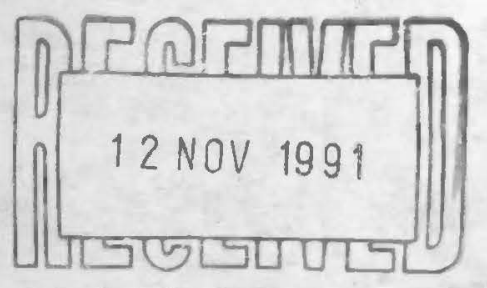

ACBAR

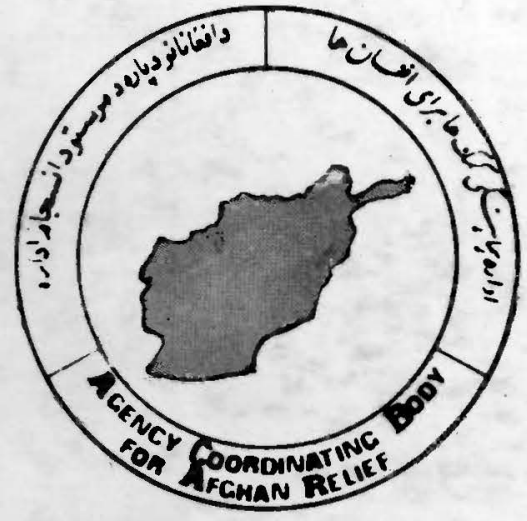

HEALTH

STANDARDS AND GUIDELINES

1991 
ACBAR

\section{HEALTH STANDARDS AND GUIDELINES}

Produced by:

Health Subcommittee

Agency Coordinating Body for Afghan Relief 2 Rehman Baba Road

University Town

Peshawar

Pakistan

Second edition - 1991 
The ACBAR Health standards and Guidelines is the product of months of research and consultation between NGOs, the UN and special consultants. In this respect it is probably the most ambitious technical document ACBAR has produced. But it should not in any sense be regarded as a textbook; rather, it is a set of recommendations specifically designed for implementing agencies in Afghanistan, taking into account local. conditions and availability of materials.

The following individuals gave a great deal of their time and energy to complete this document:

Dr Sharon McDonnell, wHO

Roberta Dworkin, HERC

Dr Gunnel Bagenholm, SCA

Dr Susan Welsby, UNICEF

Marianne Geuns, UNICEF

Dr Menno Bouma, MSH

Shon Campbell, MSF-B

Dr Maysam, IRC

Marie-Helene, AMI

Dr Haider, SCA

Dr Latif, MSH

Sajida Shah, ACBAR
Dr M.Mujibur Rahaman, wHo Mella Leiter, SCA Linda Tawfik, MSH Caroline Sergeant, UNICEF Dr Joe Carraher, UNHCR Dr Giorgio, ICD Dr Baluch, Dental Clinic Dr Akbari, IRC Dr Roshna, WHO Jeff Paulsen, CMC Marion Couldrey, ACBAR Avril caleb, ACBAR

ACBAR would also like to thank participants of the Health subcommittee for their valuable input.

Jon Bennett

Executive Director 
TABLE OF CONTENTS

Page

INTRODUCTION TO THE SECOND EDITION . . . . . . . . . 1

CHAPTER 1 - heALTH EDUCATION MEssages . . . . . . . . 3

I INTRODUCTION . . . . . . . . . . . 3

II HEALTH EDUCATION MESSAGES . . . . . . 3

Child Growth ............. . 3

Breast Feeding .......... 3

Immunization ............ . 4

Control of Diarrhoeal Diseases . . . . 4

Personal Hygiene and Environmental

Sanitation ........... . 5

Tuberculosis .........., 6

Acute Respiratory Infections . . : 6

Maternal Care ........... . 6

Malaria . . . . . . . . . . 7

CHAPTER 2 - HEALTH WORKERS AND TRAINING . . . . . . . 8

I BACKGROUND INFORMATION REGARDING HEALTH

WORKERS TRAINING AND UTILIZATION : • • • $\cdot 8$

A. Cross-border training where graduates

return to rural Afghanistan . . . . 8

B. Refugee training agencies ...... 8

II RECOMMENDATIONS . • . . . . . . . . . . 9

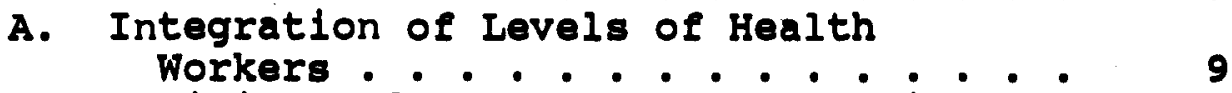

B. Tralning and Placement of community

c. Development of a Supervisory/

D. Strengthen the Curative system : : : 12

E. Importance of Primary Health Care . . . 13

F. Maternal Child Health is a Priority . - 14

G. Increased Focus on On-Site Monitoring . 14

H. Re-training and Refresher Training . . 15

III CMC/ACBAR/WHO INTRODUCTION TO HEALTH WORKER LEVELS AND TRAINING . . . . . . . . . . 16 
IV BASIC HEALTH WORKERS . . . . . . . . . . . 18

A. Primary Health Care .. . . . . . . . 18

B. Environmental Health . . . . . . . . 20

C. Nutrition . . . . . . . . . . . 22

D. Immunization ........... 23

E. Maternal Child Health . . . . . . . . 24

F. Treatment of Common Diseases and

Injuries . . . . . . . . . . . . 28

G. Health System Management Skills... 32

V MID-LEVEL HEALTH WORKERS . . . . . . . . . 34

A. Primary Health Care ... . . . . . 34

B. Environmental Health . . . . . . . . 36

C. Nutrition ......... . . . . 37

D. Immunization ........... 39

E. Maternal Child Health . . . . . . . 39

F. Treatment of Common Diseases and

Injuries .............. . 46

G. Equipment List . . . . . . . . . 53

H. Health System Management Skills. . . 55

Appendix 1 - Resources . . . . . 57

Chapter 3 - MATERNAL AND CHILd heALTH (MCH) . . . . . . . 58

I INTRODUCTION ............ 60

II MATERNAL AND CHILD HEALTH . . . . . . . . 60

A. Definition ............ 60

B. Goals and Objectives ........ 60

C. Approach for Planning . . . . . . . 61

III INDICATORS REGARDING MCH RESOURCES AND

FEASIBILITY . . . . . . . . . . . . . 62

IV DATA COLLECTION AND MONITORING . . . . . 68

V RECOMMENDATIONS FOR THE FUTURE . . . . . 68

vi CONCLUSIONS . . . . . . . . . . . . 69

Appendix 1 - The Road to Maternal Death . . 71

Appendix 2 - Classification of Health Facilities......... 72

Appendix 3 - Dal Kit . . . . . . . . 73

Appendix 4 - Issues for Training .... 74

Appendix 5 - MCH Training and Resource List 75

Appendix 6 - Health Levels . . . . . . 79

Appendix 7 - wHO Health Facility Questionnaire Form . . . . . 81

Appendix 8 - MCH care at different health lovels.......... 90 
CHAPTER 4 - CONTROI OF DIARRHOEAL DISEASES (CDD) • • • - 91

I BACKGROUND • . . . . . . . . . . . . . . . 91

A. Pakistan CDD Program . . . . . . . . 91

B. Afghan Refugee CDD Program, Pakistan . 91

C. Rural Areas CDD Program, Afghanistan . 92

D. Kabul CDD Program . . . . . . . . . . 93

II MANAGEMENT OF THE PATIENT WITH DIARRHOEA • 93

A. Assessment . . . . . . . . . . . . . . 93

B. Treatment Plans A, B, C........ 97

C. How to set up an ORT Corner in a
Health center.... . . . . . . 100

D. Treatment for other Problems . . . . 102

E. Use of Medicines for Children with 103

F. Antibiotic Treatment of Cholera and Shigella Dysentery . . . . . . . 104

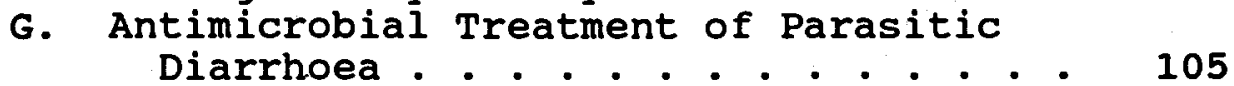

H. Protocol for Diarrhoea Outbreaks . . 105

III MANAGEMENT OF THE CDD PROGRAM . . . . . . 109

A. Storage of ORS Packets . . . . . . . . 109

B. A Recommended Breastfeeding Policy for

Health Facilities to Prevent Diarrhoee 110

c. CDD Monitoring Checklist. . . . . . . 111

IV SKILLS CHECKLISTS . . . . . . . . . . . . 114

A. Skills Checklist for Physicians... . 114

B. Skills Checklist for Mid-Level Health Workers . . . . . . . . . . . . 114

C. Skills Checklist for Basic Health workers . . . . . . . . . . . . 114

Appendix 1 - Resources . . . . . . . . 115

$\begin{aligned} \text { Appendix } 2 \text { - } & \text { Domestic or Small-Scale } \\ & \text { Chlorination of Water . . . } 117\end{aligned}$

Appendix 3 - Diarrhoea Patient Record Sheet 118

CHAPTER 5 - IMMUNIZATIONS - . . . . . . . . . . . . 119

I EXPANDED PROGRAM OF IMMUNIZATION (EPI) IN RURAL AREAS •. • . . . . . . . . . . . . . 119

II IMMUNIZATION SCHEDULE . . . . . . . . . 119

A. For Afghan Refugees in the Refugee
Camps in Pakistan . . . . . . . 119

B. For Rural Afghanistan . . . . . . . 120

III OVERVIEW OF COLD CHAIN . . . . . . . . . 121 
IV AN OVERVIEW OF COLD CHAIN IN AFGHANISTAN • 121

A. Transport . . . . . . . . . . . . . . . 122

B. Power Source . . . . . . . . . . . . 122

C. Warm Chain ............. 122

V RECOMMENDATIONS FOR IMMUNIZATION PROGRAMS

IN AFGHANISTAN . . . . . . . . . . . . . . 123

A. General . . . . . . . . . . . . 123

B. Cold Chain ............. 124

C. Immunizations..... . . . . . . 126

D. Training . . . . . . . . . . . 128

VI FUTURE NEEDS . . . . . . . . . . . . 128

Appendix 1 - organizations involved in the

Appendix 2 - Resources . . . . . . : . : 131

ChAPTER 6 - MALARIA . . . . . . . . . . . . . . 133

I MALARIA SITUATION IN AFGHANISTAN . . . . . 133

II MALARIA SITUATION AMONG AFGHAN REFUGEES IN PAKISTAN . . . . . . . . . . . . . . . . 134

III GENERAL PRINCIPLES OF MALARIA CONTROL . ... 135

A. Vector Control . . . . . . . . . . . 136

B. Environmental Management . . . . . 136

IV HEALTH EDUCATION . . . . . . . . . . . 139

A. Introduction . . . . . . . . . . . . 139

B. Prime Messages . . . . . . . . . 139

C. Communicating the Prime Messages .. . 140

V RECOMMENDATIONS . . . . . . . . . . . . . 140

A. Strengthening the Laboratory Network - 140

B. Strengthening Surveillance ...... 141

C. Enactment of a Drug Policy . . . . . . 142

D. Operational Research ........ . 144

E. Establishment of a Malaria Action

$\begin{aligned} & \text { Appendix } 1 \text { - Guidelines for Treatment of } \\ & \text { Malaria in Afghanistan . . . } 146\end{aligned}$

Appendix 2 - Resources ......... 150

CHAPTER 7 - TUBERCULOSIS . . . . . . . . . . . 151

I - BACKGROUND TO TB CONTROL PROGRAM FOR AFGHAN REFUGEES IN PAKISTAN ........... 151

II PRESENT SITUATION . . . . . . . . . . 152 
III REQUIREMENTS TO BEGIN A TB CONTROL PROGRAM IN AFGHANISTAN $\cdot \cdot \cdot \cdot \cdot \cdot \cdot \cdot \cdot \cdot \cdot \cdot \cdot \cdot 153$

A. Laboratory Facilities and Microscopist 153

B. Mid-Level Worker with appropriate training ............ 153

IV HEALTH EDUCATION . . . . . . . . . . 153

$\checkmark$ GUIDELINES FOR THE MANAGEMENT OF TB PATIENTS IN AFGHANISTAN . . . . . . . . 154

Appendix 1 - Agencies involved in TB control

Appendix 2 - Resources . . . . . . . 155

CHAPTER 8 - LABORATORY TRAINING . . . . . . . . . 157

I INTRODUCTION . . . . . . . . . . 157

II CURRENT SITUATION . . . . . . . . . 157

Appendix 1 - Examinable List for Field Microscopists . . . . . . 159

Appendix 2 - Laboratory Equipment for use by Field Microscopists . . . 161

Appendix 3 - Ten Agencies participating in Laboratory Training Coordination ........ 166

Appendix 4 - Resources .. . . . . . . 167

CHAPTER 9 - DENTAL WORK . . . . . . . . . . . . . 168

I INTRODUCTION . . . . . . . . . . 168

II SKILLS CHECKLIST FOR MID-LEVEL DENTAL WORKER •................. 169

III CURRICULUM FOR MID-LEVEL DENTAL WORKER TRAINING $\cdot . \cdot \cdot \cdot \cdot \cdot \cdot \cdot \cdot \cdot \cdot \cdot \cdot \cdot \cdot \cdot 174$

IV EQUIPMENT LIST FOR MID-LEVEL DENTAL WORKER 177

V LIST OF EXPENDABLE MATERIAL FOR MID-LEVEL DENTAL WORKER . . . . . . . . . . . 178

VI REFERRAL FORM FOR MID-LEVEL DENTAL WORKER • 180

VII SIMPLE RECORDING SHEET . . . . . . . . 181

VIII SKILLS CHECKLIST FOR BASIC DENTAL WORKER/ DENTAL FIRST AIDER . . . . . . . . . . 183

IX CURRICULUM TOPICS FOR BASIC DENTAL WORKER/ DENTAL FIRST AIDER 
$X$ LIST OF EQUIPMENT, MEDICINE AND STATIONERY FOR BASIC DENTAL WORKER . . . . . . . . 185

XI REFERRAL FORM FOR BASIC DENTAL WORKER OR FIRST AIDER . . . . . . . . . . . . 186

Appendix 1 - Resources . . . . . . . . 187 CHAPTER 10 - SANITATION/WATER SUPPLY . . . . . . . 188

I PAKISTAN . . . . . . . . . . . . 188

II AFGHANISTAN . . . . . . . . . . . . 188

III RECOMMENDATIONS . . . . . . . . . . 189

Appendix 1 - Organizations involved in Sanitation and Water Supply Projects.......... 191

Appendix 2 - Resources ......... . 192

CHAPTER 11 - EgSENTIAL MEDICINES . . . . . . . . . 194

I PHYSICIAN LEVEL LIST . . . . . . . . . 194

II MID-LEVEL HEALTH WORKER LIST . . . . . . \& 197

III BASIC HEALTH WORKER LIST . . . . . . . 201

Appendix 1 - Estimation of Numbers for Supply of Mid-Level Health Workers in Cross-Border Medical Programs . . . . 203 


\section{INTRODUCTION TO THE BECOND EDITION}

ACBAR's Health standards and Guidelines represents a community consensus regarding medical and health topics. It reflects many years of work by committed individuals from a variety of organizations both within Afghanistan and Pakistan.

Historically, there were two agencies coordinating health care for the Afghan population. The first was UNHCR working within the refugee camps in cooperation with NGOs and the Pakistan Department of Health. The second was coordination for Medical committees (CMC) - a coordinating agency for cross-border médical groups working within Afghanistan.

The Agency Coordinating Body for Afghan Relief (ACBAR) in Peshawar, Pakistan, and the Southern \& Western Afghanistan and Baluchistan Association for coordination (SWABAC) in Quetta, Pakistan, began in the summer of 1988. These sister agencies arose out of the awareness of the critical need to establish even greater coordination between the multiple partners working in Afghan development and relief.

The ACBAR Health subcommittee was and remains an open forum. All interested persons of any nationality, organizafion, or philosophical belief are welcome. It could never be restricted solely to ACBAR members. It is important for the integrity of the :vork that involvement in the process include as many individuals' input as possible.

It was within the framework of the ACBAR Health subcommittee that the first edition of ACBAR's Health standards and Guidelines was brought together by general agreement and formulated for implementation in the entire Afghan health sector. It was first published in the summer of 1989. A year later it was agreed that some changes and revisions were needed as it became possible to do more work in the health sector inside Afghanistan. This in turn means that standards and guidelines need to remain appropriate to prevalling conditions and that agencies be encouraged to follow these when setting up projects to ensure that correct and standardized procedures are followed. It will then be easier to set up a national program when this becomes possible. In addition to changes and revisions made to existing sections, it was agreed to add two new sections, one on Control of Diarrhoeal Diseases (CDD) and the other on Dental Work. 
It will be noticed that chapters vary considerably in length. This is because some areas of health already have specific guidelines for work in Afghanistan and, in such cases, these have been given as a reference. In other areas (such as Maternal and child Health (MCH), Control of Diarrhoeal Diseases (CDD), and Malaria), guidelines for work in Afghanistan have not yet been prepared and these chapters therefore contain more detail and are consequently longer.

The revision, however, proved not to be an easy or quickly completed task. Work in various parts of the health sector is in a state of change and sections could not be finalized or were found to need further revision, making it difficult to reach a point where the revision could be considered 'ready for publication'.

The second edition is therefore revised and updated as far as possible but with the understanding that changes continue to take place in the health sector and will therefore be necessary in these guidelines.

To improve the layout of the first edition and to make sections easier to find, chapters and appendices have been put together rather than being separate.

Bibliographies of resource materials form appendices to most chapters. These include materials available at the IRC, Health Education Resources Center (HERC), the library of Coordination of Medical Committees, the ACBAR Resource and Information centre (ARIC) and individual agencies. New resources are constantly added to all of these; complete, up-to-date lists of current holdings on specific topics may be requested from each of them. 


\section{CHAPTER 1 - HEALTH EDUCATION MEgBAgEs}

\section{INTRODUCTION}

The prime messages have been revised by utilization of ACBAR's Health Standards and Guidelines, UNHCR's Guidelines for Health Education, and HERC's list of messages culled from UNHCRsponsored prime message meetings in the past. Over the last two years, wording has been modified, message order changed, and in some instances messages added or deleted. More specifically, the order of the breast feeding messages has been changed for better image presentation; additional messages have been attached to the section on personal hygiene and environmental sanitation and the malaria messages, in certain instances, were rewritten and the order of the messages changed.

\section{PRIME MESSAGES}

\section{CHILD GROWTH}

Breast milk alone is the best possible food for the first four months of the child's life.

By the age of four months, the child needs other foods in addition to breast milk.

By the age of one year, the child should eat all the foods the family eats, made soft.

By the age of one year, the child needs to eat at least four times a day.

During and after an illness, a child needs extra food and extra meals.

Children should be weighed regularly until they are two years old. If there is no weight gain for two months, something is wrong.

\section{BREAST FEEDING}

Breast milk alone is the best possible food and drink for a baby in the first 4 months of life.

Babies should start to breast feed immediately after birth.

A mother who is breast feeding should eat for two. 
Breast feeding should continue up to two years of age.

Never use bottles as bottle feeding can lead to serious illness and death.

Continue breast feeding during the next pregnancy.

\section{IMMUNIZATION}

A child who is not vaccinated is more likely to become sick, disabled and die.

Childhood vaccination protects against six dangerous diseases: polio, measles, whooping cough, diphtheria, tuberculosis and tetanus.

All vaccination must be started as soon as possible after birth and should be completed in the first year of the child's life.

Every woman should be fully vaccinated against tetanus to protect both herself and her babies from tetanus.

It is safe to vaccinate newborn babies, sick children and pregnant women.

Vaccination cards are important. They must be kept safely by the family. They should be brought with the woman and child on every visit to the clinic or health worker.

Infants must complete the full course of vaccination, otherwise the vaccine may not work.

After vaccination the child may develop a fever or rash or a small sore. These are not dangerous problems and parents should not worry about them.

\section{CONTROL OF DIARRHOEAL DISEASES}

Diarrhoea can kill chilaren by draining too much liquid from the body.

A child with diarrhoea should be given extra fluids frequently as soon as it begins and as long as it continues. When a chlld has diarrhoea, it is important to continue breast feeding.

A child with diarrhoea needs food. Bottle feeding and soothers are bad and lead to diarrhoea. 
Trained help is needed if diarrhoea is more serious than usual.

After the diarrhoea stops, a child needs extra food every day for at least a week.

Medicines other than ORS should not be used for diarrhoea, except on medical advice.

The following can help prevent diarrhoea: breast feeding, using latrines, keeping food and water clean and covered, washing hands before touching food, washing hands after using latrine.

\section{PERSONAL HYGIENE AND ENVIRONMENTAL SANITATION}

Faeces contain microbes which cause diseases.

People can swallow these microbes if the microbes get into water, on to food, and on to hands.

Flies and rodents carry microbes that cause disease.

Diseases can be prevented by washing hands with water and soap after defecation and before touching food.

Diseases can be prevented by washing dishes and cooking utensils with soap and water.

Diseases can be prevented by using safe, clean latrines.

Diseases can be prevented by using safe, clean water for drinking.

Diseases can be prevented by regular washing of the body and clothes.

Diseases can be prevented by keeping food clean.

Diseases can be prevented by burning or burying household refuse and proper disposal of waste water.

Prevent disease. Sweep up rubbish in your house and yard.

Prevent disease. Put the rubbish in a covered container. 


\section{TUBERCUIOSIS}

Tuberculosis is spread by air when a person with pulmonary tuberculosis coughs or spits.

People should cover their mouth when they cough.

People should spit into a spittoon.

Persons with cough, chest pain or blood in the sputum should go to the BHU repeatedly for sputum check.

Treatment of tuberculosis is very long.

Treatment must continue even after symptoms have gone.

Only treatment taken regularly every day cures TB patients and stops the infection from spreading to others.

\section{ACUTE RESPIRATORY INFECTIONS}

If a child with a cough is breathing more rapidly than normal, the child is at risk and medical attention should be sought immediately.

A child with a cough or cold should be helped to eat and to drink plenty of fluids.

Children that are breast fed, well nourished and fully immunized are less likely to get pneumonia.

\section{MATERNAL CARE}

The risks of child birth can be reduced by going to the health worker for check-ups during pregnancy.

All women should receive immunization for tetanus prior to delivery.

A trained person should assist at every birth.

A woman needs more food during pregnancy unless she is already over-weight.

Spacing pregnancies at least two years apart and avoiding pregnancies below 18 and above 35 years greatly reduces the dangers of child bearing.

All women need iron supplementation during pregnancy and for at least one month after delivery. 


\section{MALARIA}

Malaria is transmitted by mosquitoes.

Mosquitoes bite, particularly at night when you sleep.

Adults and children with malaria get very ill with fever, shivering and sweating.

Children and adults with a fever should go to the BHU for a blood smear to be taken.

A person with malaria must take all the medicine the doctor has given. If all the pills given are not taken, you can get ill again.

Mosquitoes can be killed by insecticide spray on walls of houses.

Mosquitoes breed in stagnant water. It is dangerous to have stagnant water close to your house.

Pools with stagnant water should be filled or drained.

Everyone especially children should be protected from mosquito bites particularly at night. 
I. BACKGROUND INFORMATION REGARDING HEALTH WORKERS TRAINING AND UTIITZATION

There have been very different types of training by numerous agencies occurring in the health sector. Anticipating shifts of population across the border has led all training groups and those involved in health care to examine the potential and current health care system as well as any changes needed within their programs. In an attempt to standardize and provide guidelines for training and health workers development, it is important to understand that:

Each training group has functioned within a set of assumptions regarding the circumstances where their health workers would be working. In Pakistan there are basically two broad types of agencies providing training for Afghans. Simplified, these are described here.

A. Cross-border training where graduates return to rural Afghanistan

Cross-border training has prepared workers for a circumstance in which they will be somewhat or completely autonomous. Initially, many of them started by providing emergency medical assistance in a war situation. These workers were introduced for training by their communities or parties. After graduation they would return as salaried staff of the NGO or party, yet considered representatives of the community who supported them. The graduates were linked with the NGo for re-supply and re-training. Most of them function alone with minimal supervision and no reterral network. Over time, as more areas have become free and statistlcs were avallable regarding the ituation within Afghanistan, programs have changed to. Include more akilis relating to a primary hoalth care model and less emphasis on trauma care. However, most of the workers are too busy providing the basio health services to be more than superficially Involved in proventive programs or community aducation.

\section{B. Refugen training regncies}

In the refugee camps the focus of the training involved a circumetance with a more complete health care syotem. The utilization of numerous Pakletani (and some Afghan) calarlod health care workers In curatlve services allowed the training of other types of workers whose curriculum could concentrate on appropriate referral, community education, and proventive health. This syetem could 
provide the motivation, support and receive the benefits of volunteer and preventive health workers.

What is important to note here is not that one type of training or focus is necessarily better than the other. Both are needed. Both must be supported. However, in almost no circumstances do trainees from cross-border programs work with trainees or graduates of refugee programs. Additionally, heallth workers have a distressing lack of information about other levels and types of health workers. This has already proven problematic in both the refugee camps where public health workers or the basic health unit staff may not utilize each others' services appropriately, as well as inside Afghanistan where workers are placed in situations beyond or below their skill level.

\section{RECOMMENDATIONS}

The recommendations from this committee for health care system development and training priorities are:

A. Integration of levels of health workers Address the need to integrate all areas and levels of
health workers during repatriation.

what is crucial is that the curative workers (physicians and mid-level) who are trained in more lengthy education programs and are also considered the "experts" regarding health care see both the need and importance of the preventive workers and thereby provide support for their work. The appropriate utilization of referral channels and curative services by preventive health workers will also need to be supported. This relates to the concept of horizontal program design rather than vertical programs. In the evaluation of refugee programs by both SCF-UK and IRC, it was found that the various workers were not well integrated. This problem manifested itself in many ways. When efforts were made to integrate workers through a variety of mechanisms there was shown to be very positive results in both morale of workers as well as epidemiologic evidence of increased program effectiveness in terms of disease control.

There is a great concern that many important resources will be lost during repatriation. The pre-war system involved physician level management of other health workers with a great community respect for curative services and medications. During repatriation, the absorption capacity of public health workers, volunteer workers and other non-curative workers will be very greatly assisted if the physicians and other curative 
personnel are aware of the support, supervision, training, and importance of these workers. The system must understand what the workers are and what can be expected of them.

Suggestions for actions regarding meeting these needs included:

1. Many of the refugee based groups have offered to collaborate with the cross-border programs in the use of their facilities for training and the recruitment of their trained health workers for upgrading/re-training for the cross-border circumstances.

2. Have programs work together more during training. For example, cross-border mid-level workers could spend some of their training time in the camps becoming familiar with CHWs, Dais, CHSs, etc.

3. Coordination of training materials by both refugee and cross-border programs. These include materials for health worker and community education. Recently WHO has provided assistance to this by the support of the health education posters for clinics within Afghanistan with the prime messages of BHC. This matches with the longstanding UNICEF and UNHCR programs ongoing in the camps.

4. Physician and mid-level re-training involving the following categories:

a. utilization and support of other levels of health care workers

b. medical/health management and administration

c. preventive/public health

d. teaching methodology

e. utilization of standard/essential medication via kit system

5. Provision to health care workers who have been, or will be, working within Afghanistan in curative services; with the curricula of CHWs, Dais, and outreach workers. These health care workers are requesting such services and support staff. However, they should be given a clear idea of the skills and support of these workers.

6. Active role on the part of groups training or working within the health field to provide information about workers and facilities within Afghanistan. Refugee groups who have workers 
repatriating could seek the information needed to provide these individuals with available health systems in the area to which they are returning. The groups supporting workers or systems within Afghanistan need to assist this process by clearly defining what is in place and cross-referencing it with monitoring information. It would be very useful to follow this process over time.

B. Iraining and Placement of community Health Workere

The training or placement of community Health Workers whould not proceed at this time - elther in the context of repatriation or within Afghanistan - until the propor Ing agency can wow that the necessary supportive. management, and supervisory mechanisme are in place.

The rather strong statement regarding CHWs can be generalized omewhat to all health workers and reflects the actuality of the current conditions. The needs of all health workers but most particularly those at lower levels is for a high level of support and supervision. The current piecemeal health system within Afghanistan suffers greatly from the lack of supervision. Adding another level to absorb and support will not address the most basic and important problem.

To consider the placement/training of community health workers within Afghanistan, the initial focus needs to be on the infrastructure to support them. The lessons learned both within the refuge camps as well as Internationally support this decision.

There are certain services which cannot be left to a voluntary sytem. These include outreach for malaria, $T B$ and maternal child carei vaccination, esential medication supply, and health education. However, the services of volunteers would be an important addition. There is a precedent for voluntary assistance within Afghan society. What is considered crucial is that this precedent be motivated and supported by every means possible.

To assist this goal there should be educational programs focusing on both sources of support for voluntary services: 1 . the community

2. the health workers

At this time it is viewed that even if the volunteer workers do not have immediate placement within a system of support they will have an lmpact on the health and well-being of their immediate family and perhaps into the community. 
c. Development of a supervisory/Support structure

The focus of training should be towards the development of a supervisory/support structure for all health workers within Afghanistan.

The focus of the wHO/ACBAR task force on health workers development over the last year was to create guidelines for the training, recruitment/selection, support and management of supervisors to accompany the above recommendations. These guidelines are available upon request from WHO or ACBAR.

D. strengthen the curative system

Within Afghanistan the current needs are for strengthening the curative system in order to establish a base for preventive and primary health care programs referral and support.

The initial focus shall then be on the support and strengthening of the health care infrastructure as it relates to:

1. Health workers assessment for particular levels of training related to certain regions of Afghanistan. The graphic representation of the health workers based on geographic region within Afghanistan is included within these guidelines. The specific workers needs are very much related to the region under consideration.

2. Establishment and upgrading of facilities based on WHO criteria. The definition of health facility types has been agreed upon within the community and is provided in these guidelines.

3. The establishment and linking of a referral system. This must be done both within the training programs as well as on-site in the community.

4. Intersectoral components as they contribute to PHC network. For example, in Afghanistan the establishment of a road system as it relates to expansion of catchment area and access to avallable services or the supply of safe drinking water, education and food cannot be underestimated. Within Afghanistan the managers, supervisors and monitors working in other sectors may also provide assistance to the health system.

5. Infrastructure support - primarily in the areas of management and supervision, logistics and distribution as well as evaluation. 
E. Importance of Primary Health Care

All training programs shauld continue their current trend of increasing the amount of time on topics related to primary health care. The use of the skills checklists for all agencies providing training is strongly encouraged.

The content of the training courses for workers within Afghanistan has been increasingly shifting to PHC and community based health care. This is reflected in the new skills checklist for every level of health care worker.

Every level of health worker must be integrated into the model of health education and prevention as well as other components of PHC. The supervisors and supporters of lower level workers must also be trained in the skills and methods for preventive health. This includes midlevel as well as physicians.

For prevention to be accepted by the community, one of the most important variables is the health worker's acceptance and support by the community. To change behaviors is a very difficult task. If the community respects the individual and supports them, the messages are much more likely to be acted on. It is because of the complexity and importance of such variables that in cross-border work the individuals have generally been selected by their community and sent to the committees for training.

What is important to understand is that the lowest level of worker described in the skills checklist is the basic health worker. This refers to the results of experiences regarding community acceptability. The paid worker who is acceptable, functional, and possibly sustainable by the community as well as the NGO system within Afghanistan is important to consider. The integration of the volunteer worker (CHW) is very problematic, and at this point should be considered an issue deserving more detailed study rather than creating more of them to be absorbed. The lack of even a rudimentary infrastructure to support critical basic health programs, supply logistics and supervision is currently a very important factor in the support and training of primary health care workers. The training programs which have focused on these workers without exception have questioned the sustainability of this level. The other important consideration is the fact that priority health issues cannot be left to a volunteer or ad hoc system. The consensus at this point is to examine actively the role of various levels of health care workers within a 
priority based system. The volunteer workers currently have no central role without the rest of the system to support them.

F. Vaternal child Health is a Priority

Maternal child Health is a priority that must be addressed in numerous ways by the training groups for the health programs within Afghanistan.

The necessity for provision and support of female health care workers is unquestioned. However, with such low numbers available, there must be the recognition that there is a need for all health care workers to be trained in women's health issues. It has been shown by cross-border experience that male health care workers with appropriate training can be very effective with regard to prevention and treatment of the major causes of female morbidity and mortality. All agencies should demand basic competence in regard to recognition of risks and problems which can provide for appropriate health worker behaviors.

In certain areas there are skills that can only be accomplished by female health worker especially at lower level of health care providers, i.e. below MD. These skills are listed with certain ones marked into divisions for male or female health workers. There is definite need for the participation of refugee groups which have historically been most involved in this area. None of the training groups believe that $\mathrm{MCH}$ care is easily or well addressed generally and in cross-border projects in particular. There is need however to look forward and describe to some extent planned projects and 1deals.

G. Increased Focus on on-site Monitoring

There should be increased focus on on-site monitoring within Afghanistan. This must include the coordination of monitoring efforts by NGOs and UN agencies currently ongoing.

The lack of this information results in two significant problems:

1. The training provided may not be appropriate for the conditions in which the health worker will be functional.

2. Poor distribution of health care resources (workers and facilities) within Afghanistan. Health programs and profects tend to be clustered within Afghanistan. Certain areas of Afghanistan are saturated with health workers of many programs at 
the same or different level while other areas are devoid of health care workers of any type. The discrepancy between areas must be addressed in planning immediately, before instituting new programs or facilities or further recruitment for training. Comparison on a provincial, district and program level regarding distribution and access as well as need must.occur before new programs are added. An important component relating to this is the lack of cross-referencing monitoring and survey information with regard to health worker placement. Too many programs report workers in place that are not actually found on monitoring reports. The response by programs (if they get it at all) to this information is quite variable. This reflects poor coordination particularly over the past years as well as the lack of correlation between survey and monitoring reports with the information reported by programs. This has become more evident recently with the increase in monitoring reports available from the UN and other sources. It is generally useless to plan without this cross-relating of monitoring information. Certain programs are notable in their high profile on paper and low profile in the field. This is also true of certain levels of workers. Generally the mid-level workers are more likely to be at least in place near where they are expected. Physicians and basic health workers have the least likelihood of actually being where they are anticipated.

The focus of the ACBAR and SWABAC health subcommittees should increasingly be on planning and regional coordination of activities within Afghanistan in order to address problems related to distribution of resources and coordination.

H. Re-training and Refresher Training

The cross-border training groups in collaboration with the refugee aroups need to focus increasingly on retraining and refresher training rather than initial training.

All monitoring reports and assessment within Afghanistan have named this as a top priority.

This is the time for focusing on quality, and upgrading of the already trained and active health workers inside Afghanistan to the standard level of skills and knowledge recommended for that specific type of health worker should be considered as a priority. This links with the concept of standardization of the levels of health workers. 
The training division of WHO, in collaboration with the different training groups, is in the process of preparing the core topics as well as the skills checklist for refresher training of mid-level health workers. A similar process may be started for other levels and types of health workers. The bank of questions prepared by the wHO health worker standardization committee may assist the training groups in development of screening (selection) and evaluation tools for use by refresher courses. This will also help the community in development of a collaborative refresher and retraining program scheme that includes health workers at both ends of the curve.

It is considered a very significant problem that much of the training does not address the current or cultural practices of the Afghan population. Therefore, the content of the training does not address community belief or build on their practices.

To address this it is suggested that:

1. This type of information be collected and provided.

2. This information be incorporated within the training of health care workers and within the ofientation for the trainers (many of whom often come from overseas).

III. CMC/ACBAR/WHO INTRODUCTION TO HEALTH WORKER LEVELS AND TRAINING

The following is a breakdown of categories or levels for health workers. This has evolved after recognition of the need to differentiate between the various types or levels of workers who have been trained by different programs for inside Afghanistan. The "skills checklist" included is the definition of minimal skills necessary for each category of health worker. The process of definition has included most of the cross-border and refugee training programs, as well as international resources, in an attempt to reach a consensus regarding standard levels of health care workers for inside Afghanistan.

The continuation of this process should serve two purposes. First, to define the topics where re-training or refresher training are necessary for the health workers. Second, to result in a competency based examination with subsequent certification in an attempt to standardize medication supply and salaries in the emerging health system. 
It must be understood that for every level of health care worker defined there is also a drug and equipment supply list which is based on the skills checklist for the different types of health workers. To change this system or type of supply would affect thousands of workers within Afghanistan.

The goal is for continued development of health care workers into an integrated system based on the needs within Afghanistan. For the workers already trained this can provide quality assurance and a place within an evolving system. For training programs in progress or being initiated this is offered as a curriculum guideline. The skills and types of training needed are based on eleven years of experience by health workers at all levels within Afghanistan.

It has become crucial that each health worker have a. defined place within the system. Each must know where his/her job fits in relationship to all health care workers and in relation to the community.

It is the goal that each worker will be evaluated by competency based examination at the level for which he/she is applying for supply, certification, refresher training. The design of the examination will cover the following subcategories as is appropriate for their level:
A. Primary health care components and teaching skills
B. Signs and symptoms
C. Diagnosis and differential diagnosis
D. Treatment - management, including pharmacology

The questions are being designed to address each of these areas. It is planned that through wHO and inter-agency coordination a competency evaluation exam will be designed and implemented for all health care workers.

The training manuals utilized by the various agencies for the health workers to a large extent are an outgrowth of the skills checklists included here. Additionally, a field manual text has been written for the mid-level worker to accompany this skills checklist and the medicine supply list. The manual defines standard treatment protocols as adopted by the training programs. This is available from coordination of Medical committees (CMC). This manual is currently in use by UNHCR and most of the cross-border medical groups.

It is suggested that anyone interested in the training of health workers for Afghanistan refer to these manuals which are available in local languages and may be obtained at the WHO offices or the Health Education Resources center (HERC/IRC). 
The training of health workers based on these skills checklists suggested here can be extrapolated into specific job descriptions. This represents the beginning of a health system which meets the most pressing needs and upon which can be built more extensive systems as the infrastructure and policy base are available.

This list is by no means all inclusive of the types of health workers that will be necessary for the future of Afghanistan.

The following levels are discussed:

1. Basic Health Worker

2. Mid-level Health Worker

3. Laboratory training

4. Dental training

5. Vaccinators

6. Supervisor training

7. Nurses

8. Outreach workers

9. Traditional birth attendants (TBAs)/midwives

10. Sanitarians

For some of these workers, complete skills checklists are included and for others, simply descriptions of their roles at this point is provided.

IV. BASIC HEAITH WORKER

Introduction

Primarily a non-diagnostic role with emphasis on prevention and teaching and referral of disease to higher level of health care provider. Basic health workers are additionally responsible for recognizing and treating specified common clinical problems. These health workers have a major role in community education both by active teaching and paseive modeliing of behaviors.

\section{A. Primary Bnalth care}

For Basic Health Workers the ekills of teaching and prevention have been clted as their primary intervention. It is then very difelault and crualal akille that are placed on the shoulders of the lowent leyel workers amidst a soclety that firmly belleves in the use of medications. It is the BHW who must become the believer and toacher of these messages so that they can be effectively carried to and acted on in the community. Therefore, the BHW curriculum must reflect the following points: 
1. Health Education/Teaching Methodology

It is assumed that the basic health workers must be able to teach the following topics:
a. Use of prescribed medications.
b. How to use and make ORS.
c. Correct disposal of human waste/personal hygiene and hand washing.
d. Identification of safe water sources or how to make water safe.
e. Weaning practices and identification of available and quality foods.
f. Prevention of malaria and TB, as well as most common diseases in the community.
g. The role of vaccination in health promotion.
h. Protection of a wound from infection.
i. Referral resources for certain types of services. Where to go for $T B$ treatment and other related problems.
j. Follow-up instructions regarding referral or
k. further management
1. Dietary needs for pregnant and lactating women.
m. Dietary supplementation or practice during
n. Safe food use and preparation.
0 . What is the meaning of the MUAC measurement?
p. Inter-relation of illness and malnutrition.
q. Preparation of super-porridge (Ferni or Leti).

skills

1. Describe target behavior. What do you want them to know or do at the end of the teaching or training session?

a. Ability to make a teaching plan and follow this plan.

b. Identify teaching priorities for individual, family or community.

c. Limit health discussions to one or two topics during a visit.

2. Define what is the level of knowledge/attitudes/ practices in the target group/individual.

a. Ability to teach using language commonly used by village people, or adapted to the level of the learners.

b. Develop health education approaches which build on existing health practices and beliefs. 
3. Recognize/describe what teaching resources are available.

4. Decide/identify what teaching method is most useful in the specific circumstance.

Teaching methods to be taught for either individual or groups include:

a. Talking listening.

(lecture)/questioning/discussion/

b. Demonstration.

c. Use of visual aids such as posters, quotes from the Qoran.

Teaching methods to be taught for groups include:

a. Role playing.

b. Obtaining or checking community and/or authority consensus on a topic and the audience.

Note: It is believed that the worker will do relatively less group teaching. However, it should be taught and modelled within his/her training so that concepts can be generalized and practice with supervision can be experienced.

5. Demonstrate evaluation of teaching objectives. Has the person learned and met the target behavior? For example can the learner demonstrate how to make ORS correctly?

6. Motivating patients/family/community - use of community leaders and influential people as well as individual factors that increase motivation towards healthy behavior.

B. Environmental Health

This person is not considered to be the basis of the program but a supporter. The system and environmental problems will vary with specific regions and areas. Therefore only general principles should be taught.

The general principles include:

1. Assessment of their area with regard to practices for sanitation, sources of drinking water, community perception of whether or not there is a problem with some aspect of environmental health. 
2. From their knowledge of the causation and basis of disease, combined with the assessment mentioned above, the worker should be able to provide:
a. A problem list specific for his/her area.
b. Community motivation specifically directed based on problem identification and understanding of community.
c. : Delivery (education) and modelling of "prime messages".

\section{Skills}

1. Ability to assess environmental risk factors within their community.

2. Community motivation and interaction which is appropriate to the environmental health problems identified in their area.

3. Recognition, prevention and treatment of diseases resulting from environmental hazards created by inappropriate disposal of waste and poor hygiene.

4. Recognition, prevention and treatment of disease resulting from poor food handling.

5. Vector control - includes personal avoidance of vectors, vector eradication and control by garbage and rubbish disposal, reduce breeding sites of mosquitos and encourage proper keeping of animals.

6. Accident prevention - mine education and safety in living quarters i.e. stoves, crowding, etc.

7. Connect the treatment of the individual patients' problems with the necessary public health teaching that is needed.

8. Provide health education regarding "prime messages".

9. Recognition and prevention of diarrhoea/dehydration as well as treatment with oral Rehydration solutions (ORS).

10. Recognition and prevention of malnutrition as a result of environmental factors. 


\section{c. Nutrition}

\section{Skills}

1. Ability to describe the signs of a healthy, growing child.

2. Assessment: Describe or demonstrate an ability to gather the following kinds of information:
a. Nutritional resources in the community.
b. Beliefs relating to nutrition.
c. Identification of risk groups.

3. Recognition/screening of childhood malnutrition in the community and the individual utilizing the MidUpper Arm Circumference tape (MUAC). All health care workers must measure and record MUAC for all children visiting the clinics between the ages of 1-5 years. It is additionally recommended that health care workers be encouraged to use MUAC in community screening efforts and with vaccination campaigns.
a. Ability to use a MUAC tape correctly.
b. Ability to make a MUAC tape from locally available materials.

4. Ability to demonstrate obtaining a nutritional history from a patient/family.

5. Utilization of the information obtained to discern if there is a problem and what the root problem is, as related to:
a. Poor use of available food.
b. Lack of food in family and community.
c. Illness.

6. Ability to describe locally available foods and substitutes. This includes dietary advice to provide food supplementation or caloric reduction.

7. Teaching of the following:
a. Breast-feeding - this includes avoidance of bottles.
b. Weaning practices.
c. Dietary needs for pregnant and lactating women.
d. When and how to use and make ORS.
e. Dietary supplementation or practice during illness.


f. Safe food use and preparation.

g. What is the meaning of the MUAC measurement?

h. Inter-relation of illness and malnutrition.

i. Preparation of super-porridge (Ferni or Leti).

8. Teaching with regard to appropriate feeding during illness, and for health maintenance - weaning advice, breast feeding. Also basic dietary counselling.

9. Demonstrate the preparation of super-porridge (Ferni or Leti).

10. Prevention, recognition and treatment of the following problems as they relate to nutritional risk or compromise:
a. Anemia - recognition and treatment.
b. Goiter - recognition and referral.
c. Vitamin A deficiency - recognition and advice on foods.
d. Obesity - advice.
e. Measles - recognition with treatment of uncomplicated cases.
fastrointestinal diseases - particularly
diarrhoea/dehydration.

11. Ability to describe cultural or community practices or conditions which create "risk" to nutritional status. This includes the ability to identify practices that promote improved nutrition.

D. Immunization

Skilis

1. Educate the community as to why, how, when and where children and pregnant women should be immunized.

2. Teach immunization procedures and assist with community motivation campaigns.

3. Assist in the preparation of immunization sessions. Inform the community about availability of vaccination campaigne.

4. Find children and pregnant women who need to be immunized against the EPI target diseases.

5. Keep simple records of immunizations. 


\section{E. Maternal child Health}

This topic by necessity must be divided into skills appropriate for male and female health care workers.

Male Basic Health Workers

skills

Pregnancy

1. Provide normal prenatal care including teaching about diet, prevention of problems, prevention of anemia, neonatal tetanus.

2. Teach the importance and necessity of prenatal care.

3. Recognition of normal symptoms of pregnancy including slight oedema, urinary frequency, constipation and morning sickness.

4. Recognition of some abnormal signs of pregnancy, i.e. severe oedema or bleeding, and refer.

5. Recognition of certain diseases that are more harmful during pregnancy, e.g. malaria.

6. Drug avoidance in pregnancy. Rule is to assume all women of child-bearing age are pregnant unless proven otherwise. Advise not to take medicine, unless indicated by a health worker.

7. Teach the male members of the family regarding care of women in pregnancy.

8. Educational preparation for delivery and Improvisation of delivery kit (clean cutting instruments, clean cloth).

9. Identification of cultural factors/beliefs which might be harmful to the woman or newborn.

\section{Delfyery}

1. Recognize the symptoms of labor.

2. Male BHW should refer any delivery if possible.

3. Prevent any delivery related complications. 


\section{Postpartum}

1. Recognize abnormal signs and symptoms after delivery such as fever, bleeding, or shock and refer.

2. Advise breast feeding and diet.

3. Instruct to take fluids after delivery and the importance of colostrum. (Classically women tend to avoid "cold" foods).

4. Teach breast abscess prevention.

5. Abscess should be referred with paracetamol for pain.

Women's care

Common problems/complaints include:

1. Infertility, refer.

2. Dysmenorrhea, analgesia i.e. warm compress, paracetamol or ASA.

3. Abnormal bleeding, refer.

\section{Newborn care}

1. Advise on keeping the newborn warm.

2. Any fever in child in first month should be referred.

3. Advise immunization.

4. Advise and demonstrate normal cord care.

5. Recognize and treat simple cord infections. Refer complicated or persistent cases.

6. Prevent diaper rash. Treat with corn starch. Keep affected area dry and exposed to air. Apply gentian. violet in severe cases.

7. Instruct avoidance of bottles. However, if use is necessary, instruct on proper utilization or preferably cup and spoon.

8. Recognize and treat cradle cap (dandruff). If signs of infection, treat as impetigo with gentian violet. 
9. Recognize and advise about normal jaundice.

10. Recognize abnormal jaundice (persisting more than 5 days) and refer.

Female Basic Health Workers

Skills

\section{Pregnancy}

1. Normal prenatal care including teaching about diet and prevention of problems, prevention of anaemia, neonatal tetanus.

2. Teach prenatal care necessity.

3. Recognize normal symptoms of pregnancy including slight oedema, urinary frequency, constipation and morning sickness.

4. Recognize certain abnormal signs of pregnancy, i.e. severe oedema or bleeding, and refer.

5. Recognize certain diseases that are more harmful during pregnancy, e.g. malaria.

6. Drug avoidance in pregnancy. Rule is to assume all women of child-bearing age are pregnant unless proven otherwise. Advise not to take medicine unless prescribed by a health worker.

7. Teach members of family regarding care of women in pregnancy.

8. Educational preparation for delivery and improvisation of delivery kit (clean cutting instruments, clean cloth).

9. Identification of cultural factors/beliefs which might be harmful to the woman or newborn (for example with-holding of fluids after delivery).

\section{Delivery}

1. Recognize the symptoms and signs of labor.

2. If consulted regarding prolonged labor (defined as more than 24 hours with contractions less than 10 minutes apart), refer. 
3. Advise for delivery and when to refer to a TBA or midwife.

\section{Postpartum}

1. Recognize abnormal signs and symptoms after delivery such as fever, bleeding, shock, and refer.

2. Advise and support breast feeding and diet.

3. Instruct to take fluids after delivery and stress the importance of colostrum. (classically women tend to avoid "cold" foods).

4. Teach prevention of breast abscess.

5. Treatment of mastitis, abscess should be referred with paracetamol or aspirin for pain.

6. Retained placenta (defined here as $>1 / 2$ hour is abnormal) should be referred.

7. Advise on care of nipples during breast feeding.

Women's care

Common problems/complaints include:

1. Infertility, refer.

2. Dysmenorrhea, treat with analgesia such as paracetamol or ASA.

3. Abnormal bleeding, refer.

4. Menopause, instruct and advise.

5. Infections - recognize symptoms and treat with gentian violet, certain kinds of douches with vinegar or lemon in clean water; refer as necessary.

\section{Newborn Care}

1. Any fever in child in first month should be referred.

2. Advise immunization.

3. Advise and demonstrate normal cord care.

4. Recognize and treat simple cord infections. Refer complicated or persistent cases. 
5. Prevent diaper rash. Treat with corn starch or talcum. Keep affected area dry and exposed to air. Apply gentian violet in severe cases.

6. Instruct avoidance of bottles. However, if use is necessary, instruct on proper utilization.

7. Recognize cradle cap (dandruff) and treat. If signs of infection, treat as impetigo with gentian violet.

8. Recognize and advice about normal jaundice.

9. Recognize abnormal jaundice (persisting more than 5 days) and refer.

F. Treatment of Common Diseases and Injuries

1. Pediatrics

a. Refer for mild fever if persists for more than 3 days. For high fever ( $>39$ C of 24 hours duration), refer after first aid.

b. Recognize the following common diseases:

- measles

- mumps

- chicken pox

- diphtheria

- polio

- pertussis

- tetanus

- tuberculosis

c. Recognize and refer complications of EPI diseases as well as other common diseases.

d. Recognize and refer congenital anomalies.

2. Wound Care and First Aid

a. Basic wound care:

- clean technique

- application of dressings

- recognize and manage simple infected wounds with referral of complicated (severe) cases.

b. First Aid: application of heat or cold

- assessment of airway, breathing and circulation

- transport of injured

- immobilization of injured part

- control of bleeding

- recognition of shock and treatment prior to transport

- leg elevation and positioning (lower head) 
3. Nursing skills

a. Patient care procedures:

- obtain vital signs, temperature, pulse, respiration, $+/-$ blood pressure

- recognize vital signs, abnormalities, pulse or respiration $(t /-$ blood pressure)

- patient assessment - history (basic) and physical exam (observation) with action according to findings

- Administration of drugs:

- calculate dosage (adult and child) of drugs issued

- administer oral drugs

- administer drugs to infants and children

- Injections:

- intramuscular

- Application of topical drugs:

- eye

- ears

- skin

- irrigation of eye

- Collection of specimens:

- blood smear for malaria

- urine

- stool

b. Nursing procedures:

- Control of infection

- hand washing

- Care of sick patients:

- positioning

- personal hygiene

- diet

- Sterilization of equipment and materials by:

- heat, moisture/steam, or

- chemicals

- Handling equipment and materials:

- care of equipment

- handling of sterile instruments and materials

- disposal of contaminated materials/fluids

4. Skin/Dermatology

a. Recognition and treatment of:

- impetigo

- folliculitis

- scabies

- pediculosis 

- itching and dry skin
- local treatment of tinea
b. Prevention of cutaneous leishmaniasis.

5. Dental

a. Primary role is prevention and referral of dental problems.

b. Instruction in diet and dental care.

c. Immobilization and transport of fractured jaw.

6. Eye

a. Prevention of transmissible eye disease:

- trachoma

- conjunctivitis

b. Prevention of preventable eye disease:

- Vitamin A deficiency

- Removal of superficial foreign body by gauze or irrigation

- Reduced sight, referral

- Severe sudden eye pain and vision disturbance should be referred immediately

7. ENT (ear, nose and throat)

a. Prevention of common ENT problems including:

- otitis externa

- otitis media

- epistaxis

b. First aid treatment of epistaxis.

c. Referral of hearing 108s.

d. Thrush recognition and local treatment.

e. Diphtheria recognition and referral.

e. Differentiate imple viral pharyngitis from more complicated cases which must be referred.

The decision regarding treatment of otitis media and chronic otitis media was quite difficult. The decision to withhold antibiotice is hard to justify from workers who may be guite far away from the nearest reforral center. The difficulty in this context is the very likely riek for indiecriminate use particularly for other conditions.

8. Renplratory

a. Recognize and manage common cold (aimple viral pharyngitie).

b. Differentiate common cold from other conditions, 1.e. TB, bronchitis, pneumonia and refer when approprlate. 
c. Prevent spread of respiratory diseases.

9. Cardiovascular

a. Recognize oedema, cyanosis, dyspnea, and refer.

10. Gastroenterology

a. : Demonstrate ability to make ORS (home or packet) .

b. Recognize, treat and prevent those at risk or with diarrhoea/dehydration.

c. Recognize mild versus severe diarrhoea/ dehydration.

d. Treat mild diarrhoea/dehydration with oRs.

e. Treat severe diarrhoea/dehydration with oRs and referral.

f. Teach regarding appropriate feeding during illness, and for health maintenance-weaning advice, breast feeding.

g. Basic dietary counselling.

h. Teach regarding GI disease prevention, i.e. sanitation, food preparation, and personal hygiene - such as advice about boiling milk for prevention of GI TB.

i. Prevent and advise regarding mild constipation.

j. Recognize signs/symptoms of acute abdominal problems (severe pain, tenderness, rigidity of abdominal wall and associated vomiting) by simple examination and history, and refer.

k. Recognize certain common health problems:

- roundworms

- heartburn

- diarrhoea

- dehydration

- constipation

11. Genitourinary

a. Importance of personal hygiene and adequate fluid intake for prevention of infections.

b. Recognize abnormal symptoms/signs such as burning with urination or blood or pus in the urine, and refer.

c. Impotence/infertility - refer.

12. Infectious Diseases

Refer to other sections already mentioned for specific systems. Those not mentioned otherwise include: 
a. Malaria - these workers may be part of malarial control and treatment programs. Their role may be in screening, referral or outreach. Some programs provide and teach the use of chloroquine. Recognize symptoms and signs of malaria and refer. The need for avoiding the empiric use of chloroquine is a problem and will require a great deal of supervision and support.

b. Rabies - Recognize risk and know when to refer for animal (rabies) and human bites (infection).

c. Brucellosis - Teach regarding boiling milk for prevention of brucellosis.

13. Musculoskeletal problems

a. Instruct regarding appropriate use of body mechanics for lifting and heavy labor to avoid muscular problems (strains and sprains).

b. Symptomatic treatment of strains and sprains with analgesics (paracetamol or aspirin) and rest of affected part with possibly immobilization.

c. Symptomatic treatment of general body aches/pains (total body pain) with ahalgesia, rest, and reassurance. Referral should be given if symptoms persist or unable to perform daily activities.

\section{G. Health System Management skills}

1. Data collection

a. Community assessment regarding health risks and factors.

b. Notification of appropriate people (sanitarians, construction workers, physicians, and someday perhaps public health authorities; about health risks and problems. This may include at certain levels, instruction in basic statistics, epidemiology and public health survey.

c. Notification of EPI target diseases such as measles, pertussis, polio.

d. Notification of outbreaks of tuberculosis.

e. Outpatient Record Keeping-with referral forms. 
2. Clinic Management
a. Managing the health facility:
- maintaining cleanliness
- keep area clean
- disposal of waste products
b. Keeping supplies of drugs and equipment:
- Proper storage
- records of: stock, issue, order for resupply

3. Home visiting/Community Outreach Skills

Their skills should include home assessment for problems regarding individuals, family or larger community, and the follow-up of problems found in the home or clinic.

This is particularly important for the non-physician health workers whose role is not so well understood by the community in general. They are very often shy to present themselves within others homes particularly in a preventive capacity.

The training should include the pride and necessity of their role.

4. Management/Supervision/Cooperation

Integration of all levels of health care workers. For example, immunization workers, sanitarians, malaria supervisors, physicians, mid-level health workers, midwives, TBAs, other BHWs, specialty workers, etc. This person will work under the technical supervision of physicians and/or mid-level health workers in the future, although currently they function for the most part without this type of support.

All of the skills and activities described within this section are not currently in practice but in planning stages. What is given are the standards which will be provided in future training and refresher courses. The skills included here were agreed upon after numerous meetings with the training groups and health agencies involved within Afghanistan. 
V. MID-LEVEL HEALTH WORKERS

\section{Introduction}

Supervise and give technical support to all lower level health workers. Training includes all skills of Basic Health Worker (BHW) as well as the diagnosis and treatment of the most common diseases as seen in developing countries (these will be specifically outlined). These workers are trained to work in situations where a high degree of autonomy is necessary. over time it is anticipated that there will be increasing support and supervision for these workers allowing building of regional health system teams.

\section{A. Primary Health Care}

\section{Health Education/Teaching Methodology}

It is assumed that the mid-level health workers must be able to teach the following topics:

a. Use of prescribed medications.

b. How to use and make oRs.

c. Correct disposal of human waste/personal hygiene, hand washing.

d. Identification of safe water sources or how to make water safe.

e. Weaning practices and identification of available and quality foods.

f. Prevention of malaria and TB, as well as most common diseases in the community.

g. The role of vaccination in health promotion.

h. Protection of a wound from infection.

i. Referral resources for certain types of services. Where to go for TB treatment and other problems.

j. Child spacing on request of individual.

k. Follow-up instructions regarding referral or further management and prevention of problems.

1. Breast feeding.

m. Dietary needs for pregnant and lactating women.

n. Dietary supplementation or practice during illness.

o. Safe food use and preparation.

p. What is the meaning of the MUAC measurement?

q. Interrelation of illness and malnutrition.

$r$. Safe birth practices (sterile cord cutting, hand washing, uterus massage). 


\section{skills}

1. Describe target behavior. What do you want them to know or do at the end of the teaching or training session?

a. Ability to make a teaching plan and follow this plan.

b. : Identify teaching priorities for individual, family or community.

c. Limit health discussions to one or two topics during a visit.

2. Define what is the level of knowledge/attitudes/ practices in the target group/individual.

a. Ability to teach using language commonly used by viliage people, or adapted to the level of the learners.

b. Develop health education approaches which build on existing health practices and beliefs.

3. Recognize/describe what teaching resources (teaching aids, personnel) are available.

4. Decide/identify what teaching method is idertified as most useful in the circumstance.

Teaching methods to be taught for either individual or groups include:
a. Talking listening.
(lecture)/questioning/discussion/
b. Demonstration.
c. Use of visual aids such as posters, quotes from the Qoran.

Teaching methods to be taught for groups include:
a. Role playing.
b. Obtaining or checking community and/or authority consensus on a topic and the audience.

Note: it is believed that the worker will do relatively less group teaching. However, it should be taught and modelied within his/her training so that concepts can be generalized and practice with supervision can be experienced. 
5. Demonstrate evaluation of teaching objectives. Has the person learned and met the target behavior? For example can the learner demonstrate how to make ORS correctly?

6. Motivate patients/family/community - use of community leaders and influential people as well as individual factors that increase motivation towards healthy behaviors.

7. Model correct practices in clinic and personal life.

B. Environmental health

This person is not considered to be the basis of the program but a supporter. The health system and environmental problems will vary with specific region and areas. Therefore general principles should be taught which include:

1. Assessment of their area with regard to practices for sanitation, sources of drinking water, community perception as to whether or not there is a problem with some aspect of environmental health.

2. From their knowledge of the natural history and basis of disease combined with $1^{\prime}$ above the worker should be able to provide:

a. A problem list specific for his/her area.
b. Community motivation specifically directed
based on problem identification and
understanding of community.
c. Dellvery (education) and modelling of "prime
d. Prsages".
providing information to environmental health
programs.

\section{skills}

1. Ablilty to assess environmental risk factors within their community.

2. Community motivation and interaction which is appropriate to the environmental health problems identified in their area.

3. Recognize, prevent and treat diseases resulting from environmental hazards created by inappropriate disposal of waste and poor hygiene. 
4. Recognize, prevent and treat diseases resulting from poor food handling practices.

5. Vector Control - includes personal avoidance of vectors, vector eradication and control by garbage and rubbish disposal, reducing breeding sites of mosquitos and proper keeping of animals.

6. Accident prevention - mine education and safety in living quarters i.e. stoves and crowding.

7. Connect the treatment of the individual patients' problems with the necessary public health teaching that is needed.

8. Provide health education regarding "prime messages".

9. Recognize, prevent diarrhoea/dehydration as well as treatment with oral Rehydration Solutions (ORS).

c. Nutrition

Skills

1. Ability to describe the signs of a healthy growing child.

2. Assessment: Describe or demonstrate an ability to gather the following kinds of information.

a. Nutritional resources in the community.

b. Beliefs relating to nutrition.

c. Identification of risk groups.

d. Data collection and reporting.

3. Recognition/screening of childhood malnutrition in the community and the individual utilizing the MidUpper Arm Circumference tape (MUAC). All health care workers must measure and record MUAC for all children visiting the clinics between the ages of 1-5 years. It is additionally recommended that health care workers be encouraged to use MUAC in community screening efforts and with vaccination campaigns.

a. Ability to use a MUAC tape correctly.

b. Ability to make a MUAC tape from locally available materials.

c. Recording of the information obtained Appropriate data collection and utilization. This particular item is in the process of definition. Over time it will emerge both in 
terms of individual patient record keeping and supervisor reporting forms.

d. Ability to teach the meaning of MUAC measurement.

4. Ability to demonstrate obtaining a nutritional history from a patient/family.

5. Utilization of the information obtained to discern if there is a problem and what the root problem is, as related to:

a. Poor use of available food.

b. Lack of food in family and community.

c. Illness.

6. Ability to describe locally available foods and substitutes. This includes dietary advice to provide food supplementation or caloric reduction.

7. Be able to teach the following:

a. Breast feeding - this includes avoidance of bottles.

b. Weaning practices.

c. Dietary needs for pregnant and lactating women.

d. When and how to use and make ORS.

e. Dietary supplementation or practice during illness.

f. Safe food use and preparation.

g. What is the meaning of the MUAC measurement?

$\mathrm{h}$. Inter-relation of illness and malnutrition.

i. Preparation of super-porridge.

8. Teach regarding appropriate feeding during illness and for health maintenance - weaning advice, breast feeding and basic dietary counselling.

9. Demonstrate the preparation of super-porridge.

10. Recognize, prevent and treat the following problems as they relate to nutritional risk or compromise:
a. Anemia
b. Goiter
c. Vitamin A deficiency
d. Obesity
e. Measles
f. Gastrointestinal diseases - particularly diarrhoea and dehydration
g. Marasmus
h. Kwashiorkor 
6. Recognize diseases that are more harmful during pregnancy, e.g. malaria.

7. Drug avoidance in pregnancy. Rule is to assume all women of child-bearing age are pregnant unless proven otherwise. Advise not to take medicine unless indicated by a health worker.

8. Teach family members (particularly male members) regarding care of women in pregnancy.

9. Identify cultural factors/beliefs which might be harmful to the woman or newborn.

10. Educational preparation for delivery and improvisation of delivery kit (clean cutting instruments, clean cloth).

11. Prevent delivery related complications such as uterine massage, fluids.

12. Recognize and treat urinary tract infection.

13. Recognize and treat anemia.

14. Recognize and treat pre-eclampsia. Refer if no signs of improvement.

15. Recognize and refer eclampsia.

16. Recognize early labor. If not severe, advise treatment with bedrest. If symptoms persist or increase - transport to higher facility.

17. Recognize incomplete abortion and refer after first aid treatment.

18. Recognize and treat complete abortion.

19. Supervise and support TBAs.

\section{Delivery}

1. Recognize the symptoms of labor.

2. Refer delivery to trained personnel, if possible.

3. Use of methergine and intravenous fluids as indicated for immediate post-partum hemorrhage and transfer/refer for further evaluation. Direct female to do uterine massage and refer fluids. 
4. Early rupture of membranes or signs of infection should be treated with antibiotics and referral.

\section{Postpartum}

1. Recognize signs and symptoms of postpartum infections such as fever, bleeding or shock. Treat with antibiotics, intravenous fluids, and methergine, if indicated. Refer for dilatation and curettage.

2. Advise breast feeding and diet.

3. Instruct to take fluids after delivery and stress the importance of colostrum. (Classically women tend to avoid "cold" foods).

4. Teach regarding mastitis and breast abscess prevention.

5. Treat mastitis with cold or warm compresses (depending on stage) and use paracetamol or ASA for pain.

6. Treat breast abscess with antibiotics and paracetamol for pain with incision and drairfage as indicated.

\section{Newborn Care}

1. Any fever (>100.5 F/38 C) in child in first month should be treated as meningitis, pneumonia or sepsis.

2. Advise immunization.

3. Advise and demonstrate normal cord care.

4. Recognize and treat simple cord infections: Refer complicated or persistent cases.

5. Prevent diaper rash and treat with corn starch. Keep affected area dry and exposed to air. Apply gentian violet in severe cases.

6. Instruct avoldance of bottles. However, if use is necessary, instruct on proper utilization or preferably cup and spoon.

7. Recognize and prevent cradle cap (dandrufe) and treat. If signs of infection treat as impetigo with gentian violet. 
8. Recognize and advise on normal jaundice.

9. Recognize abnormal jaundice (persisting for more than 5 days) and refer.

10. Recognize and treat neonatal sepsis.

11. Recognize neonatal tetanus, give initial treatment, and refer.

12. Recognize, prevent and treat neonatal conjunctivitis.

Women's Care

Common problems/complaints include:

1. Infertility - refer.

2. Dysmenorrhea - treat with analgesia, i.e. paracetamol or ASA and local application of warm compress.

3. Abnormal bleeding - refer.

4. Recognize and treat vaginal discharges die to:
a. candidiasis
b. trichomoniasis
c. bacterial

5. Supervise and support TBAs.

6. Menstrual bleeding - treat with iron and refer.

\section{Female Mid-Level Health Workers}

\section{Pregnancy}

1. Provide normal prenatal care to include teaching about diet and prevention of problems, i.e. prevention of anemia, neonatal tetanus.

2. Teach prenatal care necessity.

3. Recognition of normal symptoms of pregnancy including slight oedema, urinary frequency, constipation and morning sickness.

4. Recognition of some abnormal signs of pregnancy, i.e. severe oedema or bleeding should be referred. 
5. Recognition of certain diseases which are more harmful during pregnancy, i.e. malaria.

6. Educational preparation for delivery and improvisation of delivery kit (clean cutting instruments, clean cloth).

7. Drug avoidance in pregnancy. Rule is to assume all women of childbearing age are pregnant unless proven otherwise. reach not to take medicine.

8. Teach members of family regarding care of women in pregnancy.

9. Identification of cultural factors/beliefs which might be harmful to the woman or newborn (for example withholding fluids after delivery).

10. Recognition and treatment of urinary tract infection.

11. Recognition and treatment of pre-eclampsia. Referral if not improved.

12. Recognition and referral of eclampsia.

13. Recognition of early labor. If not severe, treat with bedrest. If does not stop or increases, transport.

14. Recognition of incomplete abortion and referral after first aid treatment.

15. Recognition and treatment of complete abortion.

16. Prenatal care including pregnancy dating, fetal monitoring, fetal presentation.

17. Supervision of TBAs (Dais).

\section{Delivery}

1. Recognize the symptoms of labor.

2. If consulted regarding prolonged labor (defined as more than 24 hours with contractions less than 10 minutes apart) should refer.

3. Advise for delivery and when to refer to a trained midwife or physician. 
4. Recognition and management of abnormal delivery or presentation, i.e. breech, multiple and face. Refer transverse presentation.

5. Manual extraction of retained products of conception.

6. Delivery of dead fetus.

7. Provision of care for control of pain and psychosocial stress.

8. Treatment and prevention of immediate postpartum hemorrhage by uterine massage and breast stimulation (breast feeding).

9. Use of Methergine and intravenous fluids as indicated for immediate post-partum hemorrhage.

10. Early rupture of membranes or signs of infection should be treated with antibiotics and referred.

11. Treatment of trauma to birth canal.

\section{Postpartum}

1. Recognition of abnormal signs and symptoms after delivery such as fever, bleeding, or shock and refer.

2. Advise and support breast feeding and diet.

3. Instruction to take fluids after delivery, the - importance of colostrum. (Classically the women tend to avoid "cold" foods).

4. Teaching on mastitis and breast abscess prevention.

5. Treatment of mastitis with cold or warm compresses (depends on stage) and use of paracetamol or ASA.

6. Treatment of breast abscess with antibiotics and paracetamol for pain with incision and drainage as indicated.

7. Retained placenta (defined here as $>1 / 2$ hour is abnormal) should manage with supportive care for transfer/referral.

8. Advise regarding care of nipples during breastfeeding. 


\section{Newborn Care}

1. Any fever in child in first month should be referred.

2. Advise immunization.

3. Advise and demonstrate normal cord care.

4. Recognition and treatment of simple cord infections. Refer complicated or persistent cases.

5. Prevention of diaper rash and treatment with corn starch. Keep dry and exposed to air. Application of gentian violet in severe cases.

6. Instruction for avoidance of bottles. However, if use is necessary instruct on proper utilization.

7. Prevention and recognition of cradle cap (dandruff) and treatment. If signs of infection treat as impetigo with gentian violet.

8. Recognition and advice about normal jaundice.

9. Recognition of abnormal jaundice (persisting more than 5 days) and referral.

10. Recognition and treatment of neonatal sepsis.

11. Recognition, initial treatment and referral of neonatal tetanus.

12. Recognition, prevention and treatment of neonatal conjunctivitis.

Women's Care

Common problems/complaints include:

1. Infertility, refer.

2. Dysmenorrhea, treat with analgesia, i.e. paracetamol or ASA.

3. Abnormal bleeding, refer.

4. Recognition and treatment of vaginal discharges due to:

a. candidiasis

b. trichomoniasis

c. bacterial 
5. Supervise and support TBAs.

6. Recognition and advice regarding breast cancer.

7. Recognition and referral of problems secondary to multiple births such as cystocele, rectocele.

8. Treatment of uterine prolapse with pessary (if available) and referral.

9. Ability to perform gynecologic examination for evaluation of abnormal bleeding. Referral as indicated.

F. Treatment of Common Diseases and Injuries

Diagnostic skills include:
a. Vital signs.
b. History, physical exam.

Therapeutic skills include: a. Prescribing and instruction regarding treatment
of diseases.

1. Pediatrics

a. Recognition, advice and/or treatment of:

- measles - includes complications

- chickenpox

- pertussis

- tetanus

- protein energy malnutrition - marasmus versus kwashiorkor

- meningitis

- scarlet Iever

- rubella

- convulsions - Febrile versus other

- polio

- mumps

- tuberculosis

- diphtheria

- complications of EPI diseases with referral as necessary

- recognition and referral of congenital anomalies

b. Ablilty to perform circumcision. 
2. Wound care and First Aid

a. Basic wound care

- clean technique

- sterile technique

- application of dressings

- recognition and management of simple infected wounds with referral of complicated (severe) cases

- application of heat or cold

- recognition of abscess and management via incision and drainage at appropriate time as well as use of antibiotics and analgesics

- single layer wound closure

- surgical debridement of wounds

- local anesthesia

- recognition of degrees and proper treatment of burns

b. First Aid

- assessment of airway, breathing and circulation

- transport of injured

- immobilization of injured part.

- control of bleeding

- recognition of shock and treatment prior to transport with leg elevation and positioning (lower head)

- fluid resuscitation

- primary treatment of open fractures

- basic trauma care of chest, abdominal, and muscle injuries

3. Nursing skills

a. Patient care procedures

- obtaining vital signs, temperature, pulse, respiration, and blood pressure

- recognition of vital sign abnormalities

- patient assessment - history and physical exam with action according to findings

- administration of drugs:

- calculation of dosage (adult and child) for drugs issued

- administration of oral drugs

- administration of drugs to infants and children

- injections:

- intramuscular

- subcutaneous

- intradermal 


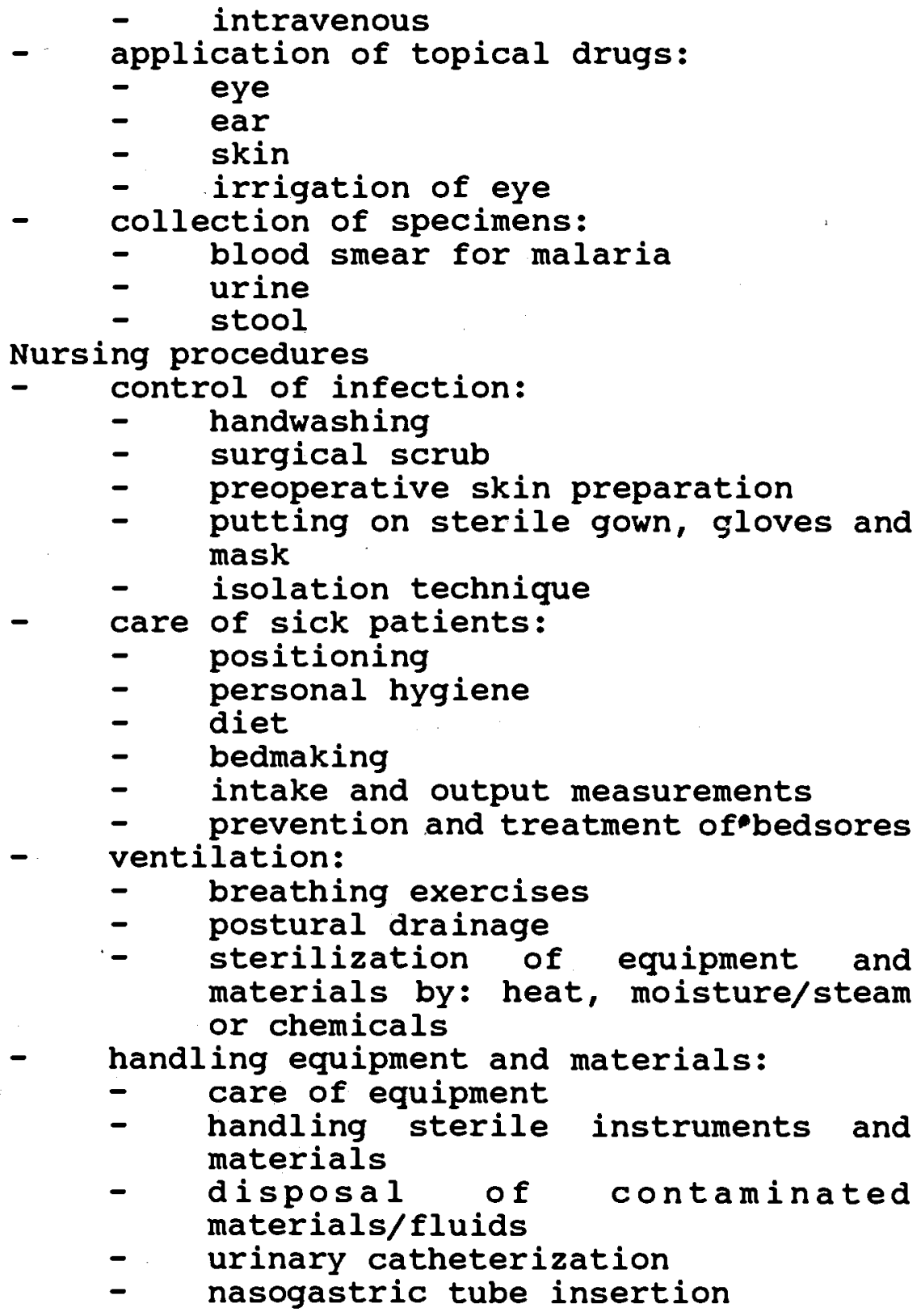

4. Dermatology

a. Recognition and treatment of:

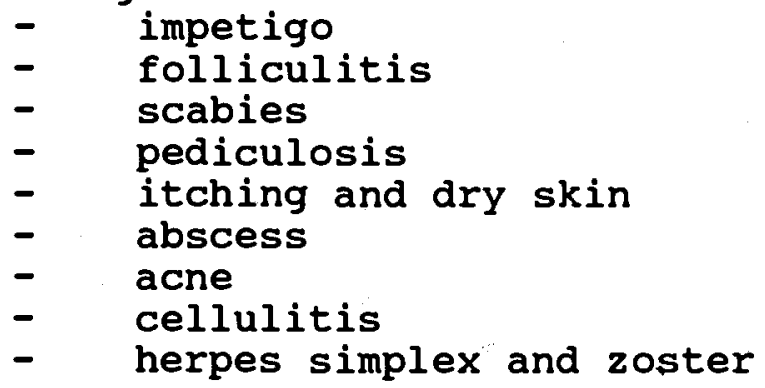


- candidiasis and dermatophytosis (tineas)

- allergic skin diseases, i.e. eczema, contact dermatitis, urticaria.

b. Recognition, prevention and referral of:

- cutaneous leprosy

- cutaneous leishmaniasis

5. Denital

a. Prevention:

- cleaning, flossing and scaling

- instruction in diet and dental care

b. First aid:

- immobilization and transport of fractured jaw

c. Curative:

- extraction with suture of sockets as needed and root removal

- placement of temporary fillings

- recognition and treatment of dental

d. Anesthesia: abscess, dental caries, gingivitis

- placement of local anesthesia appropriately

e. Recognition:

- of general disease by oral signs and symptoms

6. Eye

a. Recognition, treatment, and prevention of:

- viral conjunctivitis

- bacterial conjunctivitis

- allergic conjunctivitis

- trachoma

b. Eyelid infections

- sty

- dacryocystitis

- blepharitis

c. Eye trauma.

d. Foreign body removal - includes diagnosis of corneal ulceration.

e. Recognition, treatment and prevention of $V i t a m i n$ deficiency.

f. Pterygium.

g. Hyphema.

h. Monitoring of visual acuity.

1. Reduced sight should be referred.

j. Cataracts.

k. Recognition and referral of:

- iritis

- glaucoma 
- sudden eye pain with visual disturbance

7. ENT

a. Recognition, prevention and treatment of:

- common cold

- otitis media and otitis externa

- perforated tympanic membrane

- chronic otitis

- viral pharyngitis

- viral laryngitis

- bacterial tonsillitis

- acute and chronic sinusitis

- mastoiditis - differential diagnosis

- epistaxis - anterior packing

- diphtheria

- croup/epiglottis

- aphthous ulcer or canker sore

- allergic rhinitis

- hearing loss should be referred if sudden

or worsening

- impacted cerumen

- thrush or oral candidiasis

8. Respiratory

a. Recognition, prevention and treatment of the following diseases:

- common cold

- allergy

- bronchitis - acute and chronic

- pneumonia

- asthma

- suspected TB (referral)

- anaphylaxis prevention and treatment

b. Prevention of spread of respiratory diseases.

9. Cardiovascular

a. Recognition of oedema, cyanosis, and dyspnea.

b. Prevention, diagnosis and treatment of:

- hypertension

- acute rheumatic fever

- angina pectoris - recognition and referral after acute episode

- congestive heart failure - recognition, initial treatment and referral for further evaluation and treatment

- myocardial infarction - recognition of risk factors and symptoms. Treatment with rest and analgesics and referral when stable 
- varicose veins

- hemorrhoids

\section{Gastroenterology}

a. Differential diagnosis of types of diarrhoea with treatment including:

- viral

- parasitic - round and tape worms

- bacterial

- cholera - over-diagnosis is a concern

b. Recognition of dehydration - causes as well as degrees.

c. Demonstrate ability to make ORS (home or packet) correctly.

d. Recognition, treatment or prevention of those at risk or with diarrhoea/dehydration.

e. Treatment of dehydration with oral, NG, or

f. recognition and treatment of:

- worms (round vs tapeworms)

- typhoid

- gastritis versus ulcer and other causes of GI bleeding

- recognition of signs and symptoms of GI bleeding (lower and upper) with initial treatment and referral

- hemorrhoids

- constipation - prevention through diet with medication only as needed

- hepatitis - recognition and community control and prevention measures

- acute abdomen - recognition with preparation for transport with nasogastric tube and antibiotics as needed

- cirrhosis - recognition and referral

- ascities - recognition and referral

- cholecystitis - recognition and medical treatment and referral for surgical treatment

g. Basic dietary counseling.

h. Teaching with regard to GI disease prevention such as sanitation, food preparation, and personal hygiene. For example, the advice to boil milk for prevention of GI tuberculosis. 


\section{Genitourinary}

a. Advise on the importance of personal hygiene and adequate fluid intake for prevention of infections.

b. Recognition, prevention and treatment of:

- urinary tract infection:

- pyelonephritis

- cystitis

- epididymitis

- prostatitis

- renal colic

- urinary stones

- urinary retention

- hydrocele versus other scrotal masses

- renal failure

- testicular torsion - recognition and referral

- undescended testicles - refer if not descended after 2 years of age

- genital lesions and discharges such as syphilis, gonorrhea

- circumcision - (must prove competence to perform), treatment of complications of circumcision

- impotence/infertility- refer

\section{Infectious diseases}

Refer to other categories for specific diseases. General infectious diseases not mentioned include:

a. Recognition, prevention, and treatment of:

- malaria

- meningitis

- septicemia

- osteomyelitis

- smallpox - tends to be over-diagnosed. studies have shown the reported cases have been primarily a form of chicken pox. The workers need to learn the difference.

- rabies - recognition of risks and disease with referral if possible. Community control measures.

- tetanus - see also $\mathrm{MCH}$ and immunization section

- anthrax

- brucellosis 


\section{Musculoskeletal}

a. Instruction regarding appropriate use of body mechanics for lifting and heavy labor to avoid muscular problems (strains and sprains).

b. Symptomatic treatment of strains and sprains with analgesics (paracetamol or aspirin) and rest of affected part with possibly immobilization.

c. Symptomatic treatment of general body aches/pains (total body pain) with analgesia, rest, and reassurance. Referral should be given if persistence or impairment in daily activities.

d. Physiotherapy concepts for post-injury and polio.

e. Appropriate recognition and referral as available for the disabled.

f. Recognition and treatment of:

- septic arthritis

- rheumatoid arthritis

- osteoarthritis

- rheumatic arthritis

- common fractures

- common dislocations

- osteomyelitis

g. Differentiation of arthritis and arthralgia.

h. Treatment of chronic and acute backpain.

\section{G. Equipment List}

This list represents the set up for an initial "clinic" with 1-2 health workers at physician or mid-level. Facility type lists for more comprehensive health facilities have not been finalized but would be determined by the numbers of health workers and types of health services to be provided. Re-supply of these items is on an as needed basis.

Item

Quantity

General Medical

Otoscope

Stethoscope

Sphygmomanometer

Thermometers

Tongue depressor, metal

1

1

1

10

1

Oral airways

Adult scale

Arm Circumference tape

Tourniquets 


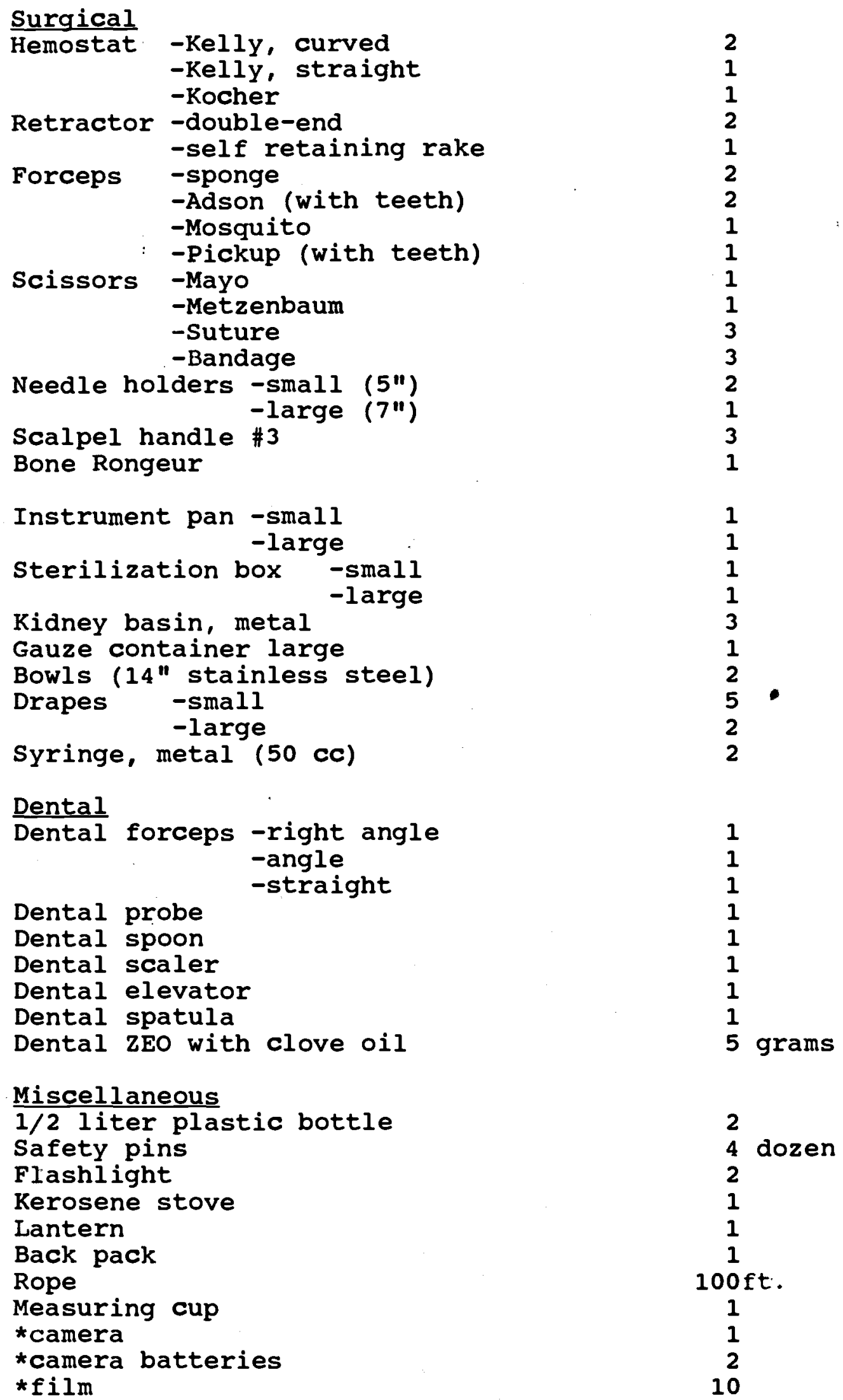


Field manuals in Dari or Pashtu:

$\begin{array}{ll}\text { Coordination of Medical Committees } & 1 \\ \text { Where there is no Dentist } & 1 \\ \text { Where there is no Doctor } & 1 \\ \text { WHO health/medical selected topics } & 1 \\ \text { HERC/IRC silkscreen posters } & 7\end{array}$

*= Special items provided only to selected clinics to assist monitoring purposes.

H. Health System Management Skills

All of the skills and activities described within this section are not currently in practice but in planning stages. What is given are the standards which will be provided in future training and refresher courses. The skills included here were agreed upon after numerous meetings with the training groups and health agencies involved within Afghanistan.

1. Data collection

a. Community assessment regarding health risks and factors.

b. Notification of appropriate people (sanitarians, construction workers, physicians, and someday perhaps public health authorities) about health risks and problems within their areas.

c. Notification of EPI target diseases such as measles, pertussis, polio, and diphtheria.

d. Notification of outbreaks of tuberculosis.

e. Outpatient and Inpatient Record Keeping - with referral forms.

Th1s may necessitate at certain levels the additional instruction in basic statistics, epidemlology and public health survey.

2. Clinte Management

a. Managing the health facility:

- maintain cleanliness

- keep area clean

- dispose of waste products

b. Keeping supplies of drugs and equipment:

- proper storage

- records of: stock, 1ssue, order for resupply 
3. Home visiting/ Community Outreach Skills

Their skills should include home assessment for problems regarding individuals, family or larger community, and the follow-up of problems found in the home or clinic.

This is particularly important for the non-physician health workers whose role is not so well understood by the community in general. They are very often shy to present themselves within others' homes particularly in a preventive capacity. The training should include the pride and necessity of their role.

\section{Management/Supervision/Cooperation}

Integration of all levels of health care workers. For example, immunization workers, sanitarians, malaria supervisors, physicians, BHWs, midwives, TBAs, other mid-level health workers, specialty workers, etc. This person will work under the technical supervision of physicians in the future, although currently they function for the most part autonomously. Encouraging these workers to begin to act in supervisory and supportive capacities with other types of lower health workers is a goal. 


\section{RESOURCES}

The Afghan Female Health Workers Trainers Manual, UNHCR/SCF (UK) /UNICEF. Available from Save the Children Fund (UK).

The community health worker: working guide, guidelines for training, guidelines for adaptation. Geneva: WHO, 1987. 467 p., ill.

Guidelines for conducting clinical training courses at health centers and small hospitals, wHO (includes teaching slides). Serial number CDD/SER/90.2.

Guidelines for training community health workers in nutrition. Geneva: WHO, 1986; vii, 121 p. : ill., charts.

Training of female health workers in Afqhan refugee villages in N.W.F.P. Pakistan / by Sophie Forman and Catherine Lidwill. Peshawar: Save the Children Fund (UK), 1989; 22 p.

The comprehensive MEDEX series of training guides published by the University of Hawaii are also available, at HERC and WHO. 


\section{CHAPTER 3 - MATERNAL AND CHIID HEALTH}

\section{INTRODUCTION}

Afghanistan has one of the highest estimated maternal, infant and child mortality rates in the world, although there has been no aggregated data due to the political environment since 1979. According to the 1975 National Demographic Survey of Afghanistan, maternal mortality was approximately 640/100,000 live births. There are many factors related to the war situation which have probably caused this rate to increase. The infant mortality rate has been estimated to be $171 / 1,000$ and child mortality roughly $300 / 1,000 .^{2}$ In 1988 the infant mortality rates in certain districts of Iran were 176 up to $241 / 1,000$ among Afghan refugees. The causes of death in children less than 1 year were primarily due to neonatal tetanus, diarrheal disease, and ARI.

The scope of women's health problems in Afghanistan is enormous. The problem of under-reporting tends to be greatest in areas with the highest rates of maternal mortality. Factors generally found to increase fertility levels in populations are: low female literacy rate, rural residence, religious and cultural preferences regarding marriage and fertility, and low socio-economic status. Afghan women have virtually no educational background with literacy rates estimated at 1-2\% in rural areas. Life is at a subsistence level with poor economic conditions. Afghan culture dictates a preference for a large family. The preference for sons contributes to perpetual child bearing. Afghan refugee camps report the highest total marital fertility rates ever recorded at 13.6 live births (compared to 9.3 prior to the war). 4 The high maternal mortality then is the main result of two immediate factors: high fertility and the high risk of dying each time a woman becomes pregnant.

${ }^{1}$ State University of New York, Buffalo, New York. "National Demographic and Family Guidance survey of the settled population of Afghanistan", 1975

${ }^{2}$ State of the World's Children, UNICEF, 1990.

${ }^{3}$ Rezai, P., "Health and Nutrition Survey of Afghan Refugees in the Islamic Republic of Iran", UNHCR, 1988.

${ }^{4}$ Krigh, Ellen, "Health Status of Afghan Women and Children: An Assessment of Trends in 10 Refugee Camps between Hangu and Thal, North West Frontier Province, Pakistan," International Rescue committee, 1987. 
In most developing countries, between a quarter and a third of the deaths of women in their reproductive years (ages 15 to 45) can be attributed to direct maternal causes hemorrhage, infection, toxemia, obstructed labor and induced abortion. It is reasonable to assume that the first four complications cause a majority of maternal deaths among Afghan women of the childbearing age group. It is predicted that in the Afghan female population of this age group the significant indirect causes of maternal death would include anemia, malaria, tuberculosis, and hepatitis.

From information of other countries, 80-98\% of all maternal deaths could be avoided with either preventive measures or the provision of proper health care. However, in this population, women do not seek health care generally and more specifically for pregnancy related problems due to cultural and geographical factors which restrict access to providers.

In Afghanistan, most births are attended by a female relative (or sometimes a traditional birth attendant) who has no training in proper delivery techniques. The limited access of even TBAs in Afghanistan to other women within the community results in low participation in community wide programs. Health services for women are rare, which is a major result of the lack of trained female medical personnel. The causes of maternal death are the result of contributing factors such as availability of health services, the woman's reproductive history, and socio-economic factors. This is shown graphically in Appendix 1 "The Road to Maternal Death".

With regard to the child health component of $\mathrm{MCH}$, Afghanistan has the same pattern of child deaths as other developing countries. Most deaths are caused by diarrhea, acute respiratory infections, infectious diseases and malnutrition. NGOS/PVOs have been reporting that 32-40\% of children inside Afghanistan are dying before the age of five. Surveys of Afghan refugees in Pakistan in 1990 by the Centers for Disease Control (CDC) found the major causes of death among this age group to be respiratory and diarrhoeal diseases, measles, neonatal tetanus, and malaria. This survey, as compared to one done in 1985 by the same group, pointed to an overall decrease in the deaths due to measles and neonatal tetanus which is considered due to the vaccination campaigns carried out in the refugee camps. ${ }^{5 \& 6}$

STangermann, R. \& Pamuk, E. " "Evaluatión of Infant Mortality and Childhood Nutritional status Among Afgkan Refugees in Pakistan, 1990," CDC (Atlanta), 1990. 
An analysis of "greenbook" (patient registers) data for morbidity among children within Afghanistan shows the leading diagnosis by health workers are diarrheas, worms, conjunctivitis, dehydration, common cold, otitis, injury and pneumonia.?

No information is available on how many women and children have been killed or maimed as a result of the war. Before 1979, women and children in rural Afghanistan were sharing a disproportionately large burden of illness and death; more than $50 \%$ of all deaths occurred to those under age five and women aged $30-40$ years had rates of reported illness almost twice as great as men of the same age. ${ }^{8}$ However, it is shown that for every woman who dies of complications of pregnancy and childbirth, there are many more who suffer serious (sometimes lifelong) illness.

\section{MATERNAL AND CHILD HEALTH}

\section{A. Definition}

The working definition for $\mathrm{MCH}$ in the context of Afghanistan is:

Any program/project or activity which is aimed at the promotion and improvement of health for women and children.

B. Goals and Objectives

The goal of maternal and child health care is to reduce the maternal, infant and child morbidity and mortality rates and to promote a good nutritional and health status for Afghan women and children.

The objectives to be achieved cannot be specified in terms of percentage reductions, as there is no baseline data available at present. This statement in and of itself presents a major challenge and defines a priority area of activity for linking health information and

${ }^{6}$ Boss, L., \& Lewis, J., "Evaluations of Infant Mortality and Childhood Nutritional status among Afghan Refugees in Pakistan, 1986," CDC (Atlanta), 1986.

${ }^{7}$ Coordination of Medical Committees - Analysis of Greenbook Data, 1990. Peshawar, pakistan.

${ }^{8}$ o'Connor, R., Ed., "Managing Health Systems in Developing Areas: Experiences from Afghanistan," Lexington, Mass, Lexington Books, 1980. 
following the effect of $\mathrm{MCH}$ interventions. In general terms the objectives for $\mathrm{MCH}$ should be to:

1. Increase the access to health care for women and children.

2. Motivate within communities for initiating $\mathrm{MCH}$ services at many levels.

3. Increase the awareness among policy makers and decision-makers on the value of $\mathbf{M C H}$ and introduce MCH program alternatives for the future of Afghanistan.

\section{c. Approach for Planning}

MCH as a general topic includes a package of problems and interventions which include: expanded program in immunization (EPI); control of diarrhoeal disease (CDD); acute respiratory infection (ARI); nutrition; as well as women's health issues. Many of these topics are discussed in detail elsewhere but should be remembered as inseparable components when considering the health of women and children.

There is one variable which is constant regarding both strategy and demand for $\mathrm{MCH}$ planning in the context of Afghanistan - that the program design must be specific to the area. Regional and sub-regional variations are significant and are the most important issue in relation to the type of $\mathrm{MCH}$ interventions that may be carried out.

Rather than provide general recommendations, the goal is to provide a common tool for planners and implementing agencies. This tool will be used for evaluating the feasibility and approach for program design in the stated target area (see below).

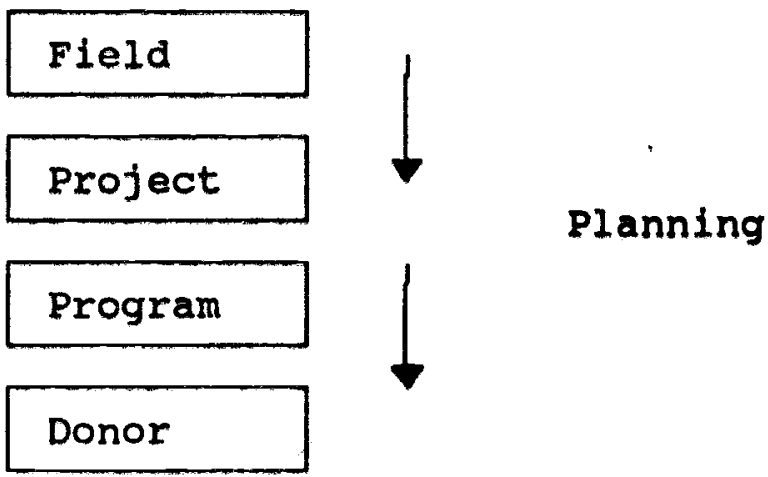


The task within this larger goal includes defining objective criteria which would assist in planning, monitoring, and encouraging activity in the topic of $\mathrm{MCH}$ using a common format for dialogue. The outcome would be a positive functional framework whereby agencies could enhance their $\mathrm{MCH}$ components in existing or planned projects despite the numerous constraints working against more commonly understood approaches to MCH. An organization's capacity to provide some minimal level of $\mathrm{MCH}$ may be expanded and justified through such a framework.

Indicators are described which relate to $\mathrm{MCH}$ and which consider health resources, community interest/demand, and feasibility within an area. By aggregating these indicators, $\mathrm{MCH}$ programs can be more realistically designed.

In this type of framework the approach will be to define geographic areas (to the finest possible detail - such as village or subdistrict) based on aggregated indicators into four levels. These four levels would then be matched with interventions that are appropriate to the profile of the area. The result is a tool for planning as well as following the profile of an area over time as interventions are applied.

\section{INDICATORS REGARDING MCH RESOURCES AND FEASIBILITY}

The following indicators are considered measurable, feasible with the current data collection system in place, and relevant to the planning or decision making for cross-border assistance within Afghanistan. Some are "Key" or "Core" indicators, crucial to the different definitions of levels (marked with asterisk). Others are supplementary indicators which would in sum provide important additional input for decision making regarding the community profile for $\mathrm{MCH}$.

A. Gender of health workers - female or male available in an area.*

B. Health facility available within the area (see Appendix 2) . *

c. Male health workers in area or health facility report seeing 0-20\% female or children patients.*

D. Male health workers in the area report seeing 20-40\% female patients.*

E. Male health workers in the area report seeing $>40 \%$ female patients.* 
F. Male health workers report contact with local TBAs (Dais) - familiarity or desire to collaborate, or local Dais have approached male health worker for backup/referral .*

G. Local Dais have been trained in the community.*

H. Community request for $\mathrm{MCH}$ program that is feasible in relation to their resources.*

I. Security for civilian population - ethnic, tribal, military.*

J. Expressed interest in women's educational programs.

K. Level of education for women or literacy above the estimated mean of 1-5\%.

L. Other programs which state relatively high involvement of women.

M. EPI - vaccination campaign in an area previously that had report of good access to female and child population.

N. Health facility or another public building has accommodation for women - either separate or integrated.

o. Target population of women and children estimated by survey (low, medium, or high).

P. Monitoring/survey/assessment reports that describe active interest or programs and correlate with some of above mentioned indicators.

Q. Expatriate women have been welcome in the community and assisted in their work.

R. Prior to the war there was an active/accepted $\mathrm{MCH}$ program.

s. Administrative structure within an area that could assist or sustain a program of any type.

T. Referral structure or network between levels of health facility.

U. Socio-economic level.

Level one

only male health workers available seeing less than $20 \%$ of 
their patients as women and children. Community expresses low willingness to support MCH activities. LOw support for women's programs. Possibly active military fighting. No contact with local Dais.

\section{Interventions}

A. Create training materials for male health workers at basic, midlevel, and MD for the topics listed within the WHO Health Worker Skills checklists on topics related to MCH, nutrition, immunization and health communication (See WHO/CMC/ACBAR Health Worker Levels and Training, Chapter 2, Pages 16-56). Distribution of these materials. This could include the "prime health message posters and Facts for Life with its prime messages.'

B. On-site or in Pakistan, begin upgrading or refresher training for male health workers on the topics listed within WHO/CMC/ACBAR Health Worker skills checklists on topics related to $\mathrm{MCH}$, nutrition, and health communication.

c. Initiate immunization services (fixed or mobile) if feasible and community interest. EPI protocols targeting female and child population as locally adapted for cross-border.

D. Insure immunization coverage within the refugee camps to prepare for repatriation and in keeping with the logic that many of the target population within the geographic area are in the camps.

E. Linking health educaton to agricultural or food supply programs if occurring.

F. Establish the referral network in use - where are women and children sent if they are heard of or seen?

\section{Level Two}

Only male health workers available who report seeing 25-40\% female patients and children. No contact or familiarity with TBAs or other FHW resources. Area is relatively stable without active military conflict. Population base "mediumhigh" for women and children.'

${ }^{9}$ Facts for Life, A Communication Challenge, UNICEF/WHO/UNESCO, in English and Dari. 


\section{Interventions}

A. Begin information flow process whereby male health worker is provided feedback and positive response for his interventions in $\mathrm{MCH}$.

B. Upgrading or refresher training for male health workers on the topics listed within WHO/CMC/ACBAR Health Worker Levels and Training on topics related to $\mathrm{MCH}$, nutrition, immunization and health communication (see chapter 2, Pages 16-56).

c. Consider approaches to community and health worker motivation for locating TBAs.

D. Meetings with community authorities, scholars, and common people to motivate for female access to health care workers.

E. Immunization campaigns with health worker involvement.

F. Consider with the health worker and the community how access to health services could be improved with existing resources, i.e. provision of a separate waiting area, separation of certain clinic functions or timing for women.

G. Integration of health topics within primary school topics.

H. Use of Media for reaching population, e.g. radio services.

\section{Level Three}

Male health workers report seeing at least $40 \%$ female patients. Male health worker has had initial or ongoing contact with TBA in community or another mechanism for working with female member of community to extend services. Female health workers, who are TBAs or other uneducated members of community, actively working with community support and having contact with male health workers. Health facility exists with supply system. Community expresses moderate to high willingness to begin/design an $\mathrm{MCH}$ program.

\section{Interventions}

A. Use of male and female health workers to provide more specific information regarding females and children within the community. Design of information gathering tools with feedback for this process. This should include a level whereby the available health facility 
resources are evaluated and discrepancies noted in looking area to area.

B. Expanded training for male health workers on support and training of TBAs either on-site or in refresher training organized outside the area.

c. Evaluate the level of knowledge and skills of TBAs.

D. Upgrade the skills as needed of TBAs. provision of the standardized manual for training of TBAs produced by UNHCR (cross-border adaptations have been done and should be reviewed).

E. Ensure supply and support mechanisms. See Append1x 3 for list of supplies which are provided in TBA kits for refugee camps.

F. Involvement of TBA in vaccination campaigns - in planning, motivating, or implementation level.

G. Initiate record keeping and information flow process for TBAs in the area. Since most are illiterate there would have to be a format for data collection by the woman and a mechanism for information flow between the TBA and the responsible health unit.

H. Strengthen and support the referral system between the male health workers (particularly mid-level and above) with the TBAs. This may be the most critical component in actually impacting maternal mortality so that high risk cases identified have means for referral. Appendix 2 - Classification of Health Facilities.)

(see

I. Survey of the area by existing health workers or visitors to the area could be possible. The TBA record keeping would form one basis for gathering information. Female surveyors would provide most rellable information and larger sample size.

J. Community education schemes for the topics included within MCH. (See Appendix 4 - Issues for Training and Appendix 5 - MCH Training and Resource list.)

K. Use of moblle teams (pllot) providing certain types of MCH services could be possible on scheduled basis to the area.

L. Use of moblle teams (pilot) to provide $\mathrm{MCH}$ training elther upgrading, refresher, for males and female health workers in the area. 
M. Begin information flow process whereby male health worker is provided feedback and positive response for his interventions in $\mathrm{MCH}$ and his contact with the TBA or other female health worker.

N. Consider with the community mechanisms for recruiting female health staff for higher level training from the area. If such a person is found (e.g. wife of health worker) training on-site or outside the immediate region may be possible.

\section{Level Four}

Female health workers, mid-level, nurse or MD available in an area. Active support by the community for these female health workers. Health facility available. security situation stable.

\section{Interventions}

A. Training or upgrading of these health workers in teaching methodology and technical skills on topics related to $\mathrm{MCH}$. Definition of skills checklists within $\mathrm{MCH}$ for female workers of various levels - mid-level, MD, nurses.

B. Create mechanism whereby female health worker has the ability to expand area of service or population coverage. This may be by the provision of transport. This would also include visit to surrounding health facilities and workers to be sure they understand the resqurces available and how best to refer problems. Define limits of catchment area in relation to geography, roads and transport, political situation, ethnic differences, or other factors.

c. Utilize these workers as trainers for other female health workers.

D. Ensure immunization is available as a service.

E. Ensure expanded supply available for scope of services the health workers can offer. This may include drugs, equipment for women's health and gynecology, nutrition rehabilitation.

F. Strengthen admin/management structure for health system in the area.

A summary of health levels is given in Appendix 6 . 
IV. DATA COLLECTION AND MONITORING

The indicators as defined above include only those based on information which is currently readily available and integrated within many programs in Afghanistan. These include greenbooks (patient registers), monitoring and assessment surveys (see appendix 7, wHO Health Facility Questionnaire Form), and interviews with health workers when they return to Pakistan. However, there are many other types of information which should be considered for future collection and analysis for action. Keeping the future goals in mind a mechanism should be designed utilizing various forms of data collection which will give more standard information regarding IMR, MMR, and under $5 \mathrm{~s}$ mortality. Certain simplified survey techniques including household survey, key informant interviews, focused group research, to name a few, would provide important baseline information. The point is that more sophisticated types of data need to be collected and the implementation of these tools is an available next step in the planning. However, the selection of target areas for action would need to be carefully considered and will be most feasible in levels three and four.

It is noteworthy that initiation of nutritional survey to define areas of need for assistance or to follow the impact of intersectoral programs could be done at all MCH levels.

The consolidation and presentation of EPI information is currently not adequate. The mapping of this information regarding where campaigns have occurred and areas of coverage would be very important. Additionally, it will be necessary to describe areas which are planned. Monitoring of the EPI activities and refinement based on this feedback is essential.

v. RECOMMENDATIONS FOR THE FUTURE

A. Selected geographical areas within Afghanistan need to be defined according to the $\mathrm{MCH}$ indicators. It is understood that the indicators and profile of an area would change over time - sometimes abruptly for the worse, sometimes gradually for the better. It is important that key fields or core indicators be selected within the categories to assist the process of "leveling". Utilizing the levels provided and considering the indicators both for planning and monitoring programs will allow experience with this framework. 
d. Define surveys that can be carried out within Afghanistan that would assist the motivation of programs and health workers towards actions related to $\mathrm{MCH}$. This would include quantifiable information such as MMR, IMR, patterns of morbidity and mortality for women. It would also include qualitative information such as cultural practices which are part of MCH and have an impact on family health.

c. Develop a format for information feedback to the field level regarding their activities/impact in the MCH component activities.

D. Use of WHO Health Information system (HIS) and input from NGOs and monitoring/assessment missions to sort health workers who have active interest in MCH programs as per the indicators described. This will allow more individualized actions as per the strategies described. The differentiation needs to be whether the health worker is limited in access to women based on individual factors or is restricted by issues within the community. The former may be addressed by training and support or recruitment; the latter will not.

E. Define in more detail the indicators for community acceptance and for socio-economic development than those listed on pages 61 and 62 .

F. Review of programs, materials and systems in the Afghan refugee camps for applicability and adaptability within Afghanistan.

G. Review and define supplies/equipment needed far MCH services for female health workers. What supplies should female midlevel workers, female physicians and nurses have?

H. Specific sections of the wHO skills checklists for different levels of health worker need to be expanded into actual training materials particularly on $\mathrm{MCH}$ related topics.

I. Develop skills checklists for female health workers including TBAs, nurses, physicians.

J. EPI guidelines regarding protocols and target ages should be used when designing MCH activities.

\section{CONCLUSIONS}

A. Male health workers represent the major health resource within Afghanistan. There is a very large pool (thousands) of thes? male health worker resources. Although they do not represent the "best" solution, they 
do represent a component of the solution. It has been shown that male health workers taught $\mathrm{MCH}$ in their training programs are more likely to work with female patients and children upon graduation and placement in their home areas. All training programs should consider how their male workers can contribute to $\mathrm{MCH}$. This includes not only general medical workers but vaccinators, and other specialty workers.

B. The selection criteria for male health workers is an important aspect of $\mathrm{MCH}$ programs. Recruitment which considers the workers' acceptance and respect within the community will increase the possibility that they will be more functional and supportive of $\mathrm{MCH}$ efforts. Additionally, a mechanism under consideration is the fact that recruitment of male workers with female family members who could also be trained will be tried. This is worth following over time. Improving and refining selection criteria will be a part of increased on-site presence by the agencies working within Afghanistan.

c. In that an estimated $80 \%$ of rural Afghanistan would be categorized between levels $1-3$, it is essential to increase the pool of female health workers. This training must be done both in Pakistan in the context of repatriation and on-site within the areas targeted for programs. This will be a long term effort but as has been shown it is possible in certain places.

D. Integration of health topics within primary schools will reach young girls in certain areas. Beyond this age the likelihood of them attending schools greatly diminishes. The health topics provided to the children (both male and female) can impact the family health status and practices. Female teachers might be of vital importance in expanding $\mathrm{MCH}$ strategy and can greatly assist health programs.

E. Following the upgrading of areas from level three to level four involves an important shift in the emphasis of $\mathrm{MCH}$ programming. It is at this level that infrastructure development, referral network and training will be essential. In level four, more sophisticated systems can be strengthened whereby the link between village and central level will be the focus of activity. Refer to Appendix 8. 


\section{The Road to Maternal Death}

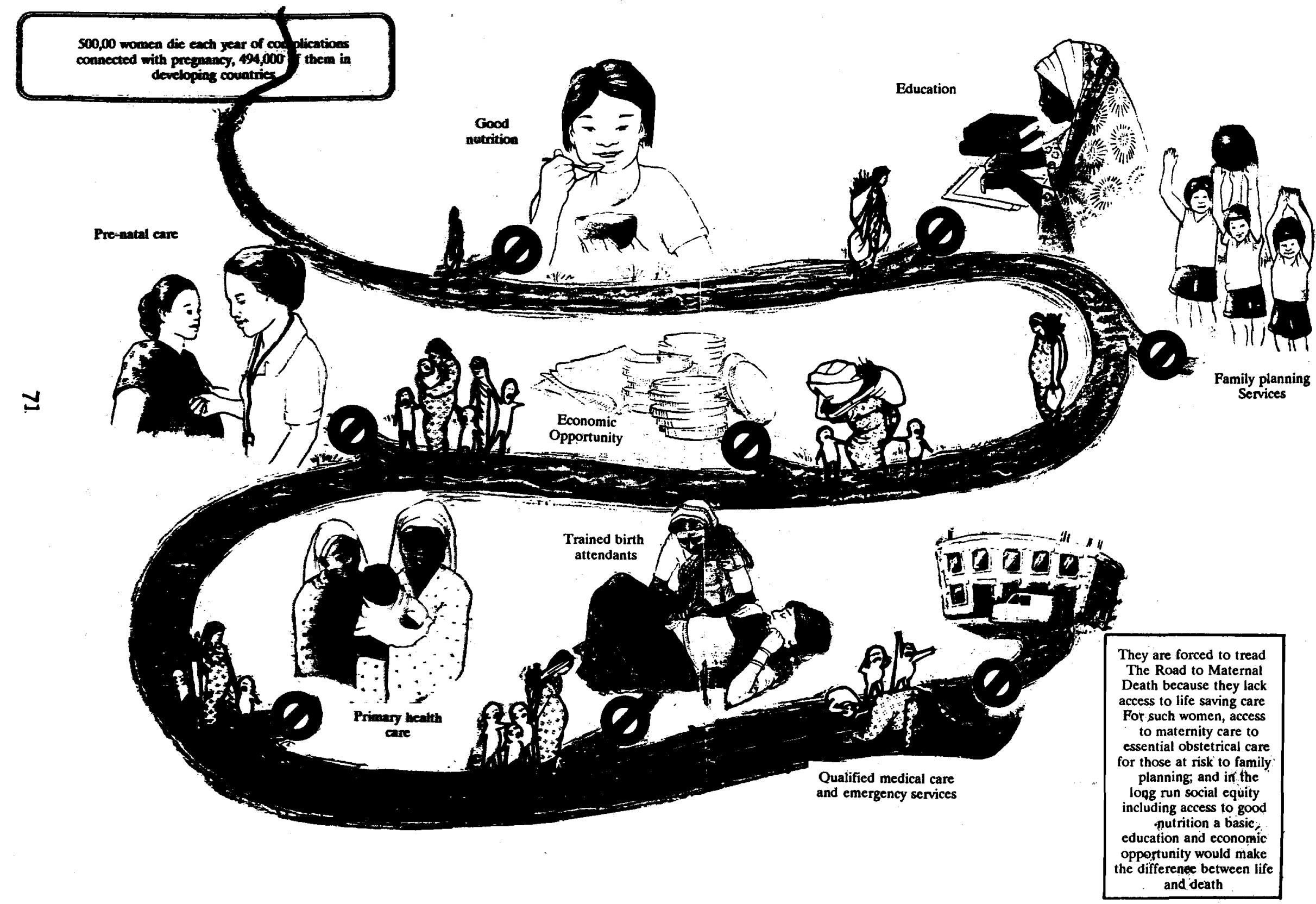




\section{APPENDIX 2}

\section{CIng8IPICATIOA OF HBATH PACITITIBB}

\begin{tabular}{|c|c|c|c|c|c|c|}
\hline DEBCRIPTION OF THE & $\begin{array}{l}\text { Regional } \\
\text { Hospital }\end{array}$ & $\begin{array}{l}\text { Province } \\
\text { Hospital }\end{array}$ & $\begin{array}{l}\text { District } \\
\text { Hospital }\end{array}$ & $\begin{array}{l}\text { Comprehe } \\
\text { nsive HC }\end{array}$ & $\begin{array}{c}\text { Basic } \mathbf{H} \\
\text { Center }\end{array}$ & $\begin{array}{l}\text { Basic } \\
\text { H. Post }\end{array}$ \\
\hline $2 \cos 202$ & $H-1$ & $H-2$ & $\dot{H}-3$ & $c-1$ & $c-2$ & $c-3$ \\
\hline $\begin{array}{l}\text { HEALTH PERSOLREL } \\
\text { - M.D Doctors } \\
\text { - Surgeons } \\
\text { - Mid-level HWs } \\
\text { - Basic H. Workers } \\
\text { - TOTAL HEALTH STAFF }\end{array}$ & $\begin{array}{c}\text { Many } \\
1+ \\
\text { Yes } \\
-- \\
16-20\end{array}$ & $\begin{array}{c}3+ \\
1+ \\
\text { Yes } \\
-- \\
12-16\end{array}$ & $\begin{array}{c}1-3 \\
\text { Maybe } \\
\text { Yes } \\
\text { Maybe } \\
8-12\end{array}$ & $\begin{array}{c}1 \\
--- \\
\text { Yes } \\
\text { Maybe } \\
4-8\end{array}$ & $\begin{array}{c}--- \\
1-- \\
\text { Maybe } \\
2-4\end{array}$ & $\begin{array}{l}--- \\
--- \\
--- \\
1+ \\
1-3\end{array}$ \\
\hline $\begin{array}{l}\text { HEALTH FACILITIEB } \\
\text { - Operation Theatre } \\
\text { - Laboratory } \\
\text { - X-Ray } \\
\text { - Inpatient Beds } \\
\text { - Specialized Progs. } \\
\text { (TB, Malaria, etc) } \\
\text { - Medical Records } \\
\text { - Transport (Reffers) }\end{array}$ & $\begin{array}{c}\text { Speciali } \\
\text { supervsr } \\
\text { Yes } \\
50-100 \\
\text { Supervi- } \\
\text {-sory } \\
\text { Yes } \\
\text { Yes }\end{array}$ & $\begin{array}{l}\text { Major } \\
\text { Refferal } \\
\text { Yes } \\
20-50 \\
\text { Yes } \\
\text { Yes } \\
\text { Maybe }\end{array}$ & $\begin{array}{l}\text { Minor } \\
\text { Field } \\
\text { Yes } \\
10-20 \\
\text { Planned } \\
\text { Pt Card } \\
\text { Maybe }\end{array}$ & $\begin{array}{l}\text { Field } \\
3-5 \\
\text { Maybe } \\
\text { Pt Card }\end{array}$ & $\begin{array}{l}--- \\
--- \\
--- \\
--- \\
--- \\
\text { Pt Card } \\
---\end{array}$ & $\begin{array}{l}--\infty \\
--- \\
--\infty \\
--\infty \\
--- \\
\text { Varies } \\
--\infty\end{array}$ \\
\hline COVERAGE & $\begin{array}{l}3-6 \text { prov } \\
\text { inces }\end{array}$ & $\begin{array}{l}1-2 \text { prov } \\
\text { inces }\end{array}$ & $\begin{array}{l}1-3 \text { dist } \\
\text { ricts }\end{array}$ & $\begin{array}{l}30-50000 \\
\text { Popula. }\end{array}$ & $\begin{array}{l}5-30000 \\
\text { Popula. }\end{array}$ & $\begin{array}{l}500-5000 \\
\text { Popula. }\end{array}$ \\
\hline BERVICES RROVIDED & $\mid \begin{array}{l}\text { Initial } \\
\text { Training }\end{array}$ & $\begin{array}{l}\text { Refreshe } \\
\text { Training }\end{array}$ & $\begin{array}{l}\text { DAI } \\
\text { Training }\end{array}$ & $-\infty$ & $-\infty$ & $-\infty$ \\
\hline
\end{tabular}




\section{APPENDIX 3}

\section{DAI RIT}

Minimum requirements are:

1. Plastic sheet

2.* Soap/soap box

3. Nail brush :

4.* Razor blades

5.* Thread to tie cord

6. 5 large cloth perineal pads

7. Four pieces of cloth to clean baby's eyes, nose, mouth and cord.

8. Plastic apron

9. Shoulder bag for carrying equipment

10.* Cotton wool

11. Report forms

*Items which are resupplied.

(Modified from Maternal \& Child Health Guidelines, Chief Commisserionate Afghan Refugees/United Nations High Commissioner for Refugees, Islamabad 1989, P.22.) 


\section{APPENDIX 4}

\section{IBBUES FOR TRAINING}

A. Women from one: village are most often taught as a group since it is difficult for them to travel to other villages.

B. Practical demonstrations combined with discussion are useful and effective for teaching TBAs.

c. Manikins have proven to be good teaching aids for illiterate women.

D. Pictures may be difficult to understand - one exception may be slides where the size of the people can be shown correctly.

E. It is better to avoid material that requires advanced technology and electricity such as video. However, audio cassettes in the local language are popular and if a cassette player is available in the village the information may reach the women well.

F. Books and written teaching materials aré useful only for those who can read. The quality and suitability must be evaluated in terms of the local situation.

G. Follow-up on a regular basis has proven difficult. The $\mathrm{MCH}$ staff must be willing to improvise and adjust accordingly.

H. Radio messages broadcast in local languages as available by $B B C$ in Pashtu and Dari have broad access and acceptability. 
APPENDIX 5

RESOURCES

The Dai (traditional midwife) in rural Baluchistan : tradition and change / Pamela Hunte, Farhat Sultana. Quetta: UNICEF, 1984; 65 p. : map, questionnaire.

Evaluation of infant mortality and childhood nutritional status among Afghan refugees in Pakistan, $1990 /$ Rudolf $H$. Tangermann, Elsie Pamuk. Islamabad: UNHCR, 1990. 30 p.: charts, stats.

Evaluation of mother-child centers program for Afghan refugees, Hanqu, Pakistan / Nancy Hatch Dupree. Durham, N.C.: the author, 1989. $31 \mathrm{p}$.

Formation pour les accoucheuses traditionneles dans de Logar : rapport de mission 11 mai au 3 aout 1989 / en colloboration avec AVICEN, Catherine Carnet pour AMI/AFGHA. Peshawar: Aide Medicale Internationale, 1989. $23 \mathrm{p}$.

Indigenous methods of fertility regulation in Afghanistan / Pamela A. Hunte in: Women's medicine: a cross-cultural estudy of indigenous, New Brunswick: Rutgers University Press, 1985. 33 p.

Infant and underfive mortality: achievements and problems encountered; lessons from ARC's Primary Health care Programme / Abdul Rahman Zamani. Peshawar: Austrian Relief Committee, 1989. 9 p. : maps, charts.

Interview (KAP-survey) with Kamila, Afghan traditional birth attendant (dai) / Petra van den Bongart and Annika Janson. Peshawar: AHSAO, 1989. 18 p. : questionnaire.

Maternal and child health: guidelines / Afghan Refugee Health Programe Pakistan. Islamabad: Chief Commissionerate Afghan Refugees, UNHCR, 1989. 44 p.: ill.

Maternal and child health handbook of Japan. Tokyo: Japanese organization for International Cooperation in Family Planning, 1981. 58 p. : forms,

Obstetric emergencies: a manual for rural health workers / by $\mathrm{J}$. Everett. Nairobi: African Medical and Research Foundation, 1987. 29 p.: ill.

Recrutement de femmes dans la vallee du Panjshir : rapport de mission - septembre octobre 89 / Catherine Carnet. Peshawar: Aide Medicale Internationale, 1989. $16 \mathrm{p}$. 
"The Role of the dai (traditional birth attendant) in urban Afghanistan : some traditional and adaptational aspects" / Pamela A. Hunte. In: Medical Anthropology, v.5, no.1, pp.17-26 (1981). $10 \mathrm{p}$.

Safe delivery: protecting your baby during high risk pregnancy / Roger K. Freeman, Susan C. Pescar., New York: McGraw-Hill, 1983. 314 p.: ill., b\&w photos.

The Traditional birth attendant (TBA) trainers manual. Peshawar: UNHCR, 198-?. $51 \mathrm{p}$.

Trainers manual: Maternal-child Health Education Project for Afghan Women / adapted by Judy Carlson, Freedom Medicine, from The Afghan female health workers training manual (UNHCR). Peshawar: Freedom Medicine, 1990. 82 p.

The Utilization of early childhood care and education programmes for delivery of MCH/PHC components : a framework for decisionmaking / Judith L. Evans with the collaboration of Robert G. Myers. Ypsilanti, Mich.: High/Scope Educational Research Foundation, 1985. $77 \mathrm{p}$.

Working with women in Ghazni, Afghanistan / Inger Rolstad. Peshawar/Oslo: Norwegian Committee for Afghanistan, 1990. 21 p. : col. photos.

In Dari and Pashtu:

Baby care programme [Dari] / S. Bacher. Peshawar: IRC Mother \& Child center, [198-]. 44 p. : ill.

Breastfeeding [flipchart] [Dari, Pashtu, Urdu] / HERC, UNICEF. Peshawar: IRC Health Education Resource Center, 1990. 8 cloth panels on wooden rod : col. ill.

Child care course [Dari/Pashtu/Urdu]. Peshawar: Pak-German Bas-Ed, 1990. 4 v. (guidelines, 2 flipcharts, English text) + audio cassettes.

Maternal and child health handbook of Japan [Dari]. Peshawar: s.n., 1989. 43 p. handwritten.

Mother's bosom [Pashtu] / by M. Kaiwon Hoven. Peshawar: SERVE, 1983. 71 p.: ill.

New-born baby [Dari] / Janie Hampton. Peshawar: IRC Mother \& Child Center, 1989. 23 p. 
No bored babies [Dari] / Jan Fisher Shea. Peshawar: IRC Mother \& Child center, 1990. 37 p. : ill.

Ready to play [Dari] / Christine Lemon. Peshawar: IRC Mother \& Child Center, 1989. $40 \mathrm{p}$.

Weaning foods [flipchart] [Dari, Pashtu, Urdu]. Peshawar: IRC Health Education Resource Center, 1990]. 6 cloth panels on wooden rod : col. ill.

IRC's Health Education Resource Center (HERC) holds many further general books on $\mathrm{MCH}$ as well as a number of audio-visual aids (audio and video tapes, slides and posters). 
TEACHING AID KIT

(produced by $\mathrm{SCF}-\mathrm{UK}$ )

contents

1. Trunk

2. Cotton bag

3. Lock

4. Ball

5. Bar of soap

6. Soap dish

7. Dexie

8. Cotton thread

9. Cotton wool

10. Metal spoon

11. Lota plastic (water container) 1

12. Washing basin (silver) 1

13. Tea cup 1

14. Plastic container 1

15. Razor blades 2

16. Nail brush 1

17. Red dye 1

18. Plastic bowls very small 2

19. Plastic sheet $1 \mathrm{~m}$

20. Cloth poster

21. Fetus

22. Doll

23. Placenta with cord 1

24. Soft uterus 1

25. Delivery box 1

26. Medium pieces of cloth for mother 3

27. Large pieces of cloth for baby 3

28. Very small pleces of cloth to clean baby's eye, ear, mouth and nose 4

29. Salt

cosT OF KIT (1989)

Rs. 1.400 .00 


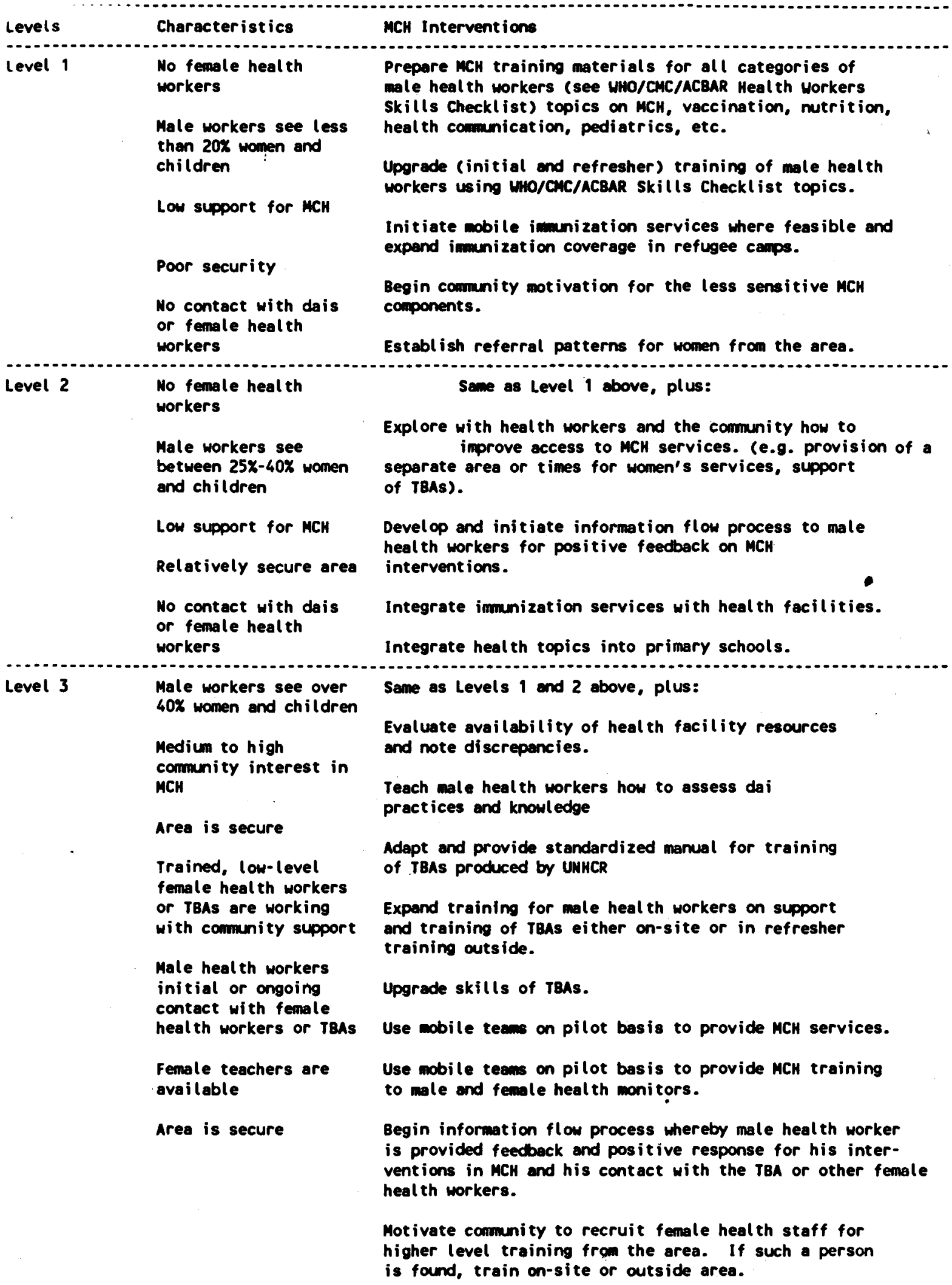


Evaluate infrastructure and referral for TBAs.

Involve TBA in vaccination campaigns.

Develop and initiate record keeping and information flow process for TBAs (for workers).

Survey the area with existing or visiting personnel.

Female surveyors would provide more reliable information and a larger sample size.

Strengthen and support the referral system between the male heal th workers (particularly mid-level and above) with the T8As. This may be the most critical component for impacting maternal mortality so that high risk cases can be referred (See appendix 4 for Classification of Health Facilities).

Implement pilot projects for providing transport for female patients.

Develop commenity education schemes for the topics included within MCH.

Level 4

\begin{abstract}
Female heal th workers (mid-level, nurse or M.D.) are available

High comminity support for MCH
\end{abstract}

Area is secure
Same as levels 1, 2, and 3 above, plus:

Define skills checklists within MCH for female health workers of various levels - mid-level, nurses, M.D.

Train and upgrade female heal th personnel in teaching methodology and technical skills on topics related to MCH.

Expand area of service or population coverage through provision of transport, and linking with other heal th resources and facilities. Define limits of catchment area in relation to geography, roads, transport, political situation, ethnic differences, etc.

Utilize these workers as trainers or other health workers.

Ensure immization is available; establish fixed services if feasible.

Ensure expanded supply for scope of services by female heal th workers (i.e. drugs, ob/gyn equipment, nutrition rehabilitation.

Strengthen admin/management structure for the area health system. 
П.H.O HEALTH FACILITY QUEBTIONNAIRE FORM (revision 28.02.90)

A. IOCATION INFORMATION

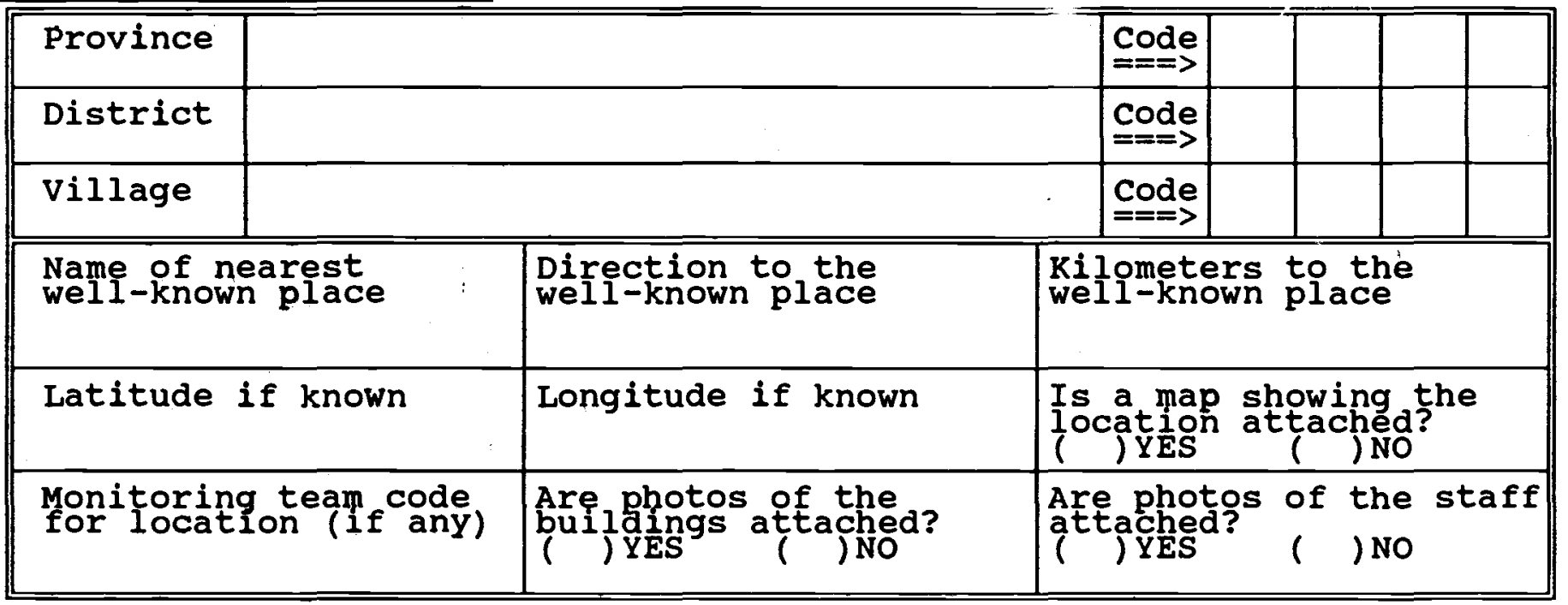

\section{B. MONITOR TEAM INFORMATION}

Fill in the information on the monitors who completed the form and the persons who provided the information to the monitors ("interviewees").

\begin{tabular}{||l|l|l|l||}
\hline $\begin{array}{l}\text { Monitors and } \\
\text { Data Sources }\end{array}$ & Name & $\begin{array}{l}\text { Position/fion } \\
\text { Organization }\end{array}$ & Date \\
\hline \hline Monitor 1 & & & \\
\hline Monitor 2 & & & \\
\hline Monitor 3 & & & \\
\hline Interviewee 1 & & & \\
\hline Interviewee 2 & & & \\
\hline Interviewee 3 & & & \\
\hline Interviewee 4 & & & \\
\hline Interviewee 5 & & & \\
\hline
\end{tabular}

\section{PACITITY IDENTIPICATION}

\begin{tabular}{|l|l||l|l|}
\hline \hline $\begin{array}{l}\text { Facility } \\
\text { Name }\end{array}$ & W.H.O. ID Number & \\
\hline Party & & Other ID Number & \\
\hline Commander & & Date Established & \\
\hline
\end{tabular}




\section{PHY8ICAL RESOURCE INFORMATION}

Where possible, fill in the information from personal observation. Circle the choice that best describes the situation or fill in "other". Some of the information, such as the status of the laboratory and $x-r a y$ machine, will have to be based on the statements of the staff at the facility.

\begin{tabular}{|c|c|c|c|c|}
\hline \multicolumn{3}{|c|}{ Number in-patient beds/spaces } & \multirow{2}{*}{\begin{tabular}{|l||l|} 
Number & Meters \\
of rooms & to water
\end{tabular}} & Kilometers to road \\
\hline spaces & real beds & planned & & drivable \\
\hline \multicolumn{2}{|c|}{ Type of location } & \multicolumn{3}{|c|}{$\begin{array}{l}\text { province-cntr / district-cntr / sub-district-cntr } \\
\text { viliage / outside village / military camp } \\
\text { other: }\end{array}$} \\
\hline \multicolumn{2}{|c|}{ Type of building } & \multicolumn{3}{|c|}{$\begin{array}{l}\text { cement / stone / wood-frame / mud / cave } \\
\text { other: }\end{array}$} \\
\hline \multicolumn{2}{|c|}{ Plan for building } & \multicolumn{3}{|c|}{$\begin{array}{l}\text { temporary-health-use / permanent-health building } \\
\text { other: }\end{array}$} \\
\hline \multicolumn{2}{|c|}{$\begin{array}{l}\text { War damage needing } \\
\text { repair }\end{array}$} & \multicolumn{3}{|c|}{$\begin{array}{l}\text { none / windows-doors-out / 25\%-structure-damage } \\
50 \% \text {-structure-damage / 75\%-structure-damage } \\
\text { other: }\end{array}$} \\
\hline \multicolumn{2}{|c|}{ Electricity source } & \multicolumn{3}{|c|}{$\begin{array}{l}\text { none / generator }(\mathrm{kw}) / \text { powerline from } \\
\text { other: }\end{array}$} \\
\hline \multicolumn{2}{|c|}{ Heat source } & \multicolumn{3}{|c|}{$\begin{array}{l}\text { none / kerosene / wood / dung / electric } \\
\text { other: }\end{array}$} \\
\hline \multicolumn{2}{|c|}{ water source } & \multicolumn{3}{|c|}{$\begin{array}{l}\text { none/ spring/ river/ stream/ well/ karez/ canal } \\
\text { other: }\end{array}$} \\
\hline \multicolumn{2}{|c|}{ Latrine } & \multicolumn{3}{|c|}{$\begin{array}{l}\text { none / yes-functioning / yes-but-not-functioning } \\
\text { other: }\end{array}$} \\
\hline \multicolumn{2}{|c|}{ Laboratory } & \multicolumn{3}{|c|}{$\begin{array}{l}\text { none / yes-functioning / yes-but-equipment-broken } \\
\text { yes-but-supplies-missing / yes-but-no-technician } \\
\text { other: }\end{array}$} \\
\hline \multicolumn{2}{|c|}{$x$-ray machine } & \multicolumn{3}{|c|}{$\begin{array}{l}\text { none/ yes-functioning / yes-but-equipment-broken } \\
\text { yes-but-supplies-missing / yes-but-no-technician } \\
\text { other: }\end{array}$} \\
\hline \multicolumn{2}{|c|}{ Operating theatre } & \multicolumn{3}{|c|}{$\begin{array}{l}\text { none / major / minor } \\
\text { other: }\end{array}$} \\
\hline \multicolumn{2}{|c|}{ Anesthesia } & \multicolumn{3}{|c|}{$\begin{array}{l}\text { none / local / ketamine / inhalation / spinal } \\
\text { other: }\end{array}$} \\
\hline \multicolumn{2}{|c|}{ sterilization } & \multicolumn{3}{|c|}{$\begin{array}{l}\text { none / chemical / pressure-cooker / autoclave } \\
\text { other: }\end{array}$} \\
\hline \multicolumn{2}{|c|}{$\begin{array}{l}\text { Transport (how many } \\
\text { of each alloted to } \\
\text { the facility) }\end{array}$} & \multicolumn{3}{|c|}{$\begin{array}{l}\text { none / ambulance( ) truck( ) motorcycle( } \\
\text { bicycle }(\text { ) horse ( ) } \\
\text { other: }\end{array}$} \\
\hline \multicolumn{2}{|c|}{$\begin{array}{l}\text { Refrigeration for } \\
\text { Vaccine Storage }\end{array}$} & \multicolumn{3}{|c|}{$\begin{array}{l}\text { none / gas-electric / kerosene-electric / gas-only } \\
\text { kerosene-only / electric-only / solar / coldbox } \\
\text { other: }\end{array}$} \\
\hline \multicolumn{2}{|c|}{ Patient records } & \multicolumn{3}{|c|}{$\begin{array}{l}\text { none / greenbook / patient-register / patient-card } \\
\text { other: }\end{array}$} \\
\hline
\end{tabular}


E. OUANTITY AND DIBTRIBUTION OF BERVICE INFORWATION

\begin{tabular}{|c|c|c|c|}
\hline FILL IN NUMBERS FOR EACH OPEN BOX & winter & Summer & Average \\
\hline Outpatient visits per month & & & 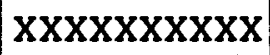 \\
\hline Inpatient admits per month & & & $\mathrm{XXXX \times X \times X \times X}$ \\
\hline Hours worked per day & & & 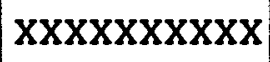 \\
\hline Percentage women patients & $\mathrm{XXXXXXXXX}$ & 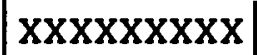 & \\
\hline Percentage patients under 5 & $\mathrm{XXXXXXXXX}$ & $\mathrm{XXXXXXXXX}$ & \\
\hline Number of villages served & 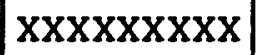 & $\mathrm{XXXXXXXXX}$ & ' \\
\hline Estimated population served & 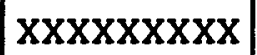 & 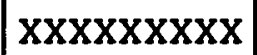 & \\
\hline
\end{tabular}

\section{F. BUPPORT INFORYATION}

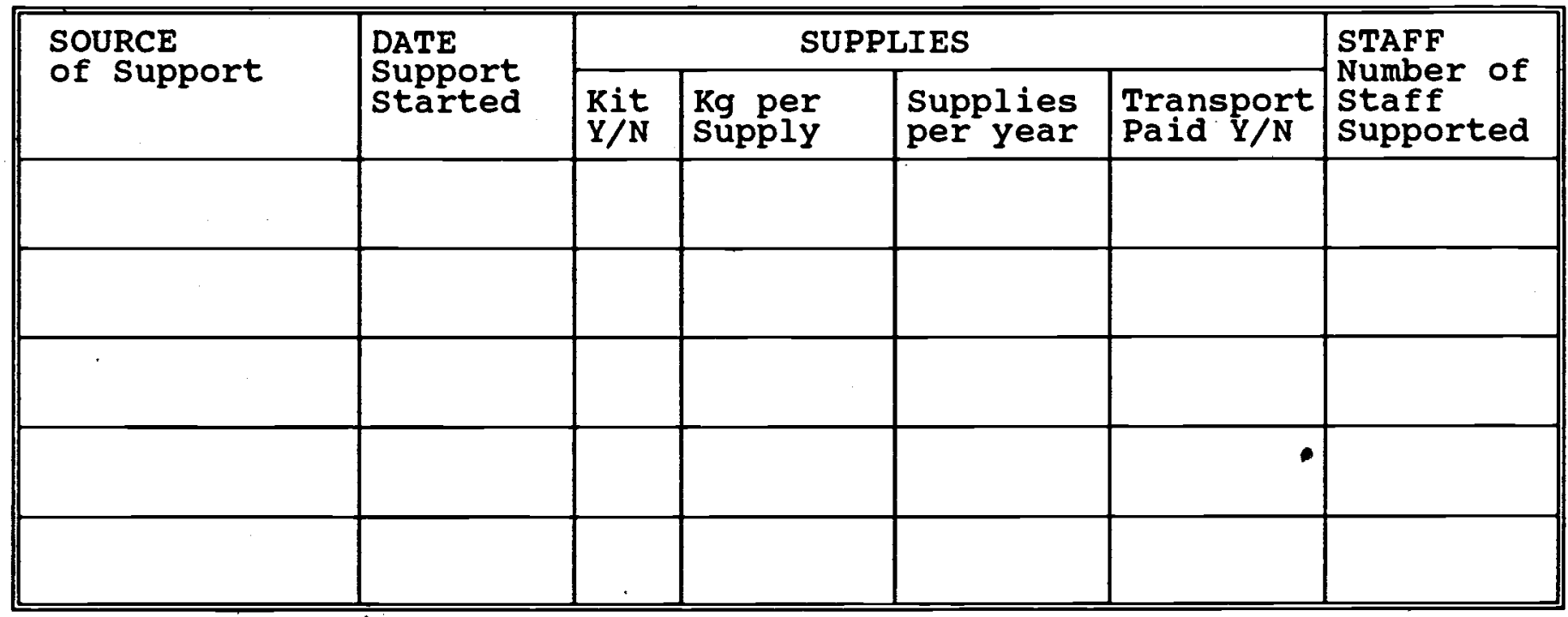

\section{G. STAFF COMPLEMENT INFORMATIOH}

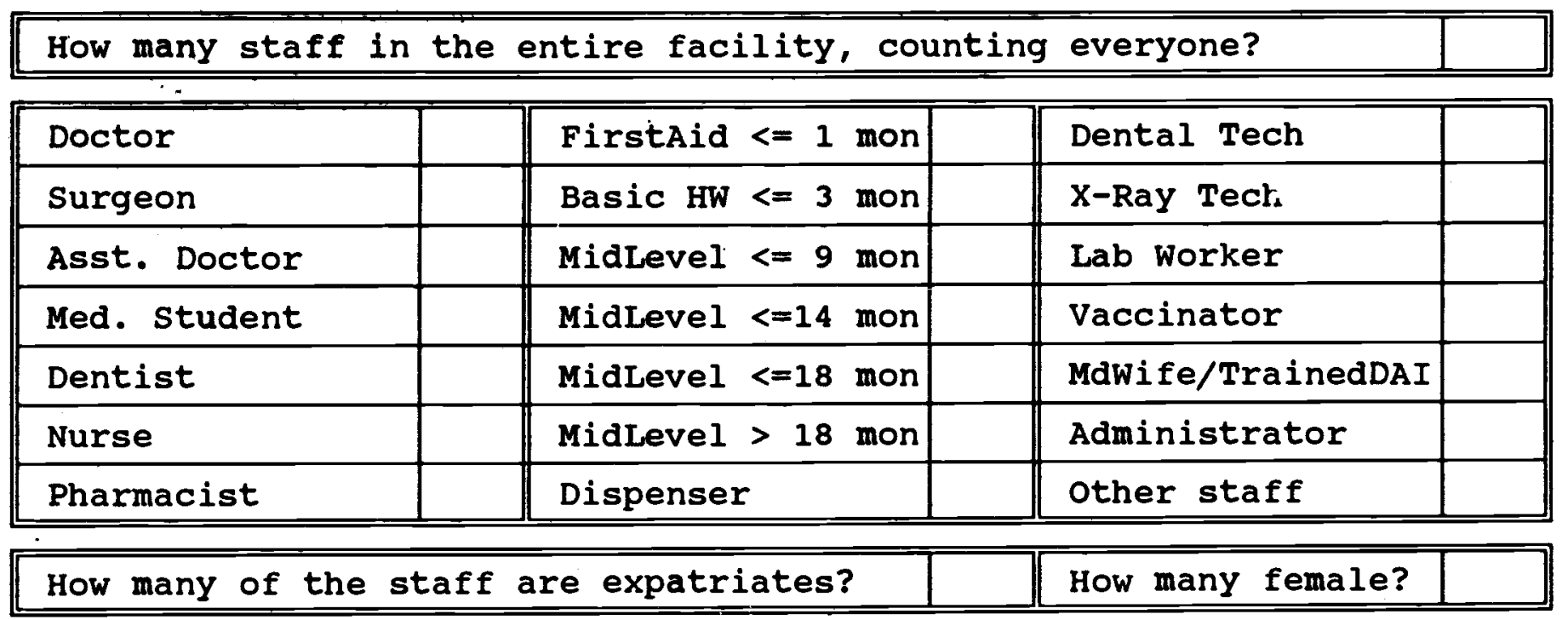




\section{H. EOUIPKENT INFORMATION}

Check to see if the following equipment is present at the facility. If it is not present do not make any mark. If it is present and functional, put an $x$ in the "GOOD" column. If it is present but not functional, put an $x$ in the "BAD" column and give a brief explanation of the problem.

\begin{tabular}{|c|c|c|c|}
\hline EQUIPMENT DESCRIPTION & GOOD & BAD & If $B A D$, describe problem \\
\hline \multicolumn{4}{|l|}{ Thermometer } \\
\hline \multicolumn{4}{|l|}{ stethescope } \\
\hline \multicolumn{4}{|l|}{ Blood Pressure Cuff: } \\
\hline \multicolumn{4}{|l|}{ Baby scale } \\
\hline \multicolumn{4}{|l|}{ Oxygen Tanks } \\
\hline \multicolumn{4}{|l|}{ Anesthesia machine } \\
\hline \multicolumn{4}{|l|}{ suture instruments } \\
\hline \multicolumn{4}{|l|}{ Operating table } \\
\hline \multicolumn{4}{|l|}{ Emergency amputation instruments } \\
\hline \multicolumn{4}{|l|}{ Emergency laparotomy instruments } \\
\hline \multicolumn{4}{|l|}{ External fracture fixation instr. } \\
\hline \multicolumn{4}{|l|}{ Internal fracture fixation instr. } \\
\hline \multicolumn{4}{|l|}{ Dental hand instruments } \\
\hline \multicolumn{4}{|l|}{ Dental drill } \\
\hline \multicolumn{4}{|l|}{ Suction equipment (respiratory/GI) } \\
\hline \multicolumn{4}{|l|}{ Microscope } \\
\hline \multicolumn{4}{|l|}{$\begin{array}{l}\text { T3 slide supplies (Carbol Fuchsin } \\
\text { stain AND either Methylene Blue } \\
\text { OR Malachite Green stain) }\end{array}$} \\
\hline \multicolumn{4}{|l|}{$\begin{array}{l}\text { Malaria slide supplies (Giemsa OR } \\
\text { Field stain) }\end{array}$} \\
\hline \multicolumn{4}{|l|}{ Hematocrit/Hemoglobin instrument } \\
\hline Laboratory record book & & & \\
\hline
\end{tabular}




\section{SPECIAL PROGRAYS OFFERED BY FACILITY}

If you have a special program of one of these types, put an $X$ in the "Yes" column. Circle the program description(s) that apply to your program. If you have one of these types of programs, but the descriptions do not fit your program, describe it in a few words in the "other" space.

\begin{tabular}{|c|c|c|}
\hline TYPE OF PROGRAM & YES & Circle program descripition(s) or describe \\
\hline $\begin{array}{l}\text { Prenatal \& } \\
\text { Postnatal Care }\end{array}$ & & $\begin{array}{l}\text { special hours or days / prenatal protocol } \\
\text { female health workers } \\
\text { other: }\end{array}$ \\
\hline Dai Training & & $\begin{array}{l}\text { dai trainers / number trained ( ) } \\
\text { other: }\end{array}$ \\
\hline $\begin{array}{l}\text { Well Child, } \\
\text { Growth Monitoring }\end{array}$ & & $\begin{array}{l}\text { special clinic hours or days / growth cards } \\
\text { baby scales } \\
\text { other: }\end{array}$ \\
\hline $\begin{array}{l}\text { Other Maternal, } \\
\text { Child Health }\end{array}$ & & $\begin{array}{l}\text { female waiting area / female providers } \\
\text { female clinic hours or days } \\
\text { other: }\end{array}$ \\
\hline Immunization & & $\begin{array}{l}\text { trained vaccinators / vaccination register } \\
\text { vaccines for child / women vacciation (TT) } \\
\text { mobile vaccination team / cold chain ability } \\
\text { other: }\end{array}$ \\
\hline Rehabilitation & & $\begin{array}{l}\text { trained rehab staff / special work area } \\
\text { other: }\end{array}$ \\
\hline Prostheses & & $\begin{array}{l}\text { trained prosth. staff / prosthesis workroom } \\
\text { other: }\end{array}$ \\
\hline Tuberculosis & & $\begin{array}{l}\text { patient register / TB workers / TB inpatients } \\
\text { microscope \& TB microscopist } \\
\text { other: }\end{array}$ \\
\hline Malaria control & & $\begin{array}{l}\text { malaria microscopist / spraying / education } \\
\text { follow-up slide testing } \\
\text { other: }\end{array}$ \\
\hline Leprosy & & $\begin{array}{l}\text { leprosy patient register / leprosy workers } \\
\text { other: }\end{array}$ \\
\hline Health Training & & $\begin{array}{l}\text { initial or } \\
\text { refresher }\end{array}$ \\
\hline $\begin{array}{l}\text { Patient \& } \\
\text { Community Educ. }\end{array}$ & & $\begin{array}{l}\text { meetings with community leaders / posters } \\
\text { other: }\end{array}$ \\
\hline
\end{tabular}


For sections $J$ an $K$, refer to written records if possible. Otherwise, get estimates from the most informed health worker. Check whether data is from written records or estimate, and tell who estimated it for you.

\section{J. HEALTH PROBLEM INFORMATION}

COMMON HEALTH PROBLEMS -- Out of every 100 patients you see in winter and in summer for common health problems, approximately how many have each of the following conditions. (If actual data is available from your records, please use this data to answer the question.)

\begin{tabular}{|l|l|l||}
\hline DATA FROM: ( )WRITTEN RECORDS ( ) ESTIMATED BY: \\
\hline \hline HEALTH PROBLEM & \# PER 100 SUMMER & \# PER 100 WINTER \\
\hline $\begin{array}{l}\text { Diarrheal diseases, vomiting } \\
\text { Including dysentary, amoeba) }\end{array}$ & & \\
\hline $\begin{array}{l}\text { Respiratory diseases, (bronchitis, } \\
\text { common colas, pnemonia, etc.) }\end{array}$ & & \\
\hline Malaria & & \\
\hline $\begin{array}{l}\text { Eye Diseases, (trachoma, } \\
\text { conjunctivitis, etc.) }\end{array}$ & & \\
\hline $\begin{array}{l}\text { Skin Diseases (not including } \\
\text { leprosy) }\end{array}$ & & \\
\hline Gynecological problems & & \\
\hline Nutritional problems & & \\
\hline $\begin{array}{l}\text { Various symptoms (dizziness, } \\
\text { headache, arthritis, weakness) }\end{array}$ & & \\
\hline Mine injuries & & \\
\hline War injuries (not including mines) & & \\
\hline other problems not listed & & \\
\hline
\end{tabular}

SPECIAL HEALTH PROBLEMS -- HOW many actual cases of the following special health problems have you treated, cared for, heard of, or diagnosed during the last 4 'weeks or last 3 months?

\begin{tabular}{|c|c|c|}
\hline DATA FROM:（）WRITTEN RECORDS & TIMATED BY: & \\
\hline HEALTH PROBLEM & LAST 4 WEEKS? & LASTT 3 MONTHS? \\
\hline suspected malaria TREATED & & 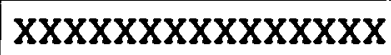 \\
\hline mine injuries TREATED & & 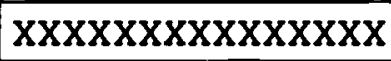 \\
\hline war injuries (not mines) TREATED & & 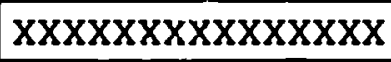 \\
\hline pregnant women CARED FOR & 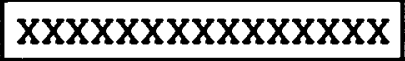 & \\
\hline measles in children under 5 TREATED & 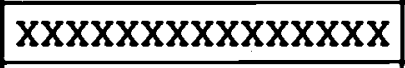 & \\
\hline neonatal tetanus HEARD ABOUT & 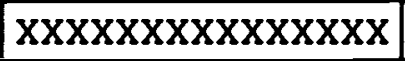 & \\
\hline polio HEARD ABOUT & 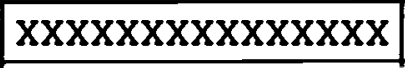 & \\
\hline new cases of tuberculosis DIAGNOSED & 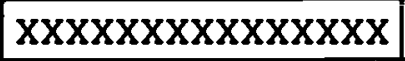 & \\
\hline new cases of leprosy DIAGNOSED & 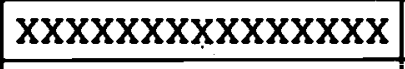 & \\
\hline new cases of goiter DIAGNOSED & 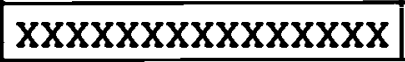 & \\
\hline
\end{tabular}




\section{HEALTH PROBLEMS (CONTINUED)}

CAUSES OF DEATH -- List the last three deaths that have occured in your area. Give approximate date of death and age of deceased, along with probable cause of the death.

\begin{tabular}{||l|r|r|l|l|}
\hline DATA FROM: ( & \multicolumn{4}{|l|}{ IWRITTEN RECORDS ( JESTIMATED BY: } \\
\hline \hline & DATE & & & \\
\hline & & & & \\
\hline & & & & \\
\hline & & & \\
\hline
\end{tabular}

OTHER HEALTH PROBLEMS -- Are there any other important health problems in your area which have not been mentioned in the sections above?

\begin{tabular}{||l||}
\hline \\
\hline \\
\hline \\
\hline \\
\hline \\
\hline
\end{tabular}

\section{R. REFERRAL INFORMATION}

Estimate the number of patients referred to the types of locations listed below during the last 3 months. For each type, give the name of the city usually referred to. If actual data is available, please provide it.

\begin{tabular}{||l|l|l||}
\hline DATA FROM: ( )WRITTEN RECORDS ( ) ESTIMATED BY: \\
\hline \hline TYPE OF LOCATION & $\begin{array}{l}\text { NUMBER } \\
\text { REFERRED }\end{array}$ & $\begin{array}{l}\text { NAME OF CITY/VILLAGE } \\
\text { Woluswali/Alakadarie }\end{array}$ \\
\hline Another facility in this district & & \\
\hline Another location in Afghanistan & & \\
\hline City or facility in Pakistan & & \\
\hline City or facility in Iran & & \\
\hline Other country (not Pakistan, Iran) & & \\
\hline
\end{tabular}




\section{DETAILED STAFF MEMBER INFORYATION}

Provide the following information for the health care provider staff at the facility. Include all technicians, health workers and administrators, but do not include guards, cleaners, etc. Attach extra pages if needed.

\begin{tabular}{|c|c|c|c|c|c|}
\hline NAME & FATHER'S NAME & SEX & AGE & $M / S$ & Expat \\
\hline OCCUPATIONAL CATAGORY & TYPE OF TRAINING & \multicolumn{2}{|c|}{ \# MONTHS } & \multicolumn{2}{|c|}{ GRAD. DATE } \\
\hline TRAINING PROGRAM/SCHOOL & CERTIFICATION & \multicolumn{4}{|c|}{ SALARY PAID BY } \\
\hline HOME PROVINCE & HOME DISTRICT & \multicolumn{4}{|c|}{ HOME VILLAGE } \\
\hline 1) & $f / n$ & $\mathbf{s}$ & a & $\mathrm{m}$ & e \\
\hline catg & type & \multicolumn{2}{|l|}{ mnth } & \multicolumn{2}{|l|}{ grad } \\
\hline prog & cert & \multicolumn{4}{|l|}{ siry } \\
\hline prov & dist & \multicolumn{4}{|l|}{ vill } \\
\hline 2) & $f / n$ & $\mathbf{s}$ & a & $\mathrm{m}$ & e \\
\hline catg & type & \multicolumn{2}{|l|}{ mnth } & \multicolumn{2}{|l|}{ grad } \\
\hline prog & cert & \multicolumn{4}{|l|}{ siry } \\
\hline prov & dist & \multicolumn{4}{|l|}{ vill } \\
\hline 3) & $f / n$ & $\mathbf{s}$ & a $\bullet$ & & e \\
\hline catg & type & \multicolumn{2}{|l|}{ mnth } & \multicolumn{2}{|l|}{ grad } \\
\hline prog & cert & \multicolumn{4}{|l|}{ siry } \\
\hline prov & dist & \multicolumn{4}{|l|}{ vill } \\
\hline 4) & $f / n$ & $\mathbf{s}$ & $a$ & $\mathrm{~m}$ & e \\
\hline catg & type & \multicolumn{2}{|l|}{ mnth } & \multicolumn{2}{|l|}{ grad } \\
\hline prog & cert & \multicolumn{4}{|l|}{ slry } \\
\hline prov & dist & \multicolumn{4}{|l|}{ vill } \\
\hline 5) & $f / n$ & $\mathbf{s}$ & $a$ & $\mathrm{~m}$ & e \\
\hline catg & type & \multicolumn{2}{|l|}{ mnth } & \multicolumn{2}{|l|}{ grad } \\
\hline prog & cert & \multicolumn{4}{|l|}{ siry } \\
\hline prov & dist & \multicolumn{4}{|l|}{ vill } \\
\hline
\end{tabular}

ATTACH ADDITIONAL PAGES IF NEEDED 
L. DETAILED STAFF MEMBER INFORMATION (Continued: this is extra page

Provide the following information for the health care provider staff at the facility. Include all technicians, health workers and administrators, but do not include guards, cleaners, etc. Number each entry like 6), 7), etc.

\begin{tabular}{|c|c|c|c|c|c|}
\hline NAME & FATHER'S NAME & SEX & AGE & $M / S$ & Expat \\
\hline TRAINING SCHOOL/PROGRAM & TYPE OF TRAINING & \multicolumn{2}{|c|}{ \# MONTHS } & \multicolumn{2}{|c|}{ GRAD. DATE } \\
\hline TRAINING LOCATION & CERTIFICATION & \multicolumn{4}{|c|}{ SALARY PAID BY } \\
\hline HOME PROVINCE & HOME DISTRICT & \multicolumn{4}{|c|}{ HOME VILLAGE } \\
\hline ) & $f / n$ & $\mathbf{s}$ & $\mathbf{a}$ & $\mathrm{m}$ & e \\
\hline cato & type & \multicolumn{2}{|l|}{ mnth } & \multicolumn{2}{|l|}{ grad } \\
\hline prog & cert & \multicolumn{4}{|l|}{ stry } \\
\hline prov & dist & \multicolumn{4}{|l|}{ vill } \\
\hline ) & $f / n$ & $\mathbf{s}$ & $\mathbf{a}$ & m & e \\
\hline catg & type & \multicolumn{2}{|l|}{ meth } & \multicolumn{2}{|l|}{ grad } \\
\hline prog & cert & \multicolumn{4}{|l|}{ stry. } \\
\hline prov & dist & \multicolumn{4}{|l|}{ vill } \\
\hline$)$ & $f / n$ & $\mathbf{s}$ & a & $\mathfrak{m}$ & e \\
\hline catg & type & \multicolumn{2}{|l|}{ mnth } & \multicolumn{2}{|l|}{ grad } \\
\hline prog & cert & \multicolumn{4}{|l|}{ siry } \\
\hline prov & dist & \multicolumn{4}{|l|}{ vill } \\
\hline ) & $f / n$ & s & $\mathbf{a}$ & $\mathfrak{m}$ & e \\
\hline catg & type & \multicolumn{2}{|l|}{ mnth } & \multicolumn{2}{|l|}{ grad } \\
\hline prog & cert & \multicolumn{4}{|l|}{ siry } \\
\hline prov & dist & \multicolumn{4}{|l|}{ vill } \\
\hline 1 & $\mathbf{f} / \dot{\mathbf{n}}$ & s & $\mathbf{a}$ & $\mathbf{m}$ & e \\
\hline catg & type & \multicolumn{2}{|l|}{ mnth } & \multicolumn{2}{|l|}{ grad } \\
\hline prog & cert & \multicolumn{4}{|l|}{ siry } \\
\hline prov & dist & \multicolumn{4}{|l|}{ vill } \\
\hline
\end{tabular}


MCH should be part of any country-wide health structure. The following care should be given on different health levels:

\section{Village level}
A. Immunizations to children and mothers according to EPI program.
B. Public health education (hygiene, breastfeeding, common childhood diseases, weaning food, malaria and tuberculosis). (See Appendix 5, Prime Messages)
c. Clean delivery procedures (handwashing, sterile instruments for cord cutting. Suitable kit for a trained Dai is seen in Appendix 3.
D. Education in primary schools on prime messages. (See Appendix 5, Prime Messages)
E. Reporting on antenatal and postnatal care, deliveries, immunization.

Health Center level

All services provided at village level plus:

A. Antenatal services.

B. Growth monitoring.

C. Treatment of sick children.

D. Nutrition rehabilitation.

E. Coordination of EPI program.

F. Child spacing advice on request.

G. Training and supervision of Dais as well as supply of suitable kits and resupply.

H. Report function

J. Obstetric First Aid

Provincial level

A. Ability to treat complicated obstetrical cases (prenatal, delivery or post-partum).

B. Care of newborn sick babies.

C. Supervision of $\mathrm{MCH}$ services at Health center level.

D. Training of health staff (male and female health workers, midlevel health workers).

E. Immunization central supply.

\section{National level}

A. Training of nurse/midwives.

B. Coordination of national EPI program.

C. National $\mathrm{MCH}$ planning.

D. National planning of nutrition programs.

E. Policy and budgeting regarding $\mathrm{MCH}$ and nutrition.

F. Reporting and data collection, collation.

\section{$\mathrm{MCH}$ in Refugee Camps}

Refer to Maternal and child Health Guidelines, chief Commisserionate Afghan Refugees, United Nations High Commissioner for Refugees, Islamabad 1989. 
CHAPTER 4 - CONTROL OF DIARRHOEAL DISEASES (CDD)

\section{BACKGROUND}

\section{A. Pakistan CDD Program}

A Control of Diarrhoeal Diseases program, promoting the use of ORS packets, was first introduced in Pakistan in the early 1980s. Since 1989 Diarrhoea Training Units (DTUs), providing "hands on" practical training to health workers in oral rehydration therapy, have been established in the major teaching hospitals of every province. There are at present 2 DTUs in Peshawar (Hayat Shaheed Hospital and Lady Reading Hospital) and one in Quetta (Civil Hospital). Doctors trained at the DTUs are provided with equipment to set up an ORT corner in their own health facilities. The Pakistan program has recently changed from the promotion of salt sugar solution (SSS) to the promotion of appropriate home fluids like plain water, lassi, tea, ORS for the home treatment of diarrhoea. ORS packets of the standard one liter size are manufactured in Pakistan by the Federal Government at the National Institute of Health, Islamabad, and also by private drug manufacturers. Private manufacturers are being encouraged to produce more ORS with the aim of making Pakistan self-sufficient in ORS. Public awareness of ORT is over $90 \%$ following a very active media campaign using. radio and $\mathrm{TV}$ spots. Antimotility drugs like Imodium, Loperam, Lomotil and Rheatrol have been banned in Pakistan since 1990. The overuse and misuse of drugs in diarrhoea management by both health workers and the general public is a major problem. Antibiotic resistance to Shigella and Salmonella is on the increase.

\section{B. Afghan Refugee CDD Program, Pakistan}

Diarrhoeal diseases constitute a major bulk of the illness among Afghan refugee children. In NWFP a child will have on average 4.7 episodes of diarrhoea each year and in Baluchistan on average 12.7 episodes of diarrhoea each year. In NWFP $40 \%$ of the deaths in children under 5 years are related to diarrhoea. In Baluchistan $54 \%$ of the deaths are diarrhoea related. In 1989 UNHCR conducted a wHO household survey on diarrhoea home management. The results of the survey in NWFP are as follows:

\footnotetext{
* $\quad 75 \%$ of children are given drugs at home

* $\quad 50 \%$ of children are given food during diarrhoea

* $\quad 50 \%$ of children are given increased fluids
} 
958 of parents know about oRs but only $13 \%$ make it correctly

* Only $4 \%$ of parents give salt sugar solution (SSS) correctly

sss had been promoted by Community Health Workers (CHWs) for many years as the initial home management." The results of this household survey show sss to be poorly accepted by the community and difficult for Afghans to make. UNHCR has advised that appropriate home fluids replace sss in the home management of diarrhoea.

In 1990 a CDD unit was established in the Project Directorate of Health for Afghan Refugees and a deputy director for CDD appointed. The CDD unit trains all levels of health workers to set up ORT corners and implement the 1990 wHO guidelines on diarrhoea management in their Basic Health Units (BHUs). A DTU to provide hands on training for the Afghan program has been established at the AHSAO Children's Hospital, University Town, Peshawar. CHWs and the ORT corner staff teach. parents the prime messages and ORS preparation and administration. The preferred method of oRs preparation is to use a home container marked with a 1 liter line by the health worker who is provided with a special 1 liter jug. Research projects on appropriate home fluids, the aetiology of dysentery and antibiotic sensitivity patterns are planned in 1991.

\section{Rural Areas CDD Program, Afqhanistan}

There has been no coordinated program for the control of diarrhoeal diseases (CDD) in the rural areas of Afghanistan to date. A review of the work of mid-level health workers in Afghanistan has shown that although ORS is supplied, it is not widely used in the treatment of diarrhoea. Similarly evidence from the field suggests that anti-diarrhoeals and antibiotics are over and inappropriately prescribed. Discussions and visits with health staff working in Afghanistan have revealed that ORS is available in the bazaars and health facilities. However, it is not used effectively. At a who health strategies workshop in December 1990 a commitment was made by WHO and UNI.CEF to support the introduction of CDD activities to Afghanistan in 1991. The following have been planned:

1. A comprehensive program of training for different levels of health workers following the wHO 1990 Guidelines on diarrhoea management. 
2. Discontinue the promotion of SSS. Promote instead ORS and home fluids.

3. Establishment of ORT corners in clinics in the rural areas.

4. Distribution of 1 liter jugs, ORs packets and health education materials.

A series of training workshops conducted by WHO, UNICEF and MSH in Peshawar and Quetta are in progress. A CDD steering committee has been established to plan program activities and monitor and evaluate progress.

D. Kabul CDD Program

UNICEF Kabul has supported CDD activities in Afghanistan since 1984. An ORS production machine has been provided by UNICEF and installed at the Avecina Pharmaceutical Institute (API), Kabul. At present the API produces about 12,000 packets of ORS per day. In 1991 UNICEF plans to increase ORS production to 4 million 1 liter packets per year. UNICEF also supports the training of medical and paramedical staff in the correct management of diarrhoea and preparation of ORS. Plans also exist for the establishment of ORT corners in MCH clinics, Basic Health Centers and Polyclinics in Kabul, Mazar and Herat. Awareness campaigns and seminars are also planned along with radio and TV spots on CDD. UNICEF Kabul is now actively discouraging the promotion of $s s s$ and promoting home fluids and ORS for home management instead.

close cooperation and coordination exists between the various programs for Afghanistan and Afghan refugees in Pakistan to ensure harmonization of training materials, and program strategies and activities.

\section{MANAGEMENT OF THE PATIENT WITH DIARRHOEA}

A. Assessment

FIRST ASK:

1. Does the child have loose or watery stools?

2. How many days has the child had diarrhoea?

3. Is there any blood in the stools. If yes, then give parent a stool pot and look for visible blood.

4. Does the child have a fever? If yes, take temperature.

5. Has the child been given any fluids? Which ones? How much? How often? 
6. Has the child been given any foods? Which ones? How much? How often?

7. Has the child been given any medicines? Which ones?

Then decide which of these 3 categories of diarrhoea the patient has:-

1. Simple Diarrhoea - diarrhoea for less than 14 days

2. Dysentery - stools with blood

3. Chronic Diarrhoea - diarrhoea lasting 14 days or more

THEN ASSESS YOUR PATIENT FOR DEHYDRATION

LOOK AND FEEL FOR SIGNS OF DEHYDRATION

As you read this section, look at the table on the next page.

LOOK

1. What is the child's general condition?

a. Is he/she well and alert?

b. Is he/she restless and irritable?

c. Is he/she lethargic (abnormally sleepy), floppy, or unconscious?

2. Are the eyes normal, sunken, or very sunken and dry?

3. Does the child have tears when he/she cries?

4. Are his/her mouth and tongue wet, dry, or very dry? (Confirm your answer by feeling the child's tongue and the inside of the mouth with a clean, dry finger.)

5. When offered a drink, does the child:

a. drink normally, or seem not thirsty?

b. drink eagerly and seem thirsty?

c. drink poorly or seem unable to drink?

FEEL

When the skin of the abdomen or thigh is pinched, does it go back quickly, slowly, or very slowly (longer than 2 seconds)?

NOTE: Pinching the skin may give misleading information: In the severely undernourished patient, the skin may go back slowly even if the patient is not dehydrated.

In the obese patient, or the patient with oedema, the skin may go back quickly even if the patient is dehydrated. 


\section{ASSESS YOUR PATIENT FOR DEHYDRATION}

\begin{tabular}{|c|c|c|c|}
\hline & $\begin{array}{l}\text { NO SIGNS OF } \\
\text { DEHYDRATION }\end{array}$ & $\begin{array}{l}\text { SOME } \\
\text { DEHYDRATION }\end{array}$ & $\begin{array}{l}\text { SEVERE } \\
\text { DEHYDRATION }\end{array}$ \\
\hline $\begin{array}{l}\text { LOOK AT: } \\
\text { Condition }\end{array}$ & well, alert & $\begin{array}{l}\text { *Restless, } \\
\text { irritable* }\end{array}$ & $\begin{array}{l}\text { * Lethargic or } \\
\text { unconscious; } \\
\text { floppy* }\end{array}$ \\
\hline Eyes & Normal & Sunken & $\begin{array}{l}\text { Very sunken } \\
\text { and dry }\end{array}$ \\
\hline Tears & Present & Absent & Absent \\
\hline $\begin{array}{l}\text { Mouth and } \\
\text { Tongue }\end{array}$ & Moist & Dry & very dry \\
\hline Thirst & $\begin{array}{l}\text { Drinks } \\
\text { normally, } \\
\text { not thirsty }\end{array}$ & $\begin{array}{l}\text { *Thirsty, } \\
\text { drinks } \\
\text { eagerly* }\end{array}$ & $\begin{array}{l}\text { *Drinks poorly } \\
\text { or not able to } \\
\text { drink* }\end{array}$ \\
\hline $\begin{array}{l}\text { FEEL: } \\
\text { skin pinch }\end{array}$ & $\begin{array}{l}\text { Goes back } \\
\text { quickly }\end{array}$ & $\begin{array}{l}\text { * Goes back } \\
\text { slowly* }\end{array}$ & $\begin{array}{l}\text { * Goes back } \\
\text { very slowly* }\end{array}$ \\
\hline DECIDE: & $\begin{array}{l}\text { The patient } \\
\text { has NO SIGNS } \\
\text { OF } \\
\text { DEHYDRATION }\end{array}$ & $\begin{array}{l}\text { If the } \\
\text { patient has } \\
\text { two or more } \\
\text { signs, includ } \\
\text { ing at least } \\
\text { one key } \\
\text { *sign*, there } \\
\text { is SOME } \\
\text { DEHYDRATION. }\end{array}$ & $\begin{array}{l}\text { If the patient } \\
\text { has two or } \\
\text { more signs, } \\
\text { including at } \\
\text { least one key } \\
\text { *sign*, there } \\
\text { is SEVERE } \\
\text { DEHYDRATION. }\end{array}$ \\
\hline TREAT: & $\begin{array}{l}\text { Use Treatment } \\
\text { Plan A }\end{array}$ & $\begin{array}{l}\text { Weigh the } \\
\text { patient, if } \\
\text { possible, and } \\
\text { use Treatment } \\
\text { Plan B }\end{array}$ & $\begin{array}{l}\text { Weigh the } \\
\text { patient and } \\
\text { use Treatment } \\
\text { Plan C } \\
\text { URGENTLY }\end{array}$ \\
\hline
\end{tabular}




\section{DECIDE WHAT TREATMENT PLAN TO USE}

1. Find on the table "Assess Your Patient for Dehydration" the signs which describe the child's condition.

Notice that there are certain key signs which are in bold print and marked by asterisks (*). Experience has shown that dehydrated children usually have these key signs. They are also the signs most reliably detected by health workers. Therefore these key signs receive special attention when you determine the degree of dehydration.

2. Determine the degree of dehydration:

Look first at column $c$. If 2 or more of the signs listed in that column are present, including at least $1 \mathrm{key}$ sign (with $*$ ), conclude that the patient has severe dehydration.

If the patient does not have severe dehydration, look next at column B. If 2 or more of the signs listed in that column are present, including at least 1 key sian, conclude that the patient has some dehydration.

If the patient does not meet the criteria for some dehydration, conclude that the patient has no sians of dehydration.

3. Select the appropriate treatment plan based on the degree of dehydration.

For no signs of dehydration, select Treatment plan A - To Treat Diarrhoea at Home.

For some dehydration, select Treatment Plan B - To Treat some Dehydration. Weigh the patient, if possible, but do not delay treatment if there is no scale available.

For severe dehydration, select Treatment Plan C To Treat Severe Dehydration Quickly. Weigh the patient so that you can determine the appropriate amount of IV fluid to give. 
B. TREATMENT PLANB A, B, C

Treatment plan $\mathrm{A}$ to:-

- Continue treatment at home after leaving the health facility.

- Give early treatment for future episodes of diarrhoea.

EXPLAIN TO PARENT THE 5 RULES FOR TREATING DIARRHOEA AT HOME

Rule 1. Give child at least one extra cup of fluid after each watery stool to replace water loss.

- Give fluids like breastmilk, rice water, weak tea, plain water, lassi.

- Give a cup of these fluids after each watery stool as soon as diarrhoea starts.

- Give as much of these fluids as the child will take.

- Continue giving these extra fluids until diarrhoea stops.

- Extra fluids will prevent the child becoming dehydrated by replacing the water lost in the watery stools.

Rule 2. Continue feeding the child.

- Breastfeed more frequently.

- If the child is 4 months or older also give soft foods like rice, kitchri, kheer, banana, potato, yoghurt or whatever the child wants to eat. Add a teaspoon of oil to each serving.

- Offer smaller amounts of food more often, at least 6 times a day.

- Give freshly prepared foods.

- Give an extra meal each day for 2 weeks after the diarrhoea has stopped.

Rule 3. Do not give medicines for diarrhoea; they may be dangerous and should only be prescribed by the health facility staff.

Rule 4. Take the child to the health facility if the child has any one of the following:

- Blood in the stool

- Fever

- More frequent watery stools

- Frequent vomiting

- Becomes very thirsty

- Eats or drinks poorly

continue giving fluids on the way to the health farility. 
Rule 5. Prevent the child getting a further episode of diarrhoea by advising the parent to:

- Give breastmilk and no other fluids or foods for the first 4 months of life.

- Never use a feeding bottle; use a cup an spoon instead.

- Wash hands with soap before preparing food or feeding the child.

TEACH PARENT HOW TO USE FLUIDS AND ORB AT HOME

SHOW PARENT HOW TO PREPARE ORS

- Pour 1 liter of clean water into a container preferably a container like a kettle or jug brought by the parent from their own home, so that a 1 liter level can be marked with a knife by the health facility staff. Alternatively 4 pao-sized (250 mls) glasses can be used.

- Empty one whole packet of ORS into the water and stir with a clean spoon.

- Cover container.

- Throw away any remaining ORS after 24 hrs and prepare a fresh liter.

SHOW PARENT HOW TO GIVE FLUIDS AND ORS

- Give at least one cup after each diarrhoea stool and more if the child wants more.

- Give a teaspoonful every 1 minute for a child under 2 years.

- Give frequent sips from a cup for an older child.

- If the child vomits, wait 10 minutes, and then give more slowly, a teaspoon every 2-3 minutes.

- If the diarrhoea continues after the ORS packets are used up, tell parent to give other fluids as described in the first rule above and return to the health facility.

ENSURE THAT PARENT CAN EXPLAIN THE 5 RULES AND HOW TO PREPARE AND GIVE ORS BEFORE LEAVING THE HEALTH FACILITY

GIVE PARENT 2 ORS PACKETS TO TAKE HOME 
Treatment Plan B

Treatment Plan B is used for patients with some dehydration.

USE CHART BELON TO DECIDE UPON THE AMOUNT OF ORB REQUIRED

TO REHYDRATE THE CHILD IN THE FIRST 4 HOURS

\begin{tabular}{|c|c|c|c|c|c|c|}
\hline AGE & $\begin{array}{l}\text { Less than } \\
4 \text { months }\end{array}$ & $\begin{array}{l}4-11 \\
\text { months }\end{array}$ & $\begin{array}{l}12-23 \\
\text { months }\end{array}$ & $\begin{array}{l}2-4 \\
\text { years }\end{array}$ & $\begin{array}{l}5-14 \\
\text { years }\end{array}$ & $\begin{array}{l}15 \text { years } \\
\text { or older }\end{array}$ \\
\hline WEIGHT & $\begin{array}{l}\text { Less than } \\
5 \mathrm{~kg}\end{array}$ & $\begin{array}{c}5-7.9 \\
\mathrm{~kg}\end{array}$ & $\begin{array}{c}8-10.9 \\
\mathrm{~kg}\end{array}$ & $\begin{array}{c}11-15.9 \\
\mathrm{~kg}\end{array}$ & $\begin{array}{l}16-29.9 \\
\mathrm{~kg}\end{array}$ & $\begin{array}{l}30 \mathrm{~kg} \\
\text { or more }\end{array}$ \\
\hline $\begin{array}{l}\text { Mls. } \\
\text { ORS. }\end{array}$ & $\begin{array}{l}200- \\
400 \\
\text { mls. }\end{array}$ & $\begin{array}{l}400- \\
600 \\
\text { mls. }\end{array}$ & $\begin{array}{l}600- \\
800 \\
\text { mls. }\end{array}$ & $\begin{array}{c}800- \\
1200 \\
\mathrm{mls} .\end{array}$ & $\begin{array}{l}1200- \\
2200 \\
\mathrm{mls} .\end{array}$ & $\begin{array}{l}2200- \\
4000 \\
\mathrm{mls} .\end{array}$ \\
\hline
\end{tabular}

SHOW PARENT HOW TO PREPARE ORS AS EXPLAINED IN TREATMENT PLAN A

OBSERVE THE CHILD CAREFULLY AND HELP PARENT GIVE ORS

- Show parent how to give ORS - a teaspoon every minute for a child under 2 years, frequent sips from a cup for an older child.

- If the child wants more ORS than shown in the chart, give more.

- Encourage the mother to continue breastfeeding.

- Check from time to time to see if parent is having any problems.

- If the child vomits, wait 10 minutes and then continue giving ORS, but more slowly, a teaspoonful every 2-3 minutes.

REASSESS THE CHILD AFTER ORS REQUIREMENT IS COMPLETED UEING THE ASEESBMENT CHART, THEN BELECT PLAN A, B OR C TO CONTINUE TREATMENT

- If there are No signs of dehydration, shift to Plan A. When dehydration has been corrected the child usually passes urine or may also become tired and fall asleep.

- If signs indicating som dehydration are still present, repeat Plan B, but start to offer soft food and flulds as recommended in Plan $A$.

- If signs Indicating 8EVERE dehydration have appeared, shlft to Plan $C$.

- Offer soft foods to children over 4 months of age before they leave.

IF PARENT MUST LEAVE BEFORE COMPLETING TREATMENT PLAN B

- Show how much ORS to give to finish the 4 hour treatment at home.

- Explain the 5 rules for home treatment in Plan A. 
ENSURE THAT PARENT CAN EXPLAIN THE 5 RULES AND HON TO PREPARE AND GIVE ORS BEFORE GOING HOME

\section{GIVE PARENT 2 ORS PACKETS TO TARE HOME}

\section{c. How to set up an ORT corner in a Health Center}

A special area in the health center should be arranged for oral rehydration therapy. This is needed because mothers and their children who need oRS solution will stay at the health center for several hours. A conveniently located and adequately equipped "ORT corner" will help the staff to manage dehydrated cases more easily.

1. Select the location for the ORT corner. This should be a place that:

a. staff frequently pass by, so that they can observe the child's progress and encourage the mother, such as near the reception area or examination room, but not in a passage;

b. is near a water source;

c. is near a toilet and washing facilities;

d. is pleasant and well-ventilated.

2. Arrange furniture in the ORT corner:

a. a table for mixing ors solution and holding supplies:

b. plastic sheet where the mother can sit comfortably while holding the child;

c. posters of prime messages where mothers can see them:

d. Samovar for hand washing.

3. Organize supplies in the ORT corner:

a. ORS packets (2 packets/diarrhoea case);

b. water container or samovar;

c. metal containers like those that mothers will have at home:

d. large stirring spoon;

e. knife for marking liter line on home container:

f. cups;

g. spoons;

h. Mother's Cards - this is a card with the Prime Messages which reminds mothers how to care for a child with diarrhoea. They are given to mothers to take home:

i. soap (for hand washing);

j. waste basket;

k. tally sheet (optional) - a tally is kept of diarrhoea cases treated each day;

1. plastic sheet for mothers to sit on. 


\section{TFEATHEMTR FLAM C}

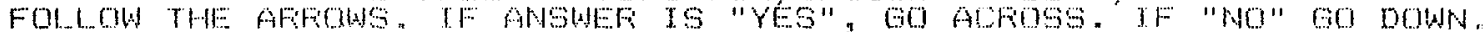

Intravenous flud therepy should be used"in the following cases:

1. Child with 2 or more signs of severe dehydration including at least

one tKey signt.

2. Child in a conatose state who is unable to drink.

3. Heavy purging where ORS intake is not enough to keep up with the mater lost in the stools.

4. Uncontrollable voniting.

\begin{tabular}{|c|c|c|c|}
\hline \multirow{2}{*}{ 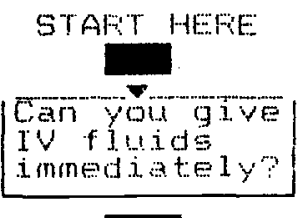 } & \multicolumn{3}{|c|}{$\begin{array}{l}\text { Start IV therapy ingediately using Ringer's } \\
\text { Lactate Solution. Give 100al/kg. Use chart below } \\
\text { to decide upon the anount and rate. }\end{array}$} \\
\hline & Age & $\begin{array}{l}\text { First give } \\
30 \mathrm{ml} / \mathrm{kg} \text { in: }\end{array}$ & $\begin{array}{l}\text { Then give } \\
70.1 / \mathrm{kg} \text { in: }\end{array}$ \\
\hline & infants (under 12 aths) & 1 hour & 5 hours \\
\hline & Older children a adults. & 30 ninutes & $21 / 2$ hours \\
\hline 170 & \multicolumn{3}{|c|}{ 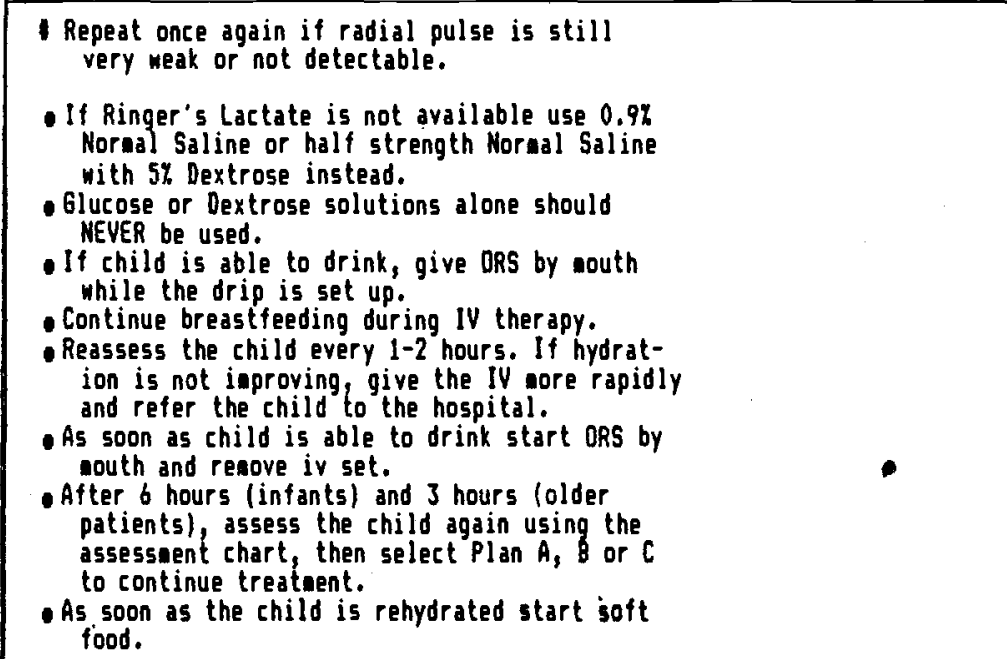 } \\
\hline
\end{tabular}

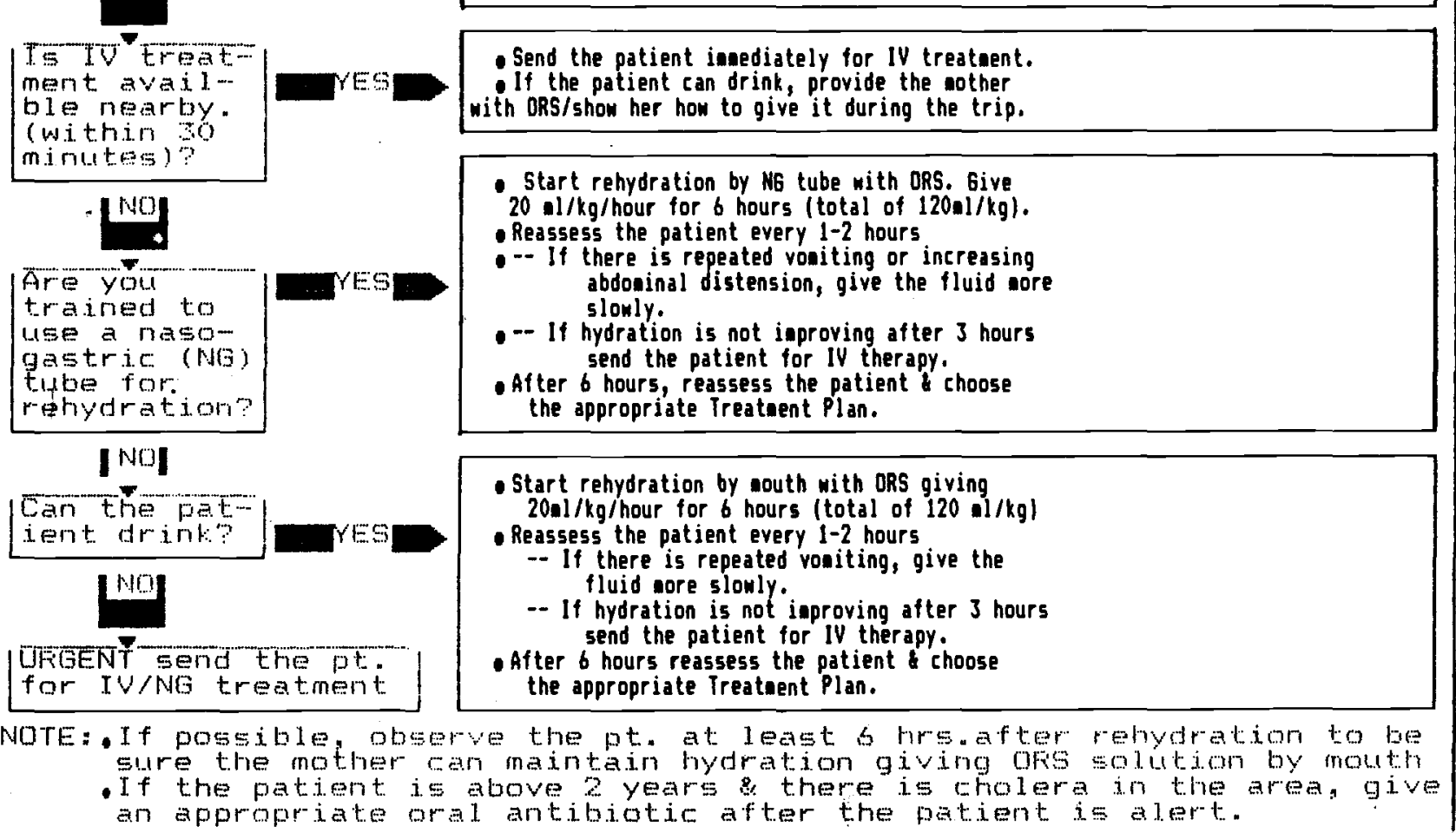


D. Treatment for other Problems

(Paramedics should refer these cases to the medical officer for treatment.)

Dysentery

IF THERE IS A HISTORY OF BLOOD IN THE STOOL:

1. Provide parents with a stool pot and ask them to collect a stool specimen from the child. Look for blood in the stool specimen.

2. If blood is present, treat as shigella and prescribe Cotrimoxazole for 5 days and 2 ORS packets. Ask parent to bring child back after 2 days. If child is improving after 2 days continue cotrimoxazole. If child is not improving change to another antibiotic recommended for shigella, such as ampicillin, for 5 days.

3. Nalidixic acid is indicated in those dysentery cases resistant to the recommended first line antibiotics.

4. Antiemetics and Antispasmodics are not indicated in the treatment of dysentery.

(Please note, a stool with mucus and NO blood is NOT dysentery.)

Chronic (Persistent) Diarrhoea

IF THERE IS A HISTORY OF DIARRHOEA FOR 14 DAYS OR MORE:

1. Weigh the child and start growth monitoring using a growth chart.

2. Teach parent to feed the child kitchri, kheer, bananas, potatoes, rice.

- Add a teaspoon of oil to each serving

- Give 6 meals a day

- Replace animal milks with yoghurt or mix them with cereals

3. Prescribe multivitamins. Folate, vitamin B12, vitamin $A$, iron and zino are particularly important. Give 2 ORS packets.

4. Tell parent to bring child back after 5 days. If diarrhoea has not stopped, do a stool examination or refer child to hospital. If diarrhoea has stopped tell parent to continue with this special diet, giving an extra meal each day for at least 1 month and gradually replacing the yoghurt with animal milk.

Diarrhoea with Malnutrition

IF THE CHILD HAS MALNOTRITION

1. Advise parent to give child the special diet as described above, at least 6 times a day, with a teaspoon of oil added to each serving. 
2. Monitor child's weight regularly using a growth chart, especially children under 2 years.

3. Give 2 ORS packets.

Diarrhoea with Fever

IF THE CHILD HAS A FEVER:

1. Give extra fluids including ORS.

2. Show parent how to cool child with a wet cloth and fanning and give a dose of paracetamol if temperature is 39 degrees $C$ or higher.

3. Examine for signs of an associated illness (for example pneumonia, malaria) and treat according to standard guidelines.

4. Give 2 ORS packets.

(Please note, dehydration may cause a slight rise in temperature which goes down once the patient has been rehydrated with ORS.)

E. Use of Medicines for Children with Diarrhoea

ANTIBIOTICS should ONLY be used for dysentery cases, systemic bacterial infections and suspected cholera. otherwise they are ineffective and should NOT be given.

METRONIDAZOLE should ONLY be used for:

- Dysentery after 2 courses of antibiotics recommended for shigella have failed or trophozoites of $E$. Histolytica containing red blood cells are seen in the stools:

- Chronic diarrhoea when cysts or trophozoites of Giardia are seen in the stools.

Medicines that should never be used for children with diarrhoea

ANTIDIARRHOEALS should NEVER be used. They are useless and sometimes dangerous.

ANTIEMETICS AND ANTISPASMODICS should NEVER be used because they cause drowsiness and therefore a reduced fluid intake. 
F. Antibiotic Treatment of Cholera and Shigella Dysentery

\begin{tabular}{|c|c|c|}
\hline Cause & Antibiotic(s) of Choice' & Alternative' \\
\hline Cholera ${ }^{2,3}$ & $\begin{array}{l}\text { Tetracycline } \\
\text { Children: } 12.5 \mathrm{mg} / \mathrm{kg} \\
4 \text { times a day } \times 3 \text { days } \\
\text { Adults: } 500 \mathrm{mg} \\
4 \text { times a day } \times 3 \text { days } \\
\text { Doxycycline } \\
\text { Adults: single dose of } \\
300 \mathrm{mg} \text { (not included in } \\
\text { Physicians Drug List) }\end{array}$ & $\begin{array}{l}\text { Furazolidone } \\
\text { Children: } 1.25 \mathrm{mg} / \mathrm{kg} \\
4 \text { times a day } \times 3 \text { days } \\
\text { Adults: } 100 \mathrm{mg} \\
4 \text { times a day } \times 3 \text { days } \\
\text { (not included in } \\
\text { Physicians Drug List) } \\
\text { or } \\
\text { Trimethoprim (TMP) }- \\
\text { Sulfamethoxazole }(\mathrm{SMX})^{4} \\
\text { Children: TMP } 5 \mathrm{mg} / \mathrm{kg} \\
\text { and SMX } 25 \mathrm{mg} / \mathrm{kg} \\
2 \text { times a day } \times 3 \text { days } \\
\text { Adults: TMP } 160 \mathrm{mg} \text { and } \\
\text { SMX } 800 \mathrm{mg} \\
2 \text { times a day } \times 3 \text { days }\end{array}$ \\
\hline $\begin{array}{l}\text { Shigella } \\
\text { Dysentery }\end{array}$ & $\begin{array}{l}\text { Trimethoprim (TMP) - } \\
\text { Sulfamethoxazole (SMX) } \\
\text { Children: TMP } 5 \mathrm{mg} / \mathrm{kg} \\
\text { and SMX } 25 \mathrm{mg} / \mathrm{kg} \\
2 \text { times a day } x 5 \text { days } \\
\text { Adults: TMP } 160 \mathrm{mg} \text { and } \\
\text { StX } 800 \mathrm{~kg} \\
2 \text { times a day } x 5 \text { days }\end{array}$ & $\begin{array}{l}\text { Nalidixic Acid } \\
\text { Children: } 15 \mathrm{mg} / \mathrm{kg} \\
4 \text { times a day } \times 5 \text { days } \\
\text { Adults: } 1 \text { gm } \\
3 \text { times a day } \times 5 \text { days } \\
\text { or } \\
\text { Ampicillin } \\
\text { Children: } 25 \mathrm{mg} / \mathrm{kg} \\
4 \text { times a day } \times 5 \text { days } \\
\text { Adults: } 1 \text { gm } \\
4 \text { times a day } \times 5 \text { days }\end{array}$ \\
\hline
\end{tabular}

1 All doses given are for oral administration unless otherwise indicated... Kg.refers to body weight.

2 The choice of antibiotic for treatment should take into account frequency of resistance to antibiotics in the area.

3 Antibiotic therapy not essential for successful therapy but shortens duration of illness and excretion of organisms in severe cases.

4 other choices include erythromycin and chloramphenicol. Dosage schedules can be found in the document "Guidelines for Cholera Control," WHO/CDD/SER/80.4 Rev.1 (1986) and many standard texts. 
G. Antimicrobial Treatment of Parasitic Diarrhoea

\begin{tabular}{|c|c|c|}
\hline Cause & Antibiotic(s) of Choice & Alternative \\
\hline $\begin{array}{l}\text { Intestinal } \\
\text { amoebiasis }\end{array}$ & $\begin{array}{l}\text { Metronidazole } \\
\text { Children: 10mg/kg } \\
3 \text { times a day } x 5 \text { days } \\
\text { (10 days for severe disease) } \\
\text { Adults: } 750 \mathrm{mg} \\
3 \text { times a day } x 5 \text { days } \\
\text { (10 days for severe disease) }\end{array}$ & $\begin{array}{l}\text { In very severe cases } \\
\text { Dehydrometine } \\
\frac{\text { hydrochloride by }}{\text { deep intramuscular }} \\
\text { injection } \\
\text { All ages: } 1-1.5 \mathrm{mg} / \mathrm{kg} \\
\text { (maximum } 90 \mathrm{mg} \text { ) for } \\
\text { up to } 5 \text { days, } \\
\text { depending on response }\end{array}$ \\
\hline Giardiasis & $\begin{array}{l}\text { Metronidazole } \\
\text { Children: } 5 \mathrm{mg} / \mathrm{kg} \\
3 \text { times a day x } 5 \text { days } \\
\text { Adults: } 250 \mathrm{mg} \\
3 \text { times a day x } 5 \text { days }\end{array}$ & $\begin{array}{l}\text { Quinacrine } \\
\text { Children: } 2.5 \mathrm{mg} / \mathrm{kg} \\
3 \text { times a day x } 5 \\
\text { days } \\
\text { Adults: } 100 \mathrm{mg} \\
3 \text { times a day x } 5 \\
\text { days }\end{array}$ \\
\hline
\end{tabular}

1 All doses given are for oral administration unless otherwise indicated. $\mathrm{Kg}$ refers to body welght.

2 Tinidazole or ornidazole can also be used.

H. Protocol for Diarrhoea Outbreaks

1. Organizational Preparedness: (Based in Pakistan) Organizations supporting health workers in Afghanistan, the coordinating bodies, WHO and UNICEF need to cooperate and collaborate in tackling diarrhoeal outbreaks in Afghanistan.

wHO can act as the focal point for receiving information from agencies and for subsequent coordination of relief activities.

The activities that need to be carried out from Pakistan once an outbreak has been reported include: a. Verification of the report and its impact regarding morbidity and mortality.

b. Organization of a team to provide technical support and supervisory skills to the health staff working in the epidemic area. The members of the team have to be identified beforehand so that they can go to the area without much delay. 
c. A certain amount of funding has to be earmarked for purchasing ORS, I/V fluids, drugs, transport and other expenses relating to the relief activities.

d. Reference laboratory will be identified which will supply the transport media and facilities for culture/sensitivity test of the stool samples brought from the epidemic area.

e. Logistic arrangements need to be defined.

2. Activities at Field Level in Case of a Diarrhoea outbreak

Reporting

Information to be collected on suspected cases: (see Appendix 3 - Diarrhoea patient record sheet).

After analyzing the case sheets the following key information categories need to be sent to the respective supervisors in the agency supporting the health worker. (This information will then be shared with other collaborating agencies.)

a. Reporting period.

b. Number of cases, number of deaths.

c. Names of districts, regions affected.

d. Estimated size of population at risk.

e. Specific information for deciding emergency measures, e.g. presence of blood in stool, deaths among children under 5, deaths in adolescents and adults following watery diarrhoea.

f. Measures taken so far.

g. Assistance requested or in pipeline (if applicable).

h. Any other relevant information, e.g. war situation in the area, communication routes open, stool samples sent for laboratory test or test results, etc.

Collection of stool samples

The supervisors should provide transport media (e.g. Carey-Blair media) for the collection of stool specimens from suspected cases.

Patients who have not been given any antibiotic or antimicrobials are the target cases.

The transport media after inoculation should be kept in a cold box or vaccine cooler. 
In case no transport media is available, stool samples can be sent by soaking clean and dry cotton gauze or cotton wool, preferably sterilized, in freshly passed stool of a diarrhoea patient. If the rectal swab is taken it must be made sure that the swab reaches the rectum, not just the anus. The swabs or cotton wool can then be put in a small plastic bag which should then be sealed with candle flame. This plastic bag should be put into another plastic bag which has to be sealed in a similar manner. The whole packet should be put into an envelope with particulars of the patient on it.

\section{Treatment of Diarrhoea Cases}

All diarrhoea patients should be assessed for degree of dehydration and treated accordingly. (Please refer to pages 97 to 101 for Treatment plans A, B and C.) Emphasis must be put on early treatment with oral rehydration therapy.

Intravenous fluids should be reserved for severely dehydrated patients or patients with high vomiting/purging rate. ORS should be started as soon as the patient is able to drink. "Ringer lactate solution is the preferred fluid. Normal saline or dextrose saline are acceptable but Dextrose water should never be used for treatment of dehydration in diarrhoea.

In the case of cholera all adult cases can be given Tetracycline; children and pregnant women can be given cotrimoxazole or furazolidine. Antibiotics decrease the duration of cholera and reduce the vibrio load in the stool. Mass chemoprophylaxis is not advisable.

In the case of dysentery the recommended treatment is to give cotrimoxazole for 5 days. If the dysentery case is not improving in 2 days, antibiotic should be changed to Ampicillin. Nalidixic acid should be reserved for resistant cases only.

Health Education Measures

The community should be advised on the following preventive and health measures. Community involvement in disseminating such messages is essential.

a. Patients should be given ORS or any other fluid available at home as soon as diarrhoea starts. 
b. Diarrhoea patients should be given food available at home. Food should not be withheld from them. Infants should continue to be breastfed more frequently.

c. Hands should be washed with soap and water after defecation, before preparing food and before eating or feeding children.

d. Excreta should be disposed in latrines or at least buried in pits.

e. Vomitus of diarrhoea patient and stool of infants and small children should also be disposed in pits. These pits can then be covered with ash or mud.

f. Drinking water should preferably be boiled or chlorinated. At least the cleanest water source should be used.

DIARRHOEA EPIDEMICS can be defined as the ocurrence of an unusually large or unexpected number of diarrhoea cases for a given place and time.

CRITERIA OF EARLY RECOGNITION OF DIARRHOEAL EPIDEMIC:

In many places diarrhoeal diseases are endemic with seasonal peaks. However, when serious outbreaks of acute diarrhoeal disease occur, the common cause is either:

Shiqella dysentery type 1; it causes Shiga dysentery with blood in stool.

It is most virulent; often resistant to antibiotics.

It causes bloody diarrhoea, serious systemic complications and deaths, particularly in children.

Shigella is highly infectious and readily transmitted by person to person contact, food, water and flies.

An epidemic of Shigella must always be considered when an increasing number of bloody diarrhoea cases occur in clusters.

Vibrio cholerae 01; it causes cholera with watery diarrhoea associated with multiple deaths.

Most people affected have no symptoms or only mild diarrhoea. However, those with severe disease can die within hours of onset due to fluid and 
electrolyte loss through profuse watery diarrhoea accompanied by vomiting.

Case fatality can be reduced to below 18 with proper facilities and care.

Spread is almost exclusively by ingestion of food or water contaminated directly or indirectly by faeces or vomitus from infected individuals, spreading along river banks or karezes.

Cholera should always be considered as a possible cause of outbreak when suspicious cases of diarrhoea occur in unusually large numbers, and particularly when deaths occur in adults and adolescents following watery diarrhoea.

\section{MANAGEMENT OF THE CDD PROGRAM}

\section{A. Storage of ORS Packets}

As with all medicines, ORS should be stored safely. Citrate is preferred because it has a longer shelf-life.

Temperatures should not exceed 30 degrees C (86,degrees F). If ORS is stored a long time above this temperature, it may melt or turn brown. In addition, humidity should not exceed 80\%. If ORS is stored a long time in high humidity, the produce is likely to cake. If you do not have a storage area which meets these two guidelines, it will be best to stock a small number of packets, such as the number that will be used in three months.

Keep storage area clear of all types of insects, rats and mice. Arrange cartons so that sharp objects will not make holes in the packets.

Arrange cartons of ORS so that identification marks and other labels can be easily seen and so that the oldest ORs (identified by date) w1ll be used first.

Every 3 months, Inspect a fow ORs packets, randomly chosen, looking for signs of damage or improper sealing of the packet. Shake the packet to check whether the powder is till free-flowing. If it is hard, lumpy or pasty, open the packet.

- If the powder is white, the produce is in perfect condition. (Even if it is hard, if it is white, it is all right.) 
- If the powder is yellow, the oRs is still effective and safe, but such stocks should be used as soon as possible.

- If the powder is brown or dark brown, the oRs has deteriorated to a stage that it should not be used. Throw away all such packets.

B. A Recommended Breastfeeding Policy for Health Facilities to Prevent Diarrhoea

BREA8T MILX I8 THE IDEAL FOOD FOR BABIES. THE HEALTE PACILITY BEOULD DO THE FOLIOWING TO PROTECY, PROYOTE AND 8UPPORT BREABTPEEDIMG.

1. Health facility staff shall ensure that all expectant mothers, at clinic visits or during outreach activities, receive education on the benefits and management of breastfeeding, the dangers of bottle feeding, and the dietary needs during pregnancy and lactation. Antenatal care shall include breast examination.

2. At delivery, newborn infants, including premature infants. shall be put on the breast within one hour of delivery. Babies should be fed on demand, every 2-3 hours, for a minimum of eight feedings within 24 hours.

3. Exclusive breastfeeding shall be promoted from birth to 4-6 months. No water, ghutti, animal milk, Infant eormula or other liquid is to be given to an exclusively breastfed infant. Trained health care stafe shail help mothers having breastfeeding problems to continue to breastieed.

4. Staff shall promote the introduction of semi-solld roods at $4-6$ months with continued breastfeeding up to 2 years.

5. No feading bottles and pactiflers shall be allowed In the health facility.

6. No promotional materiale about formula, feeding bottles and pacifiers, wch as posters, free samples or gift Items, shall be allowed in the facility nor shall they be given to the mother.

7. No health care stafe shall recelve alfts, eree samples, donations, free training, etc. from formula manufacturers. 
8. Mothers shall be given sufficient education so that they will be able to explain that:

a. breastfeeding should be started within one hour of delivery after birth because:

- colostrum is important for babies and protects them from infection.

b. : frequent breastfeeding increases breastmilk production.

c. babies should be fed only mother's milk for the first four to six months because:

- it is the best food for babies

- it prevents infections

d. bottlefeeding can cause serious illness and death.

e. supplementary foods should be started between four and six months.

f. lactating mothers should eat more food and drink more liquids to maximize their milk supply.

c. CDD Monitoring checklist

A suggested checklist for use by agencies when monitoring their diarrhoea activities or supervising their health workers is given on the following two pages. 
NAYE OF HEALTH PACILITY

DISTRICT

ACTIVITIES OF HEALTH WORKEB

PATIENT 1

ADEQUATE

Assessment of Dehydration

Selection of Treatment Plan

Referral of Complicated Cases

Preparation of ORS

Administration of ORS

Appropriate use of antibiotics

Appropriate use of other

medicines

Manner with Parents

Recording of Treatment

PARENTS KNOWLEDGE OF DIARRHOEA

1. Increase fluids

2. Continue feeding/ breastfeeding

3. No medicines except those prescribed by health

facility

4. When to bring child back

5. Importance of breastfeeding and hand washing

6. How to prepare and give ORS

NOT ADEQUATE

[ ]

PATIENT 2

ADEQUATE NOT

ADEQUAT.

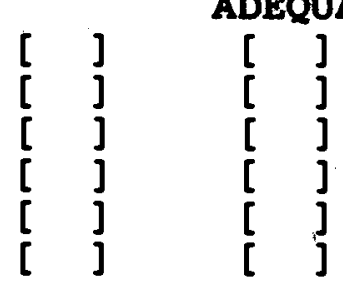

stock of ORS

Antibiotics for shigella (Cotrimoxazole, etc.)

Appropriate IV fluid (Ringer's Lactate, etc.)

IV therapy equipment (butterflies, IV lines,

etc.)

ORT Corner Equipment

Monthly Reporting of Diarrhoea/Dysentery cases [

\section{ADEQUATE/NOT ADEQUAT:}

\begin{tabular}{l|c|c}
\hline \multicolumn{2}{|c|}{ DATA FROM OUTPATIENT REGISTER ON DIARRHOEA CDYSENTERY CASES } \\
\hline AGE & DIAGNOSIS & TREATMENT \\
\hline & & \\
\hline & & \\
\hline & & \\
\hline & & \\
\hline & & \\
\hline
\end{tabular}

Simple Diarrhoea -2 cases
Dysentery
Chronic Diarrhoea -2 cases
Cases


Signature:

Designation:

Date: 


\section{SKILLS CHECKLISTS}

The following list of skills for different categories of health workers provides agencies with guidelines on the CDD training requirements of their health staff.

A. Skills Checklist for Physicians

1. Assessment of a diarrhoea case (Ask, Look, Feel).

2. Treatment Plan A. Supervise an ORT Corner.

3. Treatment Plan B.

4. Treatment Plan C.

5. Treatment of other problems (dysentery, chronic diarrhoea, diarrhoea with malnutrition, diarrhoea with fever).

6. Recording cases in daily register and compiling a monthly report.

7. Management of a suspected diarrhoea epidemic (dysentery or watery diarrhoea).

8. Supervising the diarrhoea management of mid-level and basic health workers using the CDD monitoring checklist.

9. Advising the community on the prevention of diarrhoea.

B. Skills Checklist for Mid-Level Health Workers

1. Assessment of a diarrhoea case (Ask, Look, Feel).

2. Treatment Plan A. Supervise and run an ORT Corner.

3. Treatment Plan B.

4. Treatment Plan C.

5. Treatment of other problems (dysentery, chronic diarrhoea, diarrhoea with malnutrition, diarrhoea with fever).

6. Recording cases in daily register and compiling a monthly report.

7. Management of a suspected diarrhoea epidemic (dysentery or watery diarrhoea).

8. Supervising the diarrhoea management of basic health workers using the CDD monitoring checklist.

9. Advising the community on the prevention of diarrhoea.

\section{c. Skjlis checklist for Basic Health Workers}

1. Assessment of a diarrhoea case (Ask, Look, Feel).

2. Treatment Plan $A$. Run an ORT Corner.

3. Treatment Plan B.

4. Referral of complicated cases (severe dehydration, dysentery, chronic diarrhoea, diarrhoea with malnutrition, diarrhoea with fever).

5. Recording cases in daily register.

6. Advising the community on the prevention of diarrhoea. 
Cereal based oral rehydration therapy for diarrhoea: report of the International Symposium on Cereal Based Oral Rehydration Therapy 12-14 November 1989 at the Aga Khan University / edited by Katherine Elliott, et al. Aga Khan Foundation, Geneva, 1990; 99 p.

Dialogue on diarrhoea: the international newsletter on the control of diarrhoeal diseases. If you would like to receive this free newsletter, write to: Dialogue on Diarrhoea, Imajics (Pvt) Ltrl, P.O. Box 12534, Karachi-29.

Diarrhoea morbidity, mortality and treatment practices: report of a survey conducted by UNHCR amongst Afghan Refugees in NWFP, Pakistan, January - July, 1989 / by Andrew w. Smith. Peshawar: UNHCR, 1989. ca.60 p.

Management of the patient with diarrhoea: supervisory skills. Geneva: World Health Organization, Programme for Control of Diarrhoeal Diseases, $1990.85 \mathrm{p}$. Self training package with exercises.

A Manual for the treatment of diarrhoea, wHo, 1990. Serial number WHO/CDD/SER/80.2 Rev. 2 1990. Available from UNICEF in English, Farsi.

Report on the review of control of diarrhoeal disease activities / Afghan Refugee Health Programme, NWFP. Peshawar: Afghan Refugee Health Programme, 1990. 23 p.

Treatment and prevention of acute diarrhoea: practical quidelines, WHO, 1987. Available in English, Farsi.

Wheat based oral rehydration home solutions: a field trial and implementation program for the treatment of diarrhea among Afghan refugee children / submitted by Helen H. Murphy. Peshawar: IRC, 1990. 25 p.

Wheat based oral rehydration therapy project: a fleld trial and implementation programme for the treatment of diarrhed for Afghan refugee children. phase $\# 1$ report / Helen Murphy, Peshawar: IRC, 1991. 54 p. : maps, stats.

WHO diarrhoea training unit director's quide (includes teaching slides). Serial number CDD/SER/86.1 Rev.1 (1988).

WHO quidelines for cholera control, wHO, 1986. Serial number WHO/CDD/SER/80.4 Rev. 1 . 
VIDEO RESOURCES (available from HERC and UNICEF)

Diarrhoea Management, UNICEF. 23 Modules. Available in English, Pashtu and Urdu.

The Egyptian CDD program, Dr. Norbert Hirshhorn, PRITECH.

Formula milks in Pakistan, Australian Broadcasting Corporation, 198-? A "Four Corners" documentary. Available in English in full length and edited versions.

Prescription for Health. Video about the spread and prevention of diarrhoea. Available in English and Pashtu.

Vicious circles: Imodium and formula milks in Pakistan, Yorkshire TV. Full length and edited versions available.

WHO Assessment of Dehydration (1990 Guidelines). Available in English.

TRAINING AIDS

ORT Doll for teaching signs of dehydration. Available from Save the Children Fund (UK), Peshawar.

One liter jugs. Available from UNICEF/PDH.

ORT Corner equipment. All items are avallable in any bazaar.

Diarrhoea home management prime messages. Six cloth posters; available from HERC. 


\section{APPENDIX 2}

DOMESTIC OR BMALL-SCALE CHLORINATION OF WATER

$1 \%$ stock solution is prepared by adding enough water to 4 teaspoons $(16 \mathrm{~g})$ of swimming pool hypochlorite (70\% available chlorine), or 10 teaspoons ( $40 \mathrm{~g}$ ) of bleaching powder ( $30 \%$ available chlorine), to make up one liter of solution. Mix thoroughly and keep tightly stoppered. Fresh solution should be prepared daily.

Three drops of the stock solution for one liter, or 1 teaspoon (4$5 \mathrm{~m}])$ for 30 liters, or one liter for 4,550 liters of water should be used - always adding water to the stock solution for proper mixing. The chlorinated water should be allowed to stand for 2030 minutes before use.

This procedure provides a chlorine concentration of about $2 \mathrm{mg}$ per liter. 
DIARRHOEA PATIENT RECORD BHEET

Serial no:
Date:
Clinic:
Attending physician/health worker:

Name:

Age:

Residence: Vill.

Sex: $m / f$.

Province

\section{CLINICAL FEATURES :}

a. Stool: number of stools/day: _ays:

b. Consistency of stool: watery/watery mixed with stool/ liquid stool

c. Visible blood in stool: present/not present

d. Straining during defecation: $y / n$

e. Fever:

f. Vomiting:

present/not present (temp. $y / n$

State of dehydration:
a. Mental state:
b. Thirst:
c. Eyes:
d. Tears:
e. Tongue:
f. Skin pinch:
alert/irritated/stupor thirsty/drinks normally not sunken/sunken present/not present moist/dry retracts immediately/retracts slowly/ retracts very slowly

\section{TREATMENT:}

a. Patient hospitalized: $y / n$

b. Patient treated with: (tick those applied)
i. ORS
ii. Ringer lactate solution
iii. Normal saline
iv. Antibiotics specify:
v. Others:

outcome

a. Patient dies $\mathrm{Y} / \mathrm{N}$ 


\section{CHAPTER 5 - IMMUNIZATIONS}

\section{EXPANDED PROGRAM OF IMMUNIZATION (EPI) IN RURAL AFGHANISTAN}

Communicable and antigen preventable diseases such as measles, polio, diphtheria, pertussis, tetanus and tuberculosis are still the most important causes of the high mortality and morbidity rates among Afghan children. Such diseases are preventable and can be controlled through the introduction of the Expanded Program of Immunization (EPI). Furthermore, maternal and neonatal deaths caused by titanus are among the highest in the world. Immunization is considered to be one of the most effective health services and, where introduced, has contributed to the reduction of mortality and morbidity from the six vaccine-preventable diseases.

The organization and implementation of the EPI in a country like Afghanistan is complex. The lack of a health infrastructure, limited health services, a dispersed population and the ongoing civil war all mitigate against the effective implementation of EPI.

However, despite the difficult circumstances EPI has been introduced into the rural areas of Afghanistan. The experiences of the last years have indicated that EPI can be developed for rural Afghanistan through improvements in the cold chain, the use of simplified schedule, a varied approach to implementation and sound program management.

In December 1990 a review was made of EPI activities in rural Afghanistan to date by UNICEF, WHO and implementing agencies. It was agreed that in 1991 the target age for rural Afghanistan would be reduced from under $5 s$ to under $2 s$. Global WHO/UNICEF policy states that immunization should occur before a child reaches 1; however special consideration has been given for 1991 to reduce the target age gradually. Particular attention therefore in 1991 will be focussed on the necessary orientation, training and social mobilization in order to facilitate the targeting of under $1 \mathrm{~s}$ in 1992.

\section{IMMUNIZATION SCHEDULE}

A. For Afghan refugees in the refugee camps in Pakistan

at birth

from 6 weeks ( $11 / 2$ months)

from 10 weeks (2 $1 / 2$ months)

from 14 weeks ( $31 / 2$ months)

from 9 months

* DPT and OPV need a booster

\author{
BCG + OPV \\ DPT $1+$ OPV 1 \\ DPT $2+$ OPV 2 \\ DPT $3+$ OPV 3 * \\ measles vaccine \\ dose one year later
}


DPT (with OPV) is given until the age of 23 months. TT is given to all women between 15 and 45 years.

A child is fully vaccinated if he/she has received:

1 dose of BCG

3 doses of DPT **

at least 3 idoses of oPV **

1 dose of measles vaccine (after 9 months)

** should be given at least 1 month apart.

Without proper refrigeration, OPV is difficult to preserve; to vaccinate the children fully, they need to be seen 4 times.

B. For rural Afqhanistan

\begin{tabular}{|c|c|c|c|c|c|c|}
\hline Vaccine & Dose & $\begin{array}{c}\text { Mode of } \\
\text { dministration }\end{array}$ & $\begin{array}{c}\text { Min } \\
\text { to }\end{array}$ & $\begin{array}{l}\text { Age } F \\
\text { start }\end{array}$ & $\begin{array}{l}\text { Fre- } \\
\text { quency }\end{array}$ & $\begin{array}{c}\text { Interval } \\
\text { between } \\
\text { doses }\end{array}$ \\
\hline BCG & $0.05 \mathrm{ml} *$ & Intradermal & & Birth & 1 & - $\quad-$ \\
\hline Measles & $0.5 \mathrm{ml}$ & subcutaneous & & 9 months & 1 & - \\
\hline DPTP & $0.5 \mathrm{ml}$ & Intramuscular & & weeks & M & $\begin{array}{c}\text { Min } 6 \text { wks; } \\
\text { max } 3 \\
\text { contacts } \\
\text { per year. }\end{array}$ \\
\hline - TT & $0.5 \mathrm{ml}$ & Intramuscular & & 5 years & 3 & $\begin{array}{l}\text { Min } 6 \text { wks } \\
\text { between } \\
\text { 1st and } \\
\text { 2nd dose; } \\
\text { min } 6 \\
\text { mnths } \\
\text { between } \\
\text { 2nd \& 3rd } \\
\text { dose. }\end{array}$ \\
\hline
\end{tabular}

*Note: $0.1 \mathrm{ml}$ for children older than 1 year.

The DPTP is a combined vaccine against diphtheria, pertussis, tetanus and (injectable) polio, and has beer: chosen instead of DPT + OPV (oral polio) since OPV is difficult to preserve.

In order to standardize the immunization schedule for urban and rural Afghanistan, efforts will be made gradually to replace DPTP by DPT plus OPV. 
As far as TT is concerned, minimum age to start is 5 years. Vaccinators are however encouraged to give the TT vaccination to younger girls if possible.

\section{OVERVIEW OF COLD CHAIN}

Vaccines can be damaged in two ways:

A. Time - vaccines have an expiry date and should not be used beyond that date.

B. Temperature - vaccines are destroyed by very high or low temperatures.

In most cases, a vaccine should be used within two or three years of leaving the laboratory of origin and should be kept within 0 degrees $\mathrm{C}$ and +8 degrees $\mathrm{C}$.

A cold chain consists of transporting a vaccine to its destination under the best possible conditions.

To do this a variety of materials are used:

cooling mechanisms :

cold rooms and refrigerators for long term conservation of vaccines at a fixed point.

cold containers :

Isothermic cases for the conservation of vaccines for short term or transport.

A cold chain must be inspectable at all times and it is absolutely necessary to check and control the temperature constantly. There are gauges to measure actual temperatures, monitors to register the accumulated temperatures for each vaccine through a specific period, and other indicators to warn of a radical rise or drop in temperature.

In summary, a cold chain will be affected by:

A. The quality of the equipment

B. The control facility

C. The efficiency of the utilizer

IV. AN OVERVIEW OF COLD CHAIN IN AFGHANISTAN

In addition to the problems stated above, three more factors are encountered in Afghanistan: 
Trucks are used for some of the transportation but the majority is done by horses, mules and camels or is carried by hand. The quantity of vaccines transported is dictated by the terrain, weight assessment (in relation to the numbers of animals or porters), "and volume (in relation to the intended route). It is therefore necessary to use easily transportable equipment.

Refrigerators and isothermic cases should be maneuverable, solid and reliable while not taking up too much space or weight. Electrolux equipment has been found to be best adapted for this kind of situation.

B. Power source

Three sources of power are used in Afghanistan for refrigerators.

1. Kerosene is the most common power source in Afghanistan. Unfortunately, the maintenance of kerosene powered refrigerators is difficult and complicated and the use of this system is therefore not advised.

2. Electricity is rare in Afghanistan. It is possible, if necessary, to use generators. However, their round-the-clock use is not reliable. The use of this system is not advised (unless it comes with spare parts and there are several back-ups).

3. Gas is the least accessible power source in Afghanistan, yet the most efficient for the use of refrigerators as it is both clean and easily maintained. Each refrigerator should be stocked with a reserve of gas ( 1 cylinder of gas lasts from four to six weeks with the Electrolux RCW 42 EG refrigerator).

\section{Warm chain}

Temperatures ranging from +45 degrees $c$ to -30 degrees $C$ are to be found in Afghanistan. In winter vaccination campaigns, the problem is to protect vaccines against the extreme cold as vacciries tend to freeze, rather than against the heat.

Refrigerators which are "thermo-stabilizers" (controlling both the rise and drop in temperature) are available but lack reliability, are hi-tech and expensive. 
During the winter, the vaccine containers will remain in the isothermic cases. The warm chain will depend essentially on the vigilance of the utilizer.

V. RECOMMENDATIONS FOR IMMUNIZATION PROGRAMS IN AFGHANISTAN

A. General

1. The population inside Afghanistan has been estimated by Dr. Eighmy of USAID. 1 This data should be accepted by all EPI partners as the basis for denominators in coverage calculations. If organizations can demonstrate that the population in a given district is different from the USAID figure, the information should be shared with other EPI partners for consideration in the setting of a task force.

2. Goals and targets should be set primarily on sound epidemiological principles.

3. Organizations should be discouraged from offering only one antigen.

4. Every opportunity should be taken to move forward immunization teams operating from fixed locations instead of the mainly mobile teams approach used at present. There is likely to be a period when a mix of strategies is used. Outreach activities may continue to be the strategy of choice for some time to come in some rural areas of the country.

5. Wherever possible, the possibility should be explored whereby an existing health structure or existing health personnel can be used to assist in the immunization process.

6. Sites for cold stores should be chosen in the expectation of an improvement in the military/ political situation inside Afghanistan. Although cross-line supply of vaccines is potentially attractive from a cost effective point of view, it is felt to be politically unacceptable at present.

${ }^{1}$ Afghanistan's Population Inside and Out, Thomas H. Eighmy, office of A.I.D. Representative for Afghanistan Affairs Islamabad/ Peshawar/Quetta, 1990. 
B. Cold chain

1. Vaccinations should not be undertaken unless there is a reliable cold chain which can be maintained.

2. A cold chain should never be ruptured:

a.: avoid ruptures in supply: sufficient equipment, a buffer stock, appropriate stock manazement and need forecasting.

b. avoid ruptures in temperature control that lead to vaccines being exposed to damaging hot or cold temperatures.

3. A reliable cold chain means: appropriate equipment, the correct use of the equipment, competent monitoring and supervision, regular maintenance.

4. Vaccines

a. should be handled and transported only by trained and responsible people. Hence access to a room where vaccines are stored should be restricted.

b. should be continuously monitored

(1) for their expiry date

(2) for exposure to warm or cold temperatures

5. Monitoring instruments

Three essential monitoring instruments, to be used together, are:

a. thermometers: use thermometers with a sensor so that there is no need to open the refrigerator or coldbox

b. freeze watches: minimally 2 per refrigerator or coldbox

c. Vaccine cold chain Monitor cards (VMCs)

6. Vaccination cold Chain Monitor Cards (VMCs)

a. Their use from the laboratory to the village is obligatory. It should be contractually stipulated that laboratories have to send VMCs with the vaccines they deliver. 
b. VMCs should always be dutifully filled in.

c. Sufflcient VMCs have to be provided from the beginning, to accompany the vaccines throughout the distribution network. WHO/UNICEF recommend 1 VMC per 3,000 doses of vaccine.

d.: No vaccine deliveries should be accepted if the vaccines are not accompanied by a VMC.

7. Any cold room or cold store for vaccines shouli have:

a. an appropriate electrical installation

b. a generator in correct working order that is maintained and regularly tested

c. stabilizers

d. spare parts and repair tools for the refrigerators

e. a qualified cold chain technician

f. a temperature sensitive alarm

g. ice-lining refrigerators, not the household type of refrigerator.

Refrigerators have to be regularly de-iced, to maintain their cooling capacity. The condenser and compressor elements, as well as the tubes, have to be cleaned regularly.

Ice packs have to be made in separate refrigerators. Food should never be put in a refrigerator for vaccines.

Monitoring of the temperatures should be done around the clock, 7 days a week.

\section{Transport}

The refrigerator, coldbox or vaccine carrier should be properly conditioned before loading the vaccines.

If properly conditioned at the time of departure, the refrlgerator or coldbox need not be opened during the transportation. Temperatures can be monitored through a thermometer with sensor. 
Compressor refrigerators are not recommended for transportation. Absorption refrigerators are recommended.

9. Competence

Vaccinators should be thoroughly aware of cold chain requirements. People transporting vaccines should be equally thoroughly aware. EPI supervisors should be familiar with cold chain requirements.

EPI supervisors should have a checklist for cold chain. Vaccinators may also be given a checklist for cold chain.

\section{c. Immunizations}

1. Target age groups should be revised to give priority to those under 2 years of age, but every effort should be made to increase coverage of children under 1 year of age. Even though the target is under 2 years, records will be kept so that those immunized by 1 year can be identified and used as the estimate of coverage.

2. At least 3 contacts must be made per year •at each location where immunization is carried out. To do less makes it impossible to immunize at young enough ages. Programs should not be started in areas where at least three visits a year cannot be assured. Thin scattering of resources is not epidemiologically sound. A third dose of DPTP should be offered to all target aged children.

3. Sites should be identified where at least three visits a year are possible, and the feasibility of OPV tested.

4. Tetanus vaccination ( 3 injections) for girls 5-14 years of age in addition to women 15-45 years. Interval between doses should be minimum 6 weeks between first and second dose, and minimum 6 months between second and third dose.

Experience in Afghanistan indicates that it is better to immunize pregnant women when they attend a clinic, regardiess of the term of pregnancy, because they may not attend a second time. A booster dose should be given one year after, and then for each subsequent pregnancy. 
5. BCG is administered in the left arm in Afghanistan. Both arms must be checked at the time of vaccination to prevent unnecessary re-vaccination since both arms have been used as standard in different situations.

6. Polio vaccine

a.: Oral Polio Vaccine (OPV)

The UNHCR protocols with use of OPV are advised where there is a cold chain system in place and it is possible to reach the population three to four times at one month intervals, e.g. in large cities.

b. Injectable Polio Vaccine (IPV)

IPV is considered most effective in terms of total cost and coverage for those situations without stable cold chain and could be used in remote villages, mountains, far from a large city, in places without a refrigerator. IPV is combined with DPT in DPTP, so that all 4 vaccines are given in one injection.

IPV has:

(1) superior stability to heat stress. It does not need to be frozen, but kept between 0-8 degrees $c$.

(2) a high and consistent antigenic titre. It provides immunity after 3 doses with minimum 6 weeks interval.

7. Measles

It is not advisable to immunize against measles before 9 months. But vaccination at 6 months is possible if there is a high risk because of an outbreak. In this case, a booster dose should be given at the age of 12 months.

However, as soon as a supply of Edmonston Zagreb high titer measles vaccine (EZ) for use at six months is available, consideration should be given to switching to administering $\mathrm{EZ}$ at six months.

8. When in doubt about previous immunizations, the person should be re-vaccinated; this is not harmful. If the child does not have a vaccination card and if there is no register recording the vaccinations performed previously, check if there is a BCG scar. If there is a scar, there is no need to give BCG; give the other vaccines. If no scar, start all the vaccinations again. 
However, if the immunization series is not completed, it should not be started again but should be continued at the point where it was stopped (i.e. if the vaccination card is seen).

9. The importance of keeping vaccination cards and of taking these records with them back to Afghanistan must be impressed upon the refugees.

10. Babies

Try to vaccinate babies whenever possible. Babies are not always kept inside for the first 40 days.

11. The Heaith Education messages produced by UNHCR and HERC should be promoted by all Health workers (see chapter 1).

D. Training

1. WHO and UNICEF should consider ways to establish standard examinations based on the existing curricula and organize exams, once or twice a year, where wHO certificates would be delivered.

2. The present cold chain training is very comprehensive. However, the following two issues should be given consideration:

a. steam sterilization should gradually be introduced in the vaccinator curriculum.

b. the use of foam pads in vaccine carriers should be encouraged and introduced in the curriculum.

3. Opportunities to train vaccinators in Afghanistan should be maximized.

4. The training of many more experienced supervisors is needed. Training should be the same as or similar to that developed by AVICEN already. A cadre of field supervisors is needed who can supervise all the NGOs operating cross border immunization teams.

VI. FUTURE NEEDS

A. At a recent who seminar (December 1990) it was recommended that, until there is an accepted national authority on Health and EPI, a steering committee will meet quarterly. It will be hosted initially by who to decide by consensus relevant policy and technical issues relating to EPI. 
B. Task forces should be formed to prepare detailed plans on:

1. Training (to be hosted by wHO)

2. Cold stores (to be hosted by AVICEN)

3. Data collection (to be hosted by UNICEF)

c. A central database for EPI information (coverage, health services, vaccine stores, logistics, vaccinators) should be established and made accessible to all parties. It could be located either at WHO or UNICEF or delegated to AVICEN but should be jointly supported. NGOs should be encouraged to use compatible software when storing their own information so that it can be shared.

D. Field surveys using cluster survey analysis are encouraged, having been shown to be feasible and practical.

E. Urgent attention should be given to undertaking surveillance as a routine activity by all vaccinator teams.

F. Polio lameness surveys should be undertaken in a range of social, economic and geographical situations. Based on these results, a country plan should be developed for polio control which should be a first step in attaining polio eradication by the year 2000 . Consideration should be given to applying to EPI Geneva for special funding for this plan.

G. Neonatal tetanus surveys should be undertaken to establish a baseline for this disease. A plan of action should then be drawn up for the control of the disease in collaboration with the organizations involved with the delivery of maternal and health services.

H. A study in a health center or hospital recording the age of onset of measles would enable an estimation to be made of the number and proportion of cases occurring under 9 months of age. It is possible that up to $25 \%$ of cases occur before nine months of age if the situation is similar to many countries in Africa. Demonstration of a significant amount of measles at an early age would be a strong indication for use of high titre Edmonston Zagreb measles vaccine administered at six months of age. There are already strong grounds for considering this new vaccine for use in all refugee camp situations.

I. Feasibility studies using IPV and OPV should be undertaken to clarify which is the most suitable vaccine for use in Afghanistan. 
J. Advocacy to the rural population should be carried out to prepare them for EPI. This might include printed matter and radio messages.

K. EPI should be used as the cutting edge for introducing other primary health care services. These additional services should be added on gradually and as resources permit.

L. Evaluation of different strategies to deliver vaccines should be made, e.g. fixed versus mobile teams. 
ORGANIZATIONS INVOLVED IN THE IMMUNIZATION PROGRAM

Pakistan

21 NGOS

Project Director Health of Government of Pakistan UNHCR

AVTCEN

UN ICEF

Afghanistan

AVICEN

MSH

UN ICEF

WHO 
APPENDIX 2

RESOURCE MATERIALS

E.P.I. in rural Afghanistan, Peshawar: AVICEN, 1990. 45 p. : col. maps.

Hazarajat: the development of the EPI programme in the central provinces. Peshawar: AVICEN, 1990. 10 p.

Immunization in practice : a quide for health workers who give vaccines / World Health Organization. Oxford: Oxford U.P., 1989. vi, 361 p. : ill.

Introduction to the Afghan EPI programmes with an overview of the crossborder EPI in rural Afghanistan / Koenraad Van Brabant. Peshawar: AVICEN, 1990. 40 p.

Notions of a cold chain in Afghanistan / Gaetan Hutter. Peshawar: AVICEN, 1990. 44 p.

Report on the comprehensive review of the expanded programme on immunization in Afghan refugees N.W.F.P. Pakistan 17 september -5 October, 1989. John Snow Inc., 1989. 137 p. : ill., charts, tables.

Report on the Expanded Programme for Immunization for Afqhan Refugee Health Programme for 1988. Islamabad: UNHCR and Chief Commissionerate for Afghan Refugees, 1989. 15 p.

Reports and recommendations on Expanded Programme on Immunization in Afghanistan: cross border activities 1990. Peshawar: World Health Organization, [1991]. 82 p. : ill.

Vaccination, posters, tetanus and pharmacies in Afghanistan Bernard Faliu. Peshawar: AVICEN, 1989. [72] p. : photos.

In Dari and Pashtu:

Cold chain supervision [Pashtu] / Immunization Programme for Afghan Refugees: Peshawar: Saudi Red Crescent Society, n.d. 27 p.

Vaccination [cloth poster flipchart in English, Dari, Pashtu]. Peshawar: IRC Health Education Resource Center, 1990. 6 cloth panels on wooden rod : col. ill. 
CHAPTER 6 - MALARIA

The following chapter is adapted mostly from a recent WHO report on Malaria Control for Afghanistan and UNHCR Malaria Control Guidelines for Pakistan (see Appendix 2).

\section{MALARIA SITUATION IN AFGHANISTAN}

Traditionally, malaria is an important disease problem in Afghanistan. The distribution is focal, river valleys and irrigated lands being the areas mainly affected. In most of the country, both P.vivax and P. falciparum may be transmitted, although the transmission season is relatively short (July October). Vivax malaria is more common than falciparum, but falciparum is increasing.

A National Malaria Control Program based on DDT intradomiciliary spraying (anti-larval operations in towns) was started in 1953. The initial effects were dramatic: previously uninhabitable areas were opened up for agricultural exploitation. In 1956, malaria eradication was adapted as the goal. In 1968, 7.9 million people were covered by the eradication program: 2.6 million of these had entered the consolidation phase. In 1970, a change in the vector situation became apparent: the original (at least putative) main vector, A. superpictus, had been virtually eradicated, but replaced by the indoor resting $A$. stephensi and $A$. culicifacies and the outdoor feeding and resting $A$. hyrcanus and A. pulcherrimus. Part of the vector population developed insecticide resistance or changed from indoor to outdoor resting. There necessary, a change was made from DDT to malathion, with good results. In towns, temephos replaced diesel oil for larviciding. In the problematic rice-growing areas in the north, especially kunduz, the larvivorous fish, Gambusia, was deployed with success.

During these years, the antimalarial activities were directed by the National Institute for Malaria and Parasitology, Kabul, with strong support from international organizations and foreign countries. Despite setbacks, deficiencies and numerous constraints and obstacles, the Afghan Malaria Control Program (MCP) was generally considered relatively effective and efficient, having a strong national academic staff and a steadily increasing network of Passive Case Detection (PCD) laboratories (240 in 1979). During the late 1970s, the number of recorded infections in the country per year varied between 40,000 and 80,000 (Annual Parasite Index (API) 2.5-5 per $1,000)$ of which only about $1 \%$ were $P . f$. 
Since 1980, the war in Afghanistan has led to a progressive breakdown of all malaria control activities. Depopulation of fertile river valleys and increased population density in towns could tend to reduce the incidence of malaria but a breakdown of irrigation systems could cause an increase of potential anopheline breeding sites. Figures provided during recent years by the National Institute for Malaria and Parasitology are probably only partially representative, as the monitoring system has had its coverage gradually reduced since the war started.

In 1988, the total number of infections recorded was 379,000 (theoretical Annual Parasite Incidence (API) 36/1,000). Data from 1987 give an idea of the distribution of cases, although it must be taken into account that they are particularly incomplete for peripheral areas. API levels over 100/1,000 were recorded in Jalalabad, Laghman and Kunar (East Region) and Talogan (North East Region). Considering the unequal coverage of the PCD system, the slide Positive Rate (SPR) might give a better indication of risk. Based on this criterion, most of the North East Region, the East Region and Dilaram in the South West Region would be considered the areas most affected. Indeed, epidemics have been recorded in recent years in Jalalabad and Laghman regions. However, the potential for serious malaria outbreaks in the south is obvious, considering that the low number of cases there may mainly be due to depopulation. The proportion of infections caused by $P . f$. has remained at approximately $1 \%$ but it is suspected that the increase could be relatively rapid in the south (Helmand and Kandahar). Chloroquine-resistant P.f. has been detected in Afghanistan but an epidemiological study of this is not on record. "Fansidar" resistance has been found in a few patients in Kabul.

\section{MALARIA SITUATION AMONG AFGHAN REFUGEES IN PAKISTAN}

Malaria in Afghan refugees in Pakistan has increased over the last decade. Malaria is a serious health problem in most refugee villages in NWFP and the Punjab. The API is approximately 30 per 1,000 per year. In Baluchistan the malaria problem is less serious. Falciparum malaria is much more common in Pakistan, as compared to the malaria data from pre-war Afghanistan. The increase in the proportion of P.f. infections (relative to vivax), from less than 5\% 6 years ago to over $20 \%$ at present, is worrying, particularly because of the considerable amount of chloroquine resistance found in the prevalent strains of $\mathrm{P}$. falciparum. Extensive migration and/or repatriation may now result in severe epidemics in Afghanistan. 
The following control efforts are being made in Pakistan and should contribute to a malaria control program in Afghanistan in the future.

A. Training of microscopists for Afghanistan, which will lead to better case detection and diagnosis and appropriate treatment.

B. Attempts to reduce malaria prevalence in Afghan refugees. Special :emphasis is placed on the foci of P. falciparum.

c. Field testing of alternative malaria control techniques that are more applicable to a repatriated population whose health facilities are limited. Emphasis is placed on self-protection (e.g. bed nets).

III. GENERAL PRINCIPLES OF MALARIA CONTROL

The basic objective of malaria control is to reduce the transmission of malaria by the mosquito vector to a level where the infections no longer cause death nor are able to cause excessive sickness in a community. Transmission of malaria requires the presence of malaria carriers (people infected with malaria), the presence of the vector (anopheline mosquitoes) and favorable climatic conditions of temperature and humidity for the mosquito.

There are 5 basic approaches to the control of malaria:

Diagnosis and treatment - attack on the malaria parasite in the human host.

Vector control - attack on the adult mosquito.

Self protection - reduction of contact between humans and mosquitoes.

Environmental management - elimination or reduction of mosquito breeding sites.

Larval control - attack on the early (water) stages of the mosquito, usually with chemical larvicides.

\section{Organization of Malaria Control}

Ideally a malaria control program should be fully integrated into the overall health care program. All the health workers have key roles in the implementation of the program.

The malaria control program consists of many activities: health education, early detection, referral to the Health Facility, diagnosis, case treatment, follow-up, reduction of breeding sites for mosquitoes and monitoring and evaluation of the program. 
A. Vector control

For Afghanistan, the possibilities for vector control are limited.

It would be unrealistic to assume that larval control could play an important role in malaria control in rural Afghanistan under the present circumstances.

Building up a capacity for systematic control by intradomiciliary insecticide spraying would be an extremely. costly exercise. It would be next to impossible to carry out the necessary reconnaissance, surveys, insecticide susceptibility studies and supervision.

The only option left that could possibly lead to a reduction in transmission would be the introduction of insecticide-impregnated bed nets or related techniques. In most Afghan populations, the use of bed nets is not habitual and it is uncertain whether they could become sufficiently popular to base an MCP on. The habit of sleeping outside in the warm season is obviously a serious obstacle. However, in certain areas of Afghanistan bed nets are reportedly used on pooftops being attached to poles that are driven into the sunbaked mud covering the roofs. The cultural acceptability of impregnated bed nets is being investigated and recommendations regarding future deployment will be made later in 1991.

The existence of a capacity for intradomiciliary spraying operations in Kabul and the popular demand for this kind of intervention imply that, once peace is established, it will be difficult to avoid the recommencement of widespread spraying cycles. With the presently available products, one is driven gradually towards more and more toxic and expensive insecticides. clearly, it is too early to decide whether impregnated nets should replace wall-spraying. However, if they are to have a chance in Afghanistan, they should be introduced at a time when the traditional vector control methods are not practicable.

\section{B. Environmental Management}

Environmental management for vector control is the conducting of activities which prevent or reduce the breeding of mosquito vectors of malaria or reduce the person/malaria vector contact. It includes source reduction, a term used to describe any measure that will prevent or eliminate the breeding of mosquitoes in their natural or artificial habitats. The activities or 
environmental modifications performed commonly include drainage, land filling and levelling.

Source reduction has been used for many years as a vector control measure and when integrated into a malaria control program has been found to be very effective. When correctly applied and well maintained it has definite advantages; namely, it is safe, often cheap to implement, can be effective for years, requires limited resources and often has side benefits such as improvement in general sanitation.

\section{Methods}

Drainage is the removal of unwanted water from the land surface or below it. Drainage for mosquito control should remove water before mosquitos have time to develop to adult stage, and dispose of the water without creating a mosquito problem further down the way. Drainage for mosquito control is required before and during the transmission season. Water should not be allowed to remain on the surface for over 5-20 days depending on the temperature. Drainage is usually by the open method and can be dug by hand using pick and shovel. Ditches should be deep and narrow rather than wide and flat.

Filling of small holes, borrow pits, abandoned ditches, ponds and similar water collections are the measures which provide the longest lasting results. It can be done using handtools, for example pick and shovel and wheelbarrows for carrying soil. Land-fills may use sanitary refuse provided that earth is used to cover the fill to prevent fly breeding and smell.

Basic sanitary measures: the lack of a convenient water supply in a community leads to the stocking of water in tanks, water jars and other containers which may serve as mosquito breeding places. A.stephensi, the probable predominant Anopheline mosquito vector in refugee villages in NWFP, and in Afghanistan, is a domestic species of Anopheles that can breed in containers and tanks or in small seepages and water collections. It is also one of the few Anopheles mosquitoes that can breed in organically polluted water.

Drying by planting trees is a useful measure where the water table is high. Eucalyptus trees have been widely used for this purpose. The trees dry waterlogged land by evaporation through their leaves. They should be planted giving adequate space between trees so there is the least interference with evaporation. 
Source Reduction is a method of vector control that the community can do if it has an understanding of how and why malaria occurs and why it is necessary to prevent or reduce mosquitos breeding. Health workers can play an important role in educating people and should set an example through their own practices (Refer to section IV Health Education). They should have some understanding of environmental management and in particular source reduction. This may require additional training. They should be responsible in the village for identifying breeding areas of Anopheles mosquitoes and taking appropriate action or motivating the community to take action. Any reconstruction programs in Afghanistan should try to minimize the possibility of creating additional breeding sites for mosquitoes in the villages.

Self Protection is a malaria control method which individuals may use to reduce the contact between themselves and mosquitoes. Some methods, such as the use of smoke from bark or herbs, date back many centuries. There has been a resurgence of interest in self protection for control of malaria in recent years and there are a number of possible methods that can be used. However, for all of the methods, it is important to realize that most anopheline mosquitoes bite at night between sunset and dusk.

Bed nets remain one of the most important methods for personal protection and in some countries strong traditions for the use of bed nets have developed. If used correctly, they are effective; however, their efficacy can be greatly improved by the use of a repellent or insecticide on the net.

Hanging cots for babies, as used in Pakistan and Afghanistan, are easy to cover by a piece of netting. But only a few Afghan tribes residing in Pakistan have a tradition of using bed nets, e.g. Tajik tribes from Urgun. Their use and acceptance among the Afghan population will be further investigated in 1991.

In some health worker curricula, people are advised to wrap themselves in a blanket (patoe). This practice will not stop all mosquitoes from biting, so it is better not to emphasize this message in health eduation.

Screening of houses by meshed nylon is practiced by refugee communities and should be encouraged. To be effective, it should be total to cover all doors and windows as well as any other opening. Cracks in walls should be sealed. 
House site selection - The type and design of house and its position relative to mosquito breeding sites and to the direction of the prevailing wind at night time are important factors which can affect the mosquito-person contact. Mosquitoes can be carried some distance by the wind and houses should be built upwind, preferably, to an identified mosquito breeding area. It is important that reconstruction plans for Afghanistan take these considerations into account.

Mosquito repellents and anti-mosquito fumigants - burning of mosquito coils and leaves from eucalyptus trees are useful to repel mosquitoes.

\section{HEALTH EDUCATION}

A. Introduction

The need for health education is obvious, whether it be for the patient to understand that the complete course of tablets must be taken in order to ensure that the patient is cured or for individuals themselves to adopt measures to prevent themselves from developing malaria. All health workers or workers based in the clinic should understand the cause of malaria, the measures that can be taken to prevent it, and what should be done when a person has malaria.

\section{B. Prime Messages}

At present the community knowledge of malaria is poor. In surveys on community knowledge carried out in NWFP and Baluchistan it was shown that most Afghans in pakistan know how malaria is transmitted. The knowledge as to how to prevent malaria is very limited, and warrants further health education.

A number of prime messages have been developed for health education for malaria control in the Afghan refugee program. These messages have been adopted from UNICEF's "Facts for life" and are considered to be the most important that individuals and communities need to know to prevent malaria or to treat malaria. The messages are:

1. Malaria is transmitted by mosquitoes.

2. Everyone especially children should be protected from mosquito bites especially at night.

3. People should destroy mosquito breeding sites. 
4. Mosquitoes can be killed by insecticide spray on walls of houses.

5. Children and adults with a fever should go to the clinic for a blood smear to be taken.

6. If malaria is the cause of the fever, the person must complete the full course of the anti-malarial drugs.

All health workers should be familiar with these messages.

c. Communicating the Prime Messages

Whom in the community should we educate with the health messages?

For malaria we need to educate mothers, pregnant women, fathers, school children, community leaders, religious leaders and administration officials. The health messages on malaria need to be spread widely throughout the community.

Who should do this?

All health workers have a responsibility to communicate the messages and if other persons such as teachers, religious leaders and administration officials can also communicate the messages, this will help greatly in disseminating the information.

A silkscreen flipchart with a series of pictures which can be used to help communicate the prime messages has been developed by and is available from HERC.

other suitable health education materials that have been developed and adapted to the local conditions are listed in Appendix 2 .

V. RECOMMENDATIONS

A. Strengthening the Laboratory Network

The work started by MSF Holland/Belgium based at the Malaria Referral Laboratory in Peshawar should continue. The main elements are:

1. Training of microscopists

2. Quality control

3. Refresher courses 
Efforts are under way to add direct supervision in Afghanistan. In the future, it may be necessary to pay increased attention to logistics and to decide whether a vertical system for securing laboratory supplies will be more rational than relying on the individual sponsors. These activities should now be coordinated with other efforts in the field of malaria (see following recommendations).

\section{B. Strengthening Surveillance}

The system of PCD based on laboratory reports is only starting to work. One could suggest some simplifications; it is unnecessary, for instance, to monitor the sex distribution of malaria cases (which is included in the routine "greenbook" reporting system for all conditions). However, the managers of this system may find it more practical to continue working with the established form, avoiding the disturbance of petty improvements.

What is now needed is to start consolidation and analysis of these data together with the greenbook malaria data. The distribution of cases detected should be compared with older data from Kabul. Previous information on malaria should be elaborated and distributed to laboratories and doctors; in some cases, supplementary information may be obtained through cross-sectional surveys; the performance of such surveys may seem slightly premature considering the remoteness of possible preventive action. Nonetheless, they can add considerably to the local practitioners' understanding of malaria epidemiology as well as adding bits to the generally still vague picture. These surveys should therefore be encouraged when the laboratory personnel are certified; the slides should be sent for checking if possible.

Competent clinicians should be identified to check the correctness of the data provided by the laboratories for the PCD system and to, provide additional data on monthly cases of:

1. hospitalized malaria

2. cerebral malaria (well-defined criteria)

3. malaria deaths, if recorded

At present, the consequences of this monitoring will be limited. However, these steps will provide experience for designing a more comprehensive information and surveillance system, and will provide some baseline information for decision-making if, with time, possibilities for implementing a true malaria control program improve. 


\section{c. Enactment of a Drug Policy}

In the presence of more than one parasite species and of drug resistance, the rational use of antimalarial drugs to prevent death and severe disease depends to a large extent on the existence of an extensive laboratory network of good quality, oriented primarily towards the needs of clinical care. In addition, the enactment of a drug policy requires:

1. definition of guidelines for treatment

2. distribution of drugs

3. education of health workers

4. education of the general public

Refer to Chapter 11 - Essential Medicines.

Definition of guidelines for treatment

(Please refer to Appendix 2)

Guidelines should be based on a limited number of formulations. Under the prevailing uncontrolled transmission, primaquine has no place either for the prevention of vivax relapses or for killing $P . f$. gametocytes. The high prevalence of G-6-PD deficiency among the Pushtun population (approximately 15\%) restricts the use of primaquine as a drug in basic health care. The addition of primaquine to chloroquine as a way of limiting the spread of chloroquine-resistance is not a strategy of proven efficacy, and could theoretically lead to a selective pressure in favor of chloroquineresistant genotypes.

The existence of chloroguine-resiatance makes it necessary to deploy Fansidar tablets and quinine injectable. It is doubteul whether chloroquine injectable is really necessary, but since it will continue to be popular, its use should be guided. Quinine (t tetracycline) tablets would be the most rational choice for Fansidar-resistant cases but for the time being, these will probably be detected so rarely that they can be treated with quinine injections. Chloroquine syrup is often dosed wrongly and is not tolerated better than crushed tablets. Amodiaquine is no longer recommended by Who because of the high risk of agranulocytosis assoclated with repeated intake, and because it is only marginally (at best) more effective than chloroquine for chlorogulne-resistant malarla. Thus, the following formulations should be used:

1. Tablets of chloroquine diphosphate or sulphate, 150 mg chloroquine base per tablet. 
2. Vials of chloroquine diphosphate or sulphate injectable, $200 \mathrm{mg}$ chloroquine base per $5 \mathrm{ml}$ (40 $\mathrm{mg} / \mathrm{ml})$.

3. Tablets of sulfadoxine and pyrimethamine, "Fansidar", sulfadoxine $500 \mathrm{mg}+$ pyrimethamine 25 mg per tablet.

4. Vials of quinine dihydrochloride injectable, $600 \mathrm{mg}$ guinine salt per $2 \mathrm{ml}$.

It should be noted that a scale is an obligatory tool for treatment with antimalarials by the parenteral route.

Treatment Guidelines, available in Pushtu and Dari, will be developed by wHO Malaria Control Unit, Peșhawar, at a later date.

Distribution of drugs

Judging from the situation in Kunar Province, there is no lack of the antimalarials needed, even at the most peripheral level. Several unneeded drugs are widespread, and one should realize that this situation can, at best, only slowly be ameliorated, through the education of health personnel and the public. The aims should be the following:

1. Chloroquine tablets should always be available at all health care facilities. In isolated villages, settlements, etc., chloroquine tablets should be kept by responsible persons to be used as first aid treatment for any fever case on the basis of the poster. It may differ between areas depending on whether this deployment of chloroquine is best obtained through the "free market system" or through active promotion and distribution by health workers; also whether more trust should be put in "community leaders" or in individual families.

2. At clinics and pharmacles staffed with mid-level health workers but without a laboratory, chloroquine tablets should be avallable.

3. At clinics with a laboratory and with a mid-level health worker/doctor, "Fansidar" tablets and quinine injectable should also be avallable.

It is clear that when for instance "Fansidar" is alwaye readily avallable at a nearby pharmacy, there is no need for it to be stocked at the health care unit. In this situation, the pharmacist should be motivated not to misuse the reserve drug; the best tool for this is probably to provide him with a set of the treatment guidelines. 
It is possible that in some provinces, "Fansidar" is not readily available. In a "worst case" scenario, it would be necessary to apply "Fansidar" as first line treatment of falciparum infection.

\section{Education of health workers}

Although malaria is a major problem, it would probably not be justified to run special malaria courses for health workers. Malaria, especially diagnosis and treatment, should be included in training courses and refresher courses together with other clinical subjects. From one viewpoint, malaria belongs together with Maternity and Child Health target diseases such as diarrhoea and respiratory tract infections. From another viewpoint, malaria should be taught together with tuberculosis, because of the importance of laboratory diagnosis and the necessity of understanding drug resistance and side effects.

Education of the general public

The main points in the information to the general public should at this point be:

1. recognition of the signs of malaria

2. the necessity of early treatment with chlopoquine

3. the non-necessity and danger of chloroquine injections for patients who can take tablets

4. that early treatment of malaria is particularly important for pregnant women and children

The main vehicle for this information will probably be posters. It is always good to give information on what malaria is, how it is transmitted and the life-cycle of mosquitoes by radio or other channels, and no opportunity for this should be lost. However, due to the present lack of options for vector control, not too much emphasis should be placed on this. This may change if preliminary trials indicate that impregnated nets are both effective and acceptable.

\section{D. operational Research}

The following operational research is proposed:

1. Evaluation of the effectiveness of insecticide treated mosquito nets.

2. Evaluation of the effectiveness of treated "chadors".

3. Probing of the acceptability of impregnated bed nets in Kunar Province. 
4. Assessment of the therapeutic efficacy of chloroquine in falciparum malaria in Afghanistan.

E. Establishment of a malaria action program at wHO Field office, Peshawar

It is clear that the recommendations formulated here do not constitute a malaria control program. The measures suggested are the initial steps which over some years might develop into a malaria control program, or lead to the accumulation of experiences that could in the future prove valuable for the National MCP managed by the Institute of Malaria and Parasitology in Kabul.

WHO has set up a Malaria control Unit at its office in Peshawar to coordinate malaria control activities among the various agencies working in the health sphere in Afghanistan. 


\section{APPENDIX 1}

\section{GUIDELINES FOR TREATMENT OF MALARIA IN AFGHANISTAN}

I. First-line treatment

This is applied to cases of uncomplicated malaria, whether vivax or falciparum, diagnosed with or without the support of the laboratory. The treatment normally consists of chloroquine tablets (150 $\mathrm{mg}$ chloroquine base per tablet) in the following dosage.

\begin{tabular}{|lccc|}
\hline Age & 1st day & 2nd day & 3rd day \\
\hline $0-1$ months & $1 / 4$ & $1 / 4$ & $1 / 4$ \\
$2-3$ months & $1 / 2$ & $1 / 4$ & $1 / 4$ \\
$4-11$ months & $1 / 2$ & $1 / 2$ & $1 / 2$ \\
$1-3$ years & 1 & 1 & $1 / 2$ \\
$4-6$ years & $11 / 2$ & $11 / 2$ & $3 / 4$ \\
$7-11$ years & $21 / 2$ & $21 / 2$ & 1 \\
12 years and over & 4 & 4 & 2 \\
\hline
\end{tabular}

All cases of malaria should be treated with chloroquine tablets, including those in babies and pregnant women. Young children should be treated with crushed tablets in water.

Chloroquine injections can be dangerous. Young children, when very sick, can die from them. They should be given only when absolutely necessary and only by qualified health workers.

II. Second Line Treatment

Second line treatment with "Fansidar" is applied in cases of chloroquine-resistant falciparum malaria. Chloroquine is always more effective than "Fansidar" in vivax malaria.

"Fansidar" can have dangerous side-effects. The two most common are stevens-Johnson's syndrome and agranulocytosis. Stevens-Johnson's syndrome is a generalized allergic reaction involving the skin and the mucous membranes. Agranulocytosis is a reduction in the number of white blood cells. This can lead to any kind of severe infection. Sometimes patients treated with "Fansidar" get agranulocytosis a few weeks after the treatment. As a consequence, they may acquire a bacterial infection causins fever. A health worker without access to a laboratory may think that the patient has malaria again and treat him with "Fansidar". This may kill the patient. Therefore:

A. "Fansidar" should be reserved for cases of malaria resistant to chloroquine. Resistance can only be diagnosed with the help of microscopy (see below). 
B. "Fansidar" must never be given to a patient who has had an allergic reaction to it or to another sulfa drug (e.g. cotrimoxazol, sulfamethizol or sulfadiazine).

C. A treatment with "Fansidar" must never be repeated within an interval of 3 weeks.

D. "Fansidar" must not be given to children below the age of 8 weeks. "Fansidar" may be given to pregnant women as treatment when necessary.

\section{How is chloroquine-resistance diagnosed?}

A. Chloroquine-resistance is suspected if a patient treated for malaria with chloroquine over 3 days in correct dosage continues to have symptoms of malaria, or if the symptoms recur within a period of 4 weeks from the start of the chloroquine treatment. (If it is uncertain whether the patient has taken the full chloroquine treatment, or whether part of it may have been vomited, then the chloroquine treatment should be repeated, if possible, under supervision.)

B. If chloroquine-resistance is suspected, a slide should be prepared. (If the patient is first seen at a health care unit with no laboratory, referral to a place with laboratory is necessary.)

C. Chloroquine-resistance is proven if the slide shows asexual (Plasmodium falciparum) i.e. rings or trophozoites, and at least 7 days have passed since chloroquine treatment was started. The patient should be treated with "Fansidar".

\section{The dosage of "Fansidar"}

"Fansidar" is available in tablets containing sulfadoxine 500 $\mathrm{mg}$ and pyrimethamine $25 \mathrm{mg}$. The correct dosage is sulfadoxine $25 \mathrm{mg} / \mathrm{kg}$ body weight + pyrimethamine $1.25 \mathrm{mg} / \mathrm{kg}$ body weight. In relation to age, the dosage is as follows: 


\begin{tabular}{|lll|}
\hline Age group & Weight range & $\begin{array}{c}\text { No tablets } \\
\text { (single dose) }\end{array}$ \\
\hline 8 weeks-1 yr & $4.0-9.9 \mathrm{~kg}$ & $1 / 4-1 / 2$ \\
$1-3$ years & $10.0-14.4 \mathrm{~kg}$ & $1 / 2-3 / 4$ \\
$4-6$ years & $14.5-18.4 \mathrm{~kg}$ & 1 \\
$7-11$ years & $18.5-34.9 \mathrm{~kg}$ & $11 / 2$ \\
$12-15$ years & $35.0-59.9 \mathrm{~kg}$ & 2 \\
16 and over & $60 \mathrm{~kg}$ and over & 3 \\
\hline
\end{tabular}

"Fansidar" should not be given to children under the age of 8 weeks. These should be treated with quinine in case of chloroquine-resistance, and the same goes for other situations where "Fansidar" should not be given (see above).

\section{The Treatment of Complicated Malaria}

Complicated malaria is malaria caused by Plasmodium falciparum accompanied by complications from one or more organ systems.

Cerebral malaria is the most famous form of complicated malaria. In rigorously defined cerebral malaria, the patient is in a coma, but cases with other cerebral symptoms such as psychosis or convulsions should also be treated as cerebral malaria. On the other hand, febrile convulsions in young children, where the child quickly regains consciousness thould not be considered cerebral malaria, and the same goes for the confusion that may accompany a high fever in patients of any age.

Other important forms of complicated malaria are malaria with severe anemia, hepatic malaria (may look like hepatitis), and malaria with kidney failure and hemoglobinuria - "black water fever".

A diagnosis of complicated malaria can only be made with certainty, if a slide shows asexual P. falciparum. Usually, but not always, the parasites are numerous. If cerebrai malaria is suspected, a lumbar puncture should be performed, if possible, for a patient with bacterial meningitis may have malaria parasites in the blood. Although treatment should preferably be based on a microscopical diagnosis, it should on the other hand not be delayed if microscopy $1 \mathrm{~s}$ not at hand. If a health worker believes a patient is suffering from cerebral malaria, he/she should start. treatment at once. Sometimes it may be advisable to give a first dose of quinine, and then transfer the patient to a hospital which is better equipped. 
The best treatment for complicated malaria, now that chloroquine-resistance is appearing, is quinine by the intramuscular route.

\section{The dosage of quinine}

The dosage of quinine is $10 \mathrm{mg}$ of quinine salt per $\mathrm{kg}$ body weight every 8 hours. The vials of quinine most commonly used in Afghanistan contain $600 \mathrm{mg}$ quinine in $2 \mathrm{ml}(300 \mathrm{mg} / \mathrm{ml})$. With these, the volumes to be given in relation to weight are as follows. With different vials, the volumes are of course different. Note that, just as with chloroquine, you cannot dose quinine injections correctly without weighing the patient.

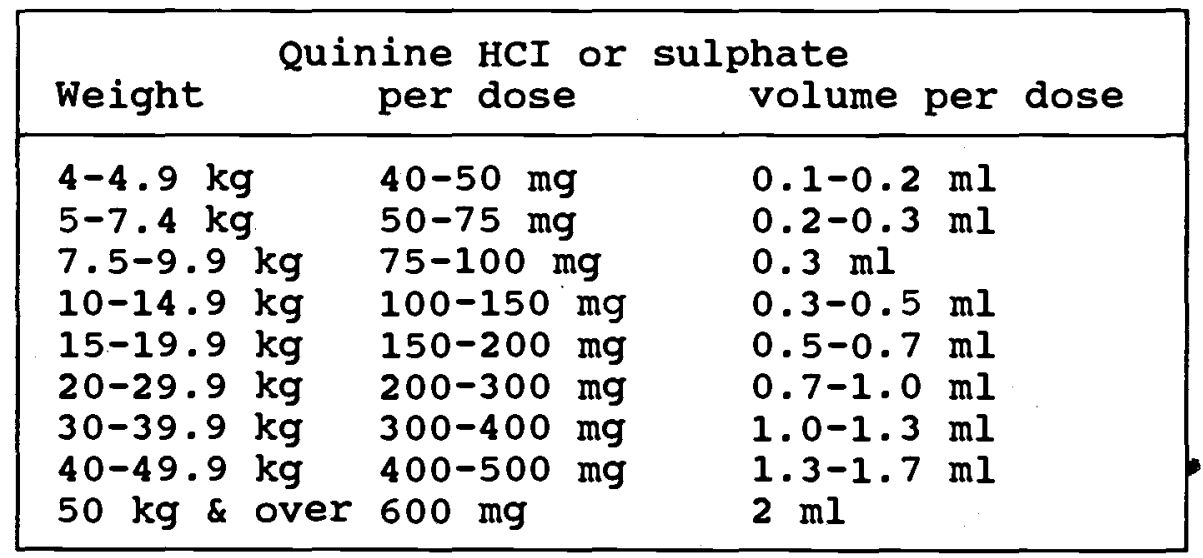

The treatment with intramuscular quinine should continue until the patient is well enough to take orạl medicine. When this happens, the patient should normally be given a single dose of "Fansidar". If no "Fansidar" is available, or the patient does not soon improve, continue with quinine injections to complete 7 days of treatment. Quinine and chloroquine together may cause dangerous side-effects, so try to avoid treating a patient with both of these drugs. Never treat a patient with quinine and chloroquine injections at the same time. 


\section{APPENDIX 2}

RESOURCES

Chemotherapy of malaria. 2nd ed. / L.J. Bruce-chwatt (ed.) Geneva: WHO, 1986. 261 p.

Guidelines: malaria control. Islamabad: Afghan Refugee Health Programme, 1990. ca. 40 p.: ill.

Malaria [cloth poster flipchart in Dari, Pashtu, Urdu]. Peshawar: IRC Health Education Resource center, 1990. 10 cloth panels on wooden rod: col. ill.

Malaria: Afghanistan. Geographical Monograph Series, Ludolph Fisher, 1968 .

Malaria in Afghan Refugee Villages in Pakistan / J. de ZuLueta. 1989, 1990. Available from UNHCR.

Manual on environmental management formosquito control with special emphasis on malaria vectors. Geneva: WHO, 1982 . 283 p. : ill.

Report on a mission to Pakistan and Afghanistan 7-27 November 1990 to assess the malaria situation in Afqhanistan with a special view to returning Afghan refugees / Allan Schapira and Jan Rozendaal. Geneva: WHO Malaria Unit, 1991; 54 p.

VIDEO RESOURCES

The Community Health Worker in Malaria Control [Pashtu] / MSF

Death of a Mosquito [Pashtu] / IRC and MSF. A puppet show for children.

Positive or Negative: the community health worker in malaria [Pashtu] / Joost Verhey. 


\section{CHAPTER 7 - TUBERCULOSIS CONTROL PROGRAMS}

I. BACKGROUND TO TB CONTROL PROGRAM FOR AFGHAN REFUGEES IN PAKISTAN

The TB Control irogram for Afghan Refugees - TBCP (AR) started in NWFP in 1984 as a methodological approach to the "TB problem" on behalf of the Government of Pakistan and of Italy, integrated within the framework of the Pakistani health system for Afghan refugees (CAR/PDH-NWFP).

During 1984 and 1985 a carefully planned and gradually phased implementation was carried out in order to share health resources and to determine correctly the priorities. In 1985, to clarify the baseline status, the goals to be reached and how and when, a tuberculin survey was also organized. At the end of 1985 the TBCP became operative with permanent services in all settlements of Afghan refugees. The activities of the TBCP included: case finding activities, case holding, technical and operational supervision and monitoring (including recording and reporting and data collection), program evaluation.

Detecting patients with open tuberculosis and curing them was irrevocably decided as first priority and since sputum smearmicroscopy is of adequate sensitivity, good specifigity and low cost, maximum effort has been paid to implement peripheral laboratories, to train peripheral health staff and microscopists and to supervise diagnostic activities both at BHU and at laboratory level (sputum collection, smear preparation, smear staining and reading, cross checking for results of sputum examinations). Suspect cases of pulmonary tuberculosis (X-rays suggestive), and patients with extrapulmonary tuberculosis were also considered but they were accorded only second priority in case-finding. It was strictly recommended that there is no place for clinical diagnosis of pulmonary tuberculosis; any attempt to justify treating "clinically diagnosed" patients was discouraged.

Case-holding was also organized based on delivery of adequate chemotherapy, providing follow up facilities, supervision of treatment and regular drug distribution, organizing search of defaulting patients and providing a reliable definition of "cured TB patient".

The short course regime was highly recommended for positive patients because of the quickness of sputum conversion into negativity. Although difficulties of applying a strictly daily supervised regime in the intensive phase were taken into consideration and a weekly drug distribution was tolerated, only the described regimes were accepted to avoid uncoritrolled multiplication of regimes that do not permit planned distribution of drugs and evaluation of efficacy. 
At the start of the TBCP it seemed pointless to make provision for retreatment regimes where success in primary treatment of all cases detected was not ensured; nevertheless a standardized retreatment regimen was later decided and included in the manual of guidelines to be applied for patients whose sputum examination persists positive after five months of the short course (failures). Nevertheless it was stressed that the causes of failure (poor compliance) must be removed: the strict daily supervision of drug intake was decided as compulsory for patients under retreatment.

Supervision was organized in a planned way (periodic and regular, after reviewing the findings of the last visit and checking the corrective actions previously taken) in order to increase the efficiency of health workers (training of newly appointed workers and refresher courses when needed) and to keep a continuous watch on program performances through program reports. The main sources for the reports were:

- daily registers for outpatients (OPD Register)

- peripheral TB registers

- treatment cards

- microscopy logbooks

Evaluation was also carried out on a regular basis by epidemiologic evaluation (annual risk of infection from which the expected incidence of AFB positive patients was derived) and operational evaluation (case-finding and case-holding coverages, mainly by cohort analysis). To ensure reliability of these indices, a second tuberculin survey was carried out in 1989 .

II. PRESENT SITUATION

There are now guidelines for TB Control programs both for Afghan refugees in camps in Pakistan ${ }^{1}$ and for cross-border work in Afghanistan ${ }^{2}$. These enable standardization of diagnosis, treatment and follow-up.

It is not possible to begin a national $T B$ control program in Afghanistan until the health system is more organized. Some agencies, however, have TB control activities arranging case finding and treatment in smaller areas. If these are well organized and coordinated, they can provide important information about $T B$ in Afghanistan now, and will be easily incorporated into a national $T B$ control program in the future.

The aims of a TB control program in Afghanistan are case finding and case holding of sputum smear positive cases.

'GOP/UNHCR/WHO/ICD Afghan Refugee Health Program Tuberculosis Control Guidelines

${ }^{2}$ Guidelines for TB Control programs in Afghanistan from: ICD/MSF-B. 
III. REQUIREMENTS TO BEGIN A TB CONTROL PROGRAM IN AFGHANISTAN

A. Laboratory facilities and Microscopist

Laboratory facilities with a microscopist trained to wHO standards (with the wHO certificate issued through the Lab Training coordination) are required.

Symptomatic diagnosis is inaccurate as many diseases have the same symptoms as TB. X-rays are not specific for TB. These are only useful for diagnosis of $\mathrm{TB}$ in children when interpreted $\mathrm{b}_{Y} \mathrm{a}$ doctor trained to read children's chest $\mathrm{X}$-rays since its interpretation is very difficult. Consequently, laboratory examination is necessary for diagnosis of TB.

The health center must have a daily connection to the lab for transport of specimens and results.

B. Mid-level Health Worker with Appropriate Training

A mid-level worker with training in TB management, who is responsible for:

1. Case finding

a. correct diagnostic procedure

2. $\quad$ Treatment

a. using the correct regimen

3. Follow up

a. sputum examinations at the due time

b. weekly drug collection in the intensive phase

c. monthly drug collection in the maintenance phase

d. checking the compliance of the patients

4. Recording and reporting of data

5. Preparation of monthly reports

IV. HEALTH EDUCATION

Increasing community awareness of TB transmission symptoms and treatment must be addressed through Health Education Programs. As the disease is spread by sputum positive patients, the symptoms (cough, hemoptysis, etc.) should be taught. Health care workers need to know where to refer 
suspected sputum positive cases. There is then a need for information flow between the TB center and the health care workers so that patients can be monitored and are seen to be taking the correct dosage for the correct length of time. The cooperation of elders, mullahs, etc. to convince the patient of the need to take the drug correctly is also important.

V. GUIDELINES: FOR THE MANAGEMENT OF TB PATIENTS IN AFGHANISTAN

The guidelines encompass all aspects of TB management:

- general considerations (including definition of a TB case, transmission)

- TB case finding

- treatment regimen (described in detail and summarized in a flow diagram)

- organization, recording and reporting (with copies of monthly reports, TB register and treatment card)

- laboratory techniques

These guidelines have been produced in English and are available from ICD. They require translation and field testing. 
Agencies involved in TB control programs

\section{Pakistan}

International Cooperation for Development (ICD)

All agencies operating in refugee clinics/BHUs

Saudi Red Crescent Hospital, Nasir Bagh

WHO supported T.B. Control programs in Baluchistan

\section{Afghanistan}

The following agencies either already have a TB control program operating in Afghanistan or are seriously considering setting up such a program:

German Afghanistan Committee

Lajnat al Dawa

Medicins du Monde

Mercy Corps International

IMC

MSH - drug supply

SCA - drug supply 


\section{APPENDIX 2}

\section{RESOURCES}

Guidelines for tuberculosis control programmes in Afghanistan. Peshawar: Medecins Sans Frontieres - Belgium.

Guidelines for tuberculosis control proarammes in developing countries. Oxford: Oxfam Health Unit, 1985. 59 p.

Guidelines: tuberculosis control programme. Peshawar: Afghan Refugee Health Programme, [198-]. 25 p.

Tuberculosis: case-finding and chemotherapy / K. Toman. Geneva: WHO, 1979. $239 \mathrm{p}$.

Tuberculosis control: a manual on methods and procedures for integrated programs. Washington, DC: Pan American Health Organization and WHO, 1986. $174 \mathrm{p}$.

Tuberculosis control as an integral part of primary health care. Geneva, WHO, 1988. 47 p.

In Pashtu:

Tuberculosis [Pashtu] / Mohammad Yousuf Laghmani. Peshawar: WUFA, [198-?]. $102 \mathrm{p}$.

Tuberculosis can be cured [Pashtu]. Peshawar: HERC and SERVE, 1987. 32 p.: col. photos. 


\section{CHAPTER 8* - ILABORATORY TRAINING}

\section{INTRODUCTION}

During 1990 coordination meetings were held by Medecins sans Frontieres - Belgium (MSF-B) to discuss standardization of laboratory training for field microscopists. A minimum skills checklist (see Appendix 1) was drawn up and a practical examination designed for qualification of laboratory workers who are then issued with a WHO certificate. A standardized supply list (see Appendix 2), a comprehensive laboratory manual for use in Afghanistan and a Practical Guide for Trainers have also been produced.

Trainers in these programs are often technically skilled but do not have educative skills. Consequently the focus of many activities of the coordination has been the training of trainers, which has standardized the techniques, improved practical teaching and the final competence level of students from the various training programs.

Activities focussing on trainers include regular trainers meetings to encourage the exchange of ideas and information, workshops dealing with technical and teaching oskills, production of the Practical Guide for Trainers (to assist technical workers to develop educative skills) and participation in the final examination procedure. They are also involved in the preparation of the laboratory manual, reviewing the text and translation, which are then discussed during trainers meetings.

\section{CURRENT SITUATION}

Practical competence examinations are carried out regularly, with students of one agency being examined by staff from various other agencies. If a student does not pass the exam, refresher training can be given and the exam re-taken. Ten agencies are participating (see Appendix 3) and, by the end of 1990, 56 students had been issued WHO certificates. An additional 47 candidates will be examined in the first quarter of 1991 .

The Field Microscopists will be competent to set up and operate a field laboratory with the laboratory skills recommended by WHO for Afghanistan. These include:

- sputum examination for tuberculosis

- blood examination for malaria, anaemia and infection

- stool examination for intestinal parasites

- urine examination for diabetes and infection 
Once in Afghanistan, slides examined by the field microscopist can be cross checked, and recommendations returned to these workers to improve their skills. Monthly reports of laboratory activities in Afghanistan are returned to MSF-B for compilation of epidemiological data. 


\section{APPENDIX 1}

\section{General Iaboratory Procedures}

* Laboratory design and preparation.

* Equipment; solution preparation, storage and quality control, cleaning, maintenance

* Microscope; adjustment, cleaning, transportation, maintenance

* Administration: specimen registration and labelling, recording and reporting results, statistics, inventory, maintenance of supplies.

* Safety; basic first aid specific to the laboratory situation, accident prevention.

* Disinfection, disposal of contaminated material, control of laboratory acquired infection.

\section{specimen collection}

* Instructions for patients, specimen storage, prioritization of specimen analysis, capillary collection of blood.

\section{slide Preparation and staining procedure}

* Blood and sputum smears, supervision of malaria supervisor in smear preparation, fixation, wet preparations for urine and stool, Giemsa and Ziehl Neelson staining.

\section{sputum Examination: TB}

* Preparation and fixation of smears, Ziehl Neelson staining, identification and quantification of AFB, statistics, quality control procedures.

\section{Parasitology ; Malaria}

* Thick and thin smears, Giemsa staining, identification of stages of falciparum and vivax parasites, quantification of malaria parasites, statistics, quality control procedures.

\section{Parasitology ; stool}

* Gross and microscopic examination, recognition of pathogens and quantification where necessary.

\section{orine Examination}

* Gross and microscoplc examination, use of indicator papers for pH, use of reagent strips for protein and glucose estimation, manual methods for protein (sulphosalicylic acid) and glucose (Benedict's), recognition and semi-quantification of deposits (uncentrifuged).

\section{Haematology}

* Differential examination and counts, cell morphology, qualitative estimation of white cell count. 
Public Health

* Basic principles of sanitation, vector and pest control, water sources, garbage disposal.

* Role and responsibilities of the community in the eradication of disease.

(From MSF-B, Coordination Office, 12 Afzalabad, University Town, Peshawar, 41870) 


\section{APPENDIX 2}

IABORATORY EOUIPMENT for use by Field Microscopists (August 1990)

The field laboratory cannot operate without the correct equipment. The quality of equipment is very variable and often poor. The equipment on this list has been tested to give reliable results. It is available in Pakistan.

IF YOU CANNOT FIND THE EXACT EQUIPMENT DESCRIBED, CONTACT THE MSF-B COORDINATION OFFICE.

\section{INITIAL SUPPLY}

\section{MEDICAL SUPPLY STORES}

1 binocular microscope with

- movable condenser

- mirror attachment

* attachments for use with electricity

* 2 pronged plug

* 3 pronged plug (for generator)

* 2 spare globes (see microscope specifications)

- x $10 / \times 40 /$ x 100 objective lenses

- blue filter

NB: CHINESE MICROSCOPES must be checked by a laboratory technician before purchasing (many are faulty).

OTHER MICROSCOPES: please check the suitability with the coordination office before purchasing.

1 centrifuge - hand operated (see Memorandum attached)

1 spirit lamp

2 forceps

2 scissors

1 loopholder

1 test tube rack

1 test tube holder

4 slide transport boxes

1 timer with alarm

4 washing bottles

5 plastic dropper bottles

$10500 \mathrm{ml}$ storage bottles

(metal; medium size)

(stainless steel; medium size)

(" "; 20cm)

(plastic - for 6 large tubes)

(plastic)

(German-Mali brand)

(plastic)

(eg. eyedrop bottles)

(polypropylene)

$10.250 \mathrm{ml}$ wking soln bottles( $50 \mathrm{ml}$ measuring cylinders ( $100 \mathrm{ml}$ $500 \mathrm{ml}$ " $"$ test tubes $1000 \mathrm{ml}$ Erlenmeyer flasks $250 \mathrm{ml}$ $250 \mathrm{ml}$ $50 \mathrm{ml}$ beakers pkt plastic droppers staining dishes + lids petri dishes

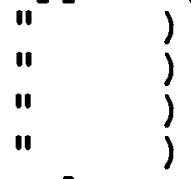

(glass - large size)

$750 \mathrm{ml}$ OR $1000 \mathrm{ml}$ thick glass bottle + ground glass lid

1 diamond pencil 
1 pkt of nichrome wire loops (small - medium size)

1 metal stool with revolving seat

1 iodine powder (500g)

1 potassium iodide powder (500g)

1 disodium hydrogen phosphate powder

1 potassium di hydrogen phosphate

1 sulphosalicylic acid(BDH / Merck)

$2250 \mathrm{ml}$ oil of cedarwood (BDH / Merck)

$1 \quad 25 \mathrm{~g}$ basic fuchsin powder (BDH / Peking Chemical Works)

$125 \mathrm{~g}$ methylene blue

$1300 \mathrm{~g}$ carbolic acid (Merck /" " )

(BDH / Merck)

2.5 litre sulphuric acid (BDH / Merck)

pkt sodium chloride Fowder(Pakistani)

$450 \mathrm{ml}$ Benedict solution

bottles of 100 urine reagent strips (Uropaper)

- expiry at least one year after date of supply

30 boxes microscope slides; Chinese Sail Brand - 72 pcs/pkt cat. no. 7101

20 pkt coverslips $\quad(100 /$ box $)$

6 cotton rolls

20 metres gauze

1 pkt filter paper (Whatman no 1)

400 specimen containers with screw lids

$105 \mathrm{ml}$ syringes + needles (plastic)

20 loml " ( ")

10 large bore needles

1 roll white sticking plaster (Paragon)

$125 \mathrm{~g}$ giemsa powder

$1 \quad 2.5$ litre glycerol

(Kochlight / BDH)

$500 \mathrm{ml}$ xylol

2.5 litre methanol

pkt $\mathrm{pH}$ papers (pH $6-8$ )

protect ive face masks

litres savlon (hospital concentrate)

pkt sodium bicarbonate powder

pkt boric acid powder

\section{PLASTIC DISHES SHOP}

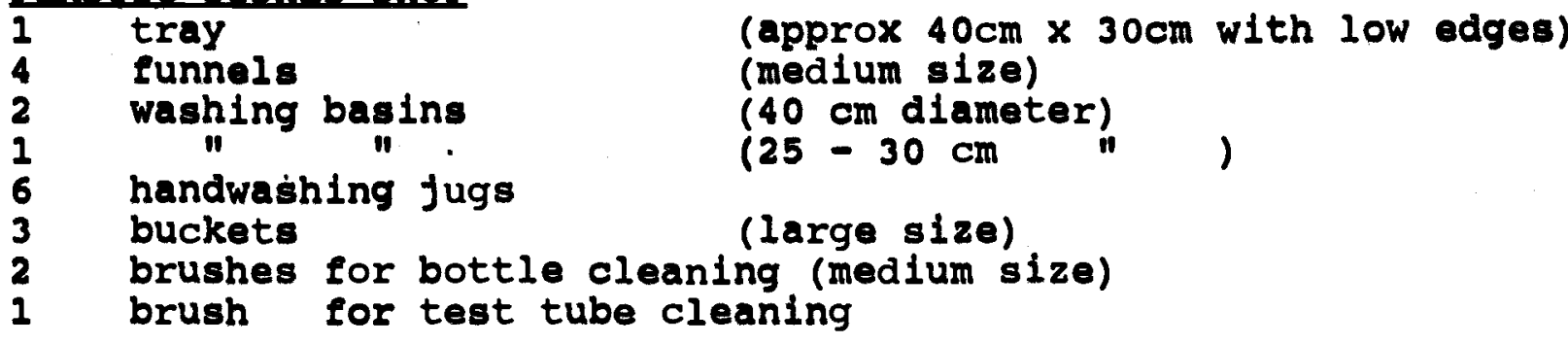




\section{STEEL CROCKERY SHOP}

1 petromax lantern (Anchor pressure lantern)

5 mantles

3 teaspoons with smooth handles

1 bucket

1 boiling pot

1 pressure stove (kerosene)

(stainless steel)

(metal; $25 \mathrm{~cm} \mathrm{high)}$

(metal; medium size)

(Pakistani - medium size)

\section{STATIONERY STORE}

1 ruler

2 rolls clear adhesive tape

2 waterproof markers

6 pencils

12 pens (blue)

3 pens (red)

6 lined notebooks with plastic covers

1 ink pad - blue / black

1 small 2 ring file.

\section{SARAFA BAZAAR}

1 balance

1 set Bullion weights $(1-100 g)$

2 sets "mg" weights (50 - 500mg)

\section{CARPENTER}

1 slide drying rack (wooden; see Photo-list)

2 slide storage boxes (wooden: see " ")

*** Materials to make a stable bench must be supplied if not present in the clinic.

\section{GENERAL STORE}

$6 \quad$ cleaning sponges

$2 \quad \mathrm{~kg}$ washing powder

12 cakes of handwashing soap

2 dozen boxes of matches

\section{Camera store}

1 airbrush

1 pkt lens paper

\section{Hardware store}

1 door lock

2 padlocks (medium size)

5 metres building wire

1 screwdriver (with a $4 \mathrm{~mm}$ blade)

\section{Plastic shop}

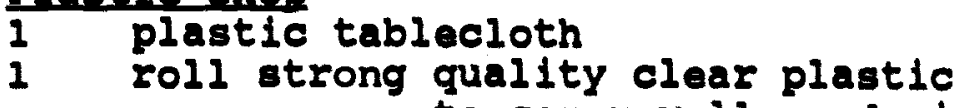
- to cover walls and windows

$(\operatorname{lm} \times 30 \mathrm{~m})$

Metal Box shop

1 good quality storage chest (metal; medium $1212>35 \mathrm{~cm}$ high) 
To be made

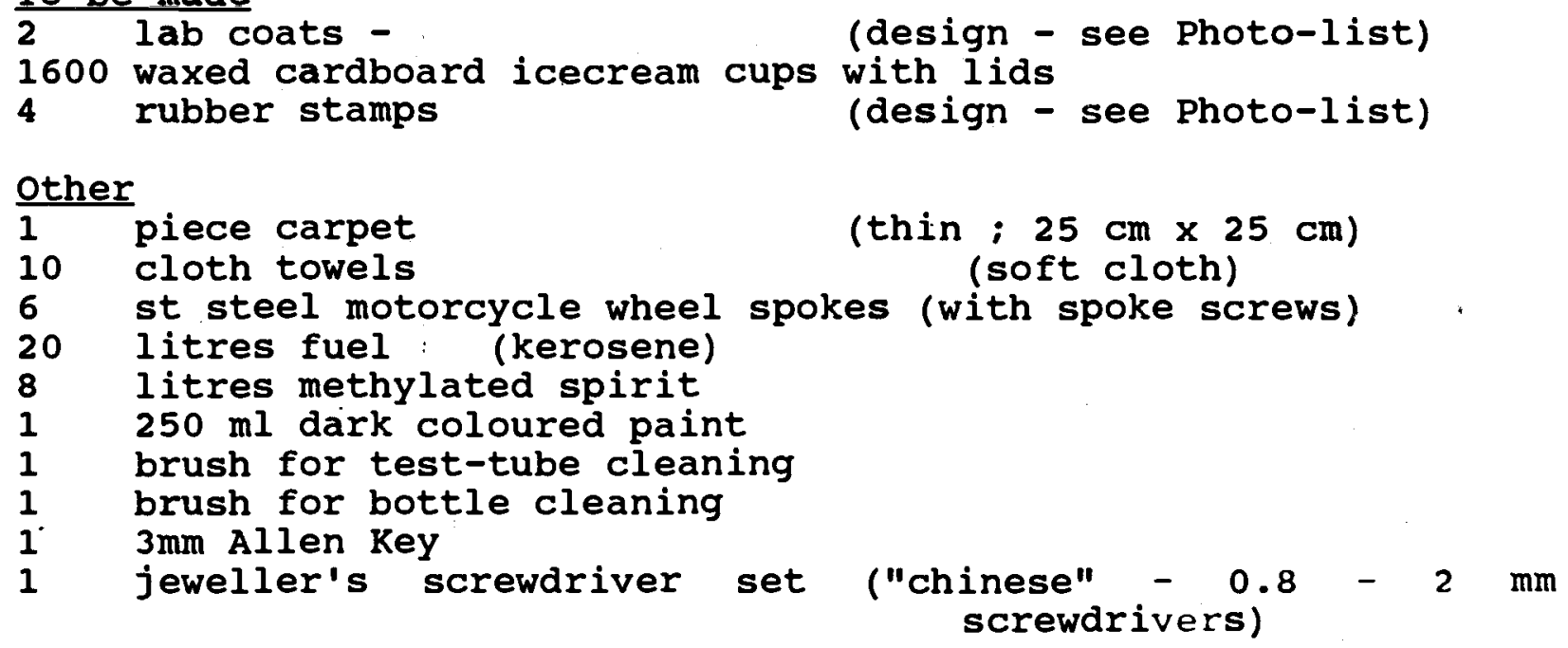

From MSF-B coordination office: (not yet available)

1 lab manual

1 booklet monthly reports

1 colour atlas

\section{MONTHLY SUPPLY}

\section{MEDICAL SUPPLY STORES}

$125 \mathrm{~g}$ basic fuchsin powder

$1 \quad 25 \mathrm{~g}$ methylene blue

1 litre 95\% ethanol

$1450 \mathrm{ml}$ Benedict solution

2 bottles of 100 urine reagent strips (Uropaper)

- expiry at least one year after date of supply

10 boxes microscope slides - Chinese Sail Brand 72 pcs/pkt

$\begin{array}{lll}20 & \text { pkts coverslips } & (100 / \text { box }) \\ 6 & \text { boxes lancets } & (200 / \text { box })\end{array}$

6 cotton rolls

20 metres gauze

1 pkt filter paper (Whatman no. 1)

400 specimen containers with screw lids

$105 \mathrm{ml}$ syringes + needles

10 loml syringes + needles

5 large bore needles

1 white sticking plaster: (Paragon)

4 litres savlon (hospital concentrate)

1 spare microscope globe (IF GENERATOR IN CLINIC)

1 pkt nichrome wire loops (small - medium)

PLASTIC WARE SHOP

$\begin{array}{lll}2 & \text { brushes for bottle cleaning (medium size) } \\ 1 & \text { brush for test tube cleaning(small " } \\ 1 & \text { plastic tablecloth }\end{array}$




\section{GENERAL STORE}

6 cleaning sponges

$2 \mathrm{~kg}$ washing powder

12 cakes of handwashing soap

2 dozen boxes of matches

5 mantles (for the petromax lantern)

\section{STATIONERY STORE}

2 rolls clear adhesive tape

2 waterproof markers

6 pencils

12 pens (blue)

3 pens (red)

3 lined notebooks with plastic covirs

\section{OTHER}

20 litres fuel (kerosene)

8 litres methylated spirit

10 cloth towels

2 lab smocks

1 lens paper

1600 waxed icecream cups with lids

\section{MONTH SUPPLY}

6 monthly supply plus

\section{MEDICAL SUPPLY STORE}

$1 \quad 25 \mathrm{~g}$ giemsa powder

12.5 litre glycerol

12.5 litre methanol

$1500 \mathrm{ml}$ xylol

$1 \quad 250 \mathrm{ml}$ oil of cedarwood

1 pkt $\mathrm{pH}$ papers (pH $6-8)$

(Kochlight / BDH)

$$
300 \mathrm{~g} \text { carbolic acid (phenol) (Pakistani) }
$$

\section{uther}

1 roll strong good quality clear plastic

$1250 \mathrm{ml}$ tin dark coloured paint

1 booklet of monthly reports (not yet available)

** WAXED ICECREAM CUPS

- manufactured by "Friend's Distributors" in 'Pindi. phone no. 70441

- cost Rs 0.40 per cup

MSF-B COORDINATION OFFICE : 12 Afzalabad, University Town, Peshawar, 41870

(From Medecins sans Frontieres - Belgium) 
1. Medecins sans Frontieres - Belgium (MSF-B)

2. Italian Cooperation for Development (ICD)

3. Saudi Red crescent (SRC)

4. Aide Medicale Internationale (AMI)

5. Ministry of Public Health (MOPH-AIG)

6. Mercy Corps International (MCI)

7. International Medical Corps (IMC)

8. International Rescue Committee (IRC)

9. Austrian Relief Committee (ARC)

10. Medecins sans Frontieres - Holland (MSF-H) 
RESOURCE\$

In English:

Basic laboratory methods in medical parasitology. Geneva: WHo, 1991. 114 p.: ill.

Basic laboratory procedure manual / Carol L. Phillips.

Islamabad: USAID, 1991. 93 p.: ill.

Manual of basic techniques for a health laboratory. Geneva: wHo, 1980. 487 p. : ill.

A Medical laboratory for developing countries /. Maurice King. London: Oxford University Press, 1973. 311 p. : ill.

In Dari and Pashtu:

Comprehensive atlas for the laboratory [Dari] / Carol L. Phillips. Islamabad: USAID, 1991. 77 p.: col. photos.

Comprehensive atlas for the laboratory [Pashtu] / Carol L. Phillips. Islamabad: USAID, 1991. 77 p. : col. photos.

Laboratory quide for ARC's laboratories [Dari] / Abdul Rahman Zamani. Mardan: Austrian Relief Committee, 1990. 31 p. 


\section{CEAPTER 9 - DENMAL WORK}

\section{INTRODUCTION}

Although during the last 11 years of war in Afghanistan many NGOs have provided medical assistance (most of the health training being on trauma treatment), it is only in the past two years, after the signing of the Geneva accords, that much attention has been given to the development of health services in Afghanistan. In spite of this development, dental health, sadly enough, has not been given much importance. Past experience in the refugee camps shows that dental problems in the Afghan community are high and cannot be ignored.

The following dental health care problems were identified. WHO and all NGOs involved in dental training, through the ACBAR Health subcommittee, have discussed these issues, while developing the dental program.

A. Lack of data particularly in dental health care and the need for:

- epidemiologic surveys to establish baseline
information concerning dental problems in general.

- population census and information regarding allocation of resources to be cross referenced with the population distribution of health workers

- monitoring and evaluation regarding efficiency and impact of health programs

B. Poor distribution of health workers and facilities within Afghanistan.

c. Lack of coordination among dental training agencies, both in refugee camps and cross border.

D. Lack of refresher training programs for dental health workers.

E. Lack of specialized dental health workers.

The microscopist training for Afghanistar has already been through this process and currently a successful standardized microscopist training is being carried out by various agencies. Following the same procedures, a standardized dental health worker training can be started. This will benefit a large portion of the rural population of Afghanistan. Prior to the war, the Ministry of Public Health reached only about $15 \%$ of the rural population. 
The Dental Work Task Force met at ACBAR between April and August 1990 and discussed the possibilities of starting a standardized dental health training. The Task Force identified and agreed on two levels of dental health workers:

A. Mid-level Dental Worker

B. Basic Dental Worker/First Aider

The goal of emergency assistance in the active fighting with severe shortage of health workers is no longer consistent with the long term goal of repatriation and creation of a primary health care system for Afghanistan.

The Task Force developed curriculum, skills checklist, equipment and supplies for the two levels of dental worker. These are now available and are recommended for use by all agencies involved in the training of dental workers. The Task Force also recommended that health education messages on dental hygiene be provided to all health workers.

II. SKIIIS CHECKIIST FOR MID-LEVEL DENTAL WORKER

The mid-level dental worker, like any other mid-level health worker, is responsible for supervising and giving technical support to all lower level dental health workers. The Skills Checklist includes all the skills of the basic dental worker plus diagnosis and treatment of the most common dental diseases as seen in Afghanistan and other developing countries.

The knowledge and capabilities as required for the mid-level dental worker are listed below:

1. Clinical Examination
a. Knowledge of normal tooth anatomy.
b. Recognize normal structures in the mouth.
c. Recognize changes in mouth related to teeth and gum disease.
d. Recognize visible pulp exposure.
e. Recognize and differentiate hard, soft and fluctuant swelling.
f. Know when and how to do:
- inspection
- palpation
- percussion

2. Dental Plaque

Recognition and advice on oral hygiene. 
3. Dental Calculus

Recognize and treat (proper scaling).

4. Dental Caries

Recognize and treat. Treatment should include permanent and milk teeth (permanent filling of enamel and dentine caries only).

5. Pulpitis

Recognize and refer to higher level dental health worker.

6. Gingivitis

Recognize and treat. Treatment should include gingivitis simplex.

7. Stomatitis

Recognize and treat. Treatment should include Aphthous Ulcer, Thrush and Herpes Simplex. Any other type of stomatitis (i.e. Ulcerosa, etc) should be referred.

8. Mouth Abscess

Recognize and treat. In case of ACUTE APICAL PERIODONTITIS reference should be made to higher level dental health worker.

9. Mouth Cellulitis

Recognize and treat.

10. Acute Percronoritis

Recognize and treat.

11. Temporo Mandibular Joint Problems

RECURRENT AND HABITUAL LUXATION OF TEMPORO MANDIBULAR JOINT: Recognize and treat.

ARTHRITIS TEMPORO MANDIBULAR JOINT: Recognize and refer to higher level dental worker.

JAW FRACTURE: Recognize, and after first aid, refer to higher level dental worker. 
12. Wilk Teeth Problems

Recognize the disorders (malformation, etc.) and refer to higher level dental worker.

13. Naxillofacial Nerve Diseases

TRIGEMINUS NEURALGIA: Recognize and refer to higher level dental worker.

14. Anesthesia

a. Know how to give anesthesia.

- selection of correct site

- proper insertion of needle

- correct amount of anesthetic to be injected

b. Know the different methods of anesthesia:

- infiltration

- mandibular block

MANAGEMENT AND PREVENTION OF COMPLICATION RELATED TO INJECTION AND ANESTHESIA

SYNCOPE: Recognize symptoms and treat.

ANAPHYLACTIC SHOCK: Recognize symptoms and treat if no doctor is available. Alternatively reference should be made to a doctor if available immediately.

BROKEN NEEDLE: Diagnose and refer.

HAEMATOMA: Recognize and advise reassurance.

MUSCLE TRISMUS: Recognize and treat.

HYPOESTHESIA: Recognize and advise reassurance.

OVER-DOSAGE OF ANESTHETIC DRUGS: Recognize and manage.

15. Extraction

a. Knowledge of the various instruments for extraction.

b. Choose the right instrument for extraction.

c. Know the correct technique of extraction to prevent the following complications during and after extraction: 
(1) sinus infury

(2) mandibular canal infury due to root entex

(3) root and sexvester to enter the gastric and respiratory system

(4) demolition of the teeth side by side

(5) fracture of bone

(6) demolition of gum

(7) demolition of arteries

(8) demolition of nerves

(9) temporo mandibular joint trauma

(10) alveolitis

(11) bleeding

Note: if these complications occur it should be referred.

d. Know the correct use of instruments

e. Know root extraction

f. Take the right position during extraction

g. Give proper advice t: parient after extraction

h. Know and deal with the following postextraction complications:

(1) bleeding: control and manage

(2) infection (muscle trismus): recognize and treat

(3) alveolitis: recognize and treat

16. Scaling
a. Identify dental plaque and dental calculus
b. Know correct scaling methods
c. Know the proper use of the scaling instrument
d. Give instructions to patient after scaling

17. Filling
a. Know when to put filling
b. Know the preparation of cavity for filling
c. Select the right material for filling
d. Know the technique of mixing cement and amalgum
e. Give proper advice/instruction to patrent regarding post filling care

18. Drainage of Abscess
a. Know when to do incision and drainage
b. Know the correct site of incision
c. Know whether to put drain or not
d. Give post incision and drainage instruction 
19. Suturing

a. Know whether suturing is necessary or not
b. Know the correct size of needle
c. Know the correct technique of suturing

20. Sterilization \& Disinfection

a. Know the different methods and procedures of sterilization

(1) boiling method

(2) formol tablet method

b. know the proper use of disinfectant:

- dettol

- spirit, dettol, hydrogen peroxide

21. Pre-operative Preparation

a. Be familiar with pre-operation preparations:

- establishing rapport with patient

- positioning of patient

- preparation of tray and instrument

- preparation of working area

- cleaning of work place

- personal hygiene (wash hands, keep clean short finger nails, wear working clothes, etc)

22. Instrument

a. Correct identification of instruments

b. Know the correct use of instruments

c. Know proper handling and care of instruments

d. Know proper packing of sterile instruments

23. Administration

a. Be familiar with the following:

- designing a clinic

- registration

- record keeping

- reporting

- ordering of supply and equipment

24. Public Health

Motivation: motivate people about oral hygiene and taking care of teeth.

Health Education: teach people

a. Cleaning and proper use of brush and meswak

b. Taking care of teeth and oral hygiene 


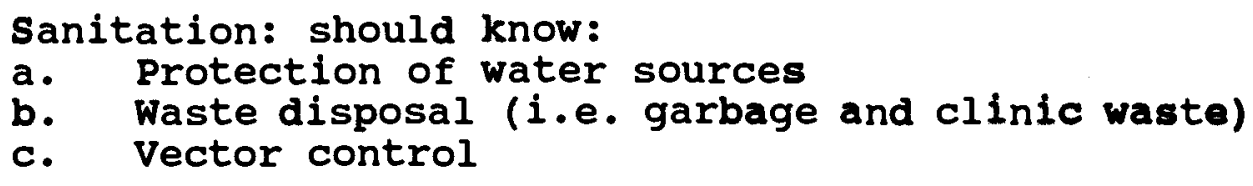

III. CURRICULUM FOR MID-LEVEL DENTAL WORKER TRAINING

Histology

General concept of the body, such as cell, tissues, organs, systems.

Anatom!

Brief review on major body bones

Brief review on muscles, nerves and joints

Anatomy of teeth

Anatomy of maxilla bones

Anatomy of mandibulla bone

Anatomy of zygomatic bone

Anatomy of temporo mandibular joint

Anatomy of nervus trigeminus

Anatomy of nervus maxilla bone

Anatomy of nervus mandibulla

Anatomy of nervus ophthalmicus

Anatomy of musculus oris

General Anatomy and Phusiology

Digestive system

Urinary system

Respiratory system

Circulatory system

Coagulation of blood

Microbiology

Introduction of microbiology

classification of microbiology

Basic features of bacteria

Classification of bacteria (morphological staining)

Pharmacology

Fundamental of pharmacology

Analgesics

Antibiotics

Antihistaminic

Antiseptics

Tranquilizers

Anesthetics

vitamins 


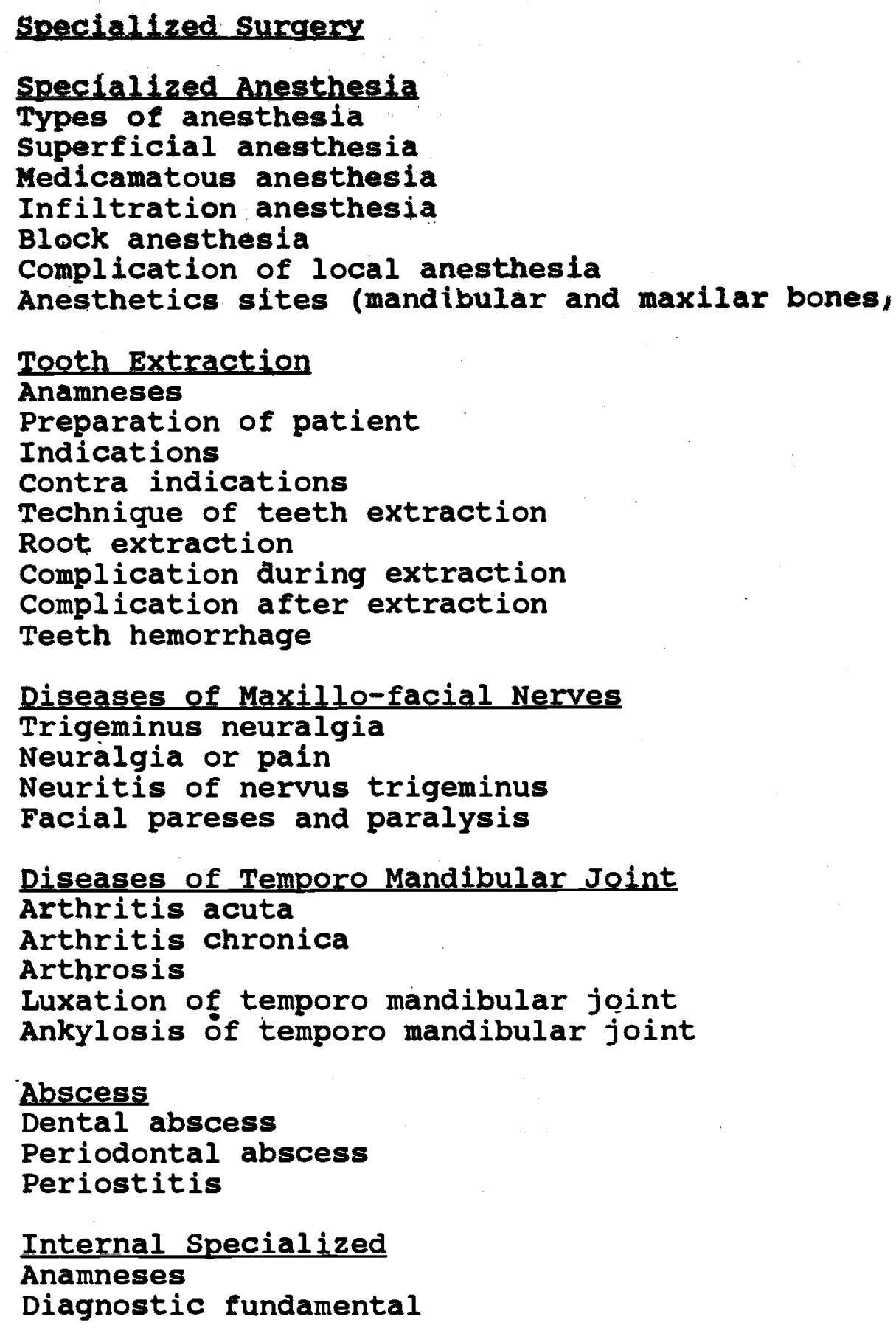

Diseases of Temporo Mandibular Joint

Arthritis acuta

Arthritis chronica

Arthrosis

Luxation of temporo mandibular joint

Ankylosis of temporo mandibular joint

\section{Abscess}

Dental abscess

Periodontal abscess

Periostitis

Internal Specialized

Anamneses

Diagnostic fundamental

\section{Caries}

History of caries Character of caries Etiology of caries Epidemiology of caries Diagnosis of caries statistic of caries 
Special Pathology and Histo Pathology of Caries

Enamel caries

Various effects on enamel development

Dentine caries

Caries profunda

Secondary caries

Caries sicca

Caries recedive

Therapy of caries

Introduction to cavity preparation

Nutrition and caries

Carbohydrate, protein and lipids

calcium, phosphorous, magnesium and iron

vitamins

Saliva and caries

Test of caries

Therapy of milk teeth

Pathology of pulp

Various pulpitis

Degeneration of pulp

Focal infection

Dental Plaque

Calculus

Calculus scaling

Types of gingivitis

Periodontitis

How to brush teeth

stomatitis

Traumatic injuries of teeth

Traumatic injuries of teeth germs

\section{Permanent Filling}

Limited to enamel and dentine caries and not to include root canal therapy

Indication

Medicamentous

\section{Sterilization Procedures}

\section{Disinfection}

\section{First Aid}

Cardiopulmonary resuscitation procedures

Bleeding control procedures

Immobilization of injured limbs

Lifting and transport of injured patients 
Public Health

Public Health: Sanitation, pest and vector control, protection of water sources

Public Administration

Community education

Motivation

Communication

IV. EOUIPMENT LIST FOR MID-LEVEL DENTAL WORKER

Furniture

1 Simple Dental Chair

1 Instrument Table

1 Revolving stool

1 Folding Table

1 Folding Chair

1 Plastic Bin/Metal Bucket

1 Sterilizator (non-electric)

1 Instrument Tray (small and medium size) with cover

1 Gauze Canister (small and medium size)

1 Cotton Container

1 Kerosene Stove

1 Kerosene Lantern

1 Hand-Washing Jug

1 water cooler (10 liters)

1 Lock (medium size)

1 Drum (25 liter capacity)

1 Large Metal Box for storing clean instruments

It was decided that a generator would not be supplied to clinics. In view of this the following list was agreed:

If there is electricity:

1 Electric Motor Machine

1 Handpiece

1 Kit containing each type of drill - round, cylindric, diamond

If there is no electricity:

1 Drill Machine with Foot

1 Kit containing each type of drill - round, cylindric, diamond

Equipment

1 Small Headlight with Batteries

1 Air Balloon/Air syringe

2 Handle Mirrors and 3 Extra Mirrors

2 Dental Tweezers

2 Dental sound

1 Each Plastic and Metal Spatula 
1 Glass Slab/Mixing Tablet

1 Sharpening stone

1 Matrix Band with Support

1 BP Apparatus

1 Protective Face Mask cloth

1 Stethoscope

1 Drinking Glass

1 Brush for Hand Washing

1 Brush for Instrument Washing

Instruments

2 Carpul Syringe for Dental Cartridge

250 Needles of each size (2 sizes)

5 Plastic syringes/Water syringes

Extraction set - 1 complete set for adults

Extraction set - 1 complete set for children

Elevator set - 1 complete set

Bone Curet - 1 complete set

1 Minor Surgical Kit

1 Cheatle/Dressing Forceps

Filling Instruments - complete set

Scalers - complete set

6 Excavators ( 2 small, 2 medium, 2 large)

1 Simple Amalgam Mixer

V. LIST OF EXPENDABLE MATERIAL FOR MID-LEVEL DENTAL WORKER

One month supply

Antibiotics

Ampicillin Syrup

Ampicillin Capsule

Erythromycin Tablet $500 \mathrm{mg}$

(patients/day

3 (patients/day

(patients/day

Erythromycin syrup

(patients/day

Anaesthetics

Xylocain 2\% $2 \mathrm{ml}$ Ampul

Analgesics

Aspirin $300 \mathrm{mg}$ Tablet

Paracetamol $500 \mathrm{mg}$ Tablet

Paracetamol Syrup

(patients/day

3 (patients/day

(patients/day

Antihistaminics

Avil Tablet

Avil Ampul (patients/day

3 (patients/day
25 bottles

1,125 capsules

1,125 tablets

25 bottles

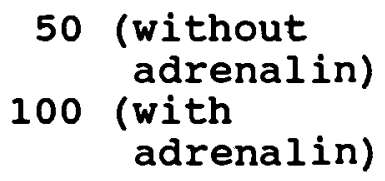

500 tablets

700 tablets

50 bottles

30 tablets

3 ampuls 
Antiseptics

Hydrogen Peroxide $100 \mathrm{ml}$

Gentian Violet Liquid $20 \mathrm{ml} 3$ (patients/day

Methylated Spirit $500 \mathrm{ml}$

Dettol

Formul Tablet

Bonjela Paste

12 bottles

3 bottles

1 bottle

1 liter

25 tablets

10 tubes

Vitamins

Vitamin c $500 \mathrm{mg}$

300 tablets

Multivitamin

300 tablets

Miscellaneous

Amalgam with Mercury

Phosphate Cement (powder, liquid) (standard)

zinc oxide Eugenol (powder, liquid)

Adrenalin $10 / 00$ Ampul

Gauze Cloth

Gauze Roll 2-3 Inches

Leucoplast

Cotton

Washing Powder

Soap

Cleaning Sponge

Match-Boxes

Pens (red and blue)

Towel

Recording Form

Kerosene oil

Amalgam Gun

Silicate Cement (powder, liquid)

Referral Form

Registration Book/Green Book

$15 \mathrm{gm}$

bottle ea bottle ea

2 ampuls

20 meters

3 rolls

1 roll *

1 roll

$\mathrm{kg}$

3 cakes

1

1 dózen

2 dozen

4 *

150 forms

5 liters

1

bottle ea

10 forms

1 book

WNote: These Items are for 6 months. 
VI. REFERRAL FORM FOR MID-LEVEL DENTAL WORKER

S/NO

DATE

NAME • • • • • • - F/NAME

AGE . . . . SEX • . . ADDRESS

H/O PRESENT ILLNESS

PAST HISTORY.

FINDING

DIAGNOSIS

TREATMENT GIVEN

NAME OF HEALTH WORKER .

REASON FOR REFERRAL

SIGNATURE. 
FATIENT'S NAME: ................... AGE .....

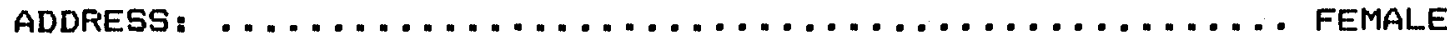

COMFLAINING

MALE

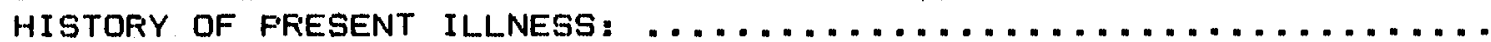

IS RATIENT FREGNANT?

YES

NO

(NOTE: PREGNANCY IS NOT A CONTRA INDICATION FOF THE TREATMENT OF COMMON DISEASES OR EMERGENCIES)

HAS PATIENT HAD AN ILLNESS WHICH AFFECTED THE FOLLOWING:

HEART LLOOD LUNGS NERVOUS

$\square$ LLOOD
(high/ $\square$ (asthma)
low pressure,
coagulation
defects)

DIABETES

coagulation

drugs

EXTERNAL EXAMINATION:

\begin{tabular}{|l|l|l|l|l|}
\cline { 2 - 5 } \multicolumn{1}{c|}{} & WOUND & SWELLING & ELEED ING & TNFFCT IONV \\
\hline SCALF & & & & \\
\hline FACE & & & & \\
\hline NECK & & $\cdot$ & & \\
\hline
\end{tabular}

INTERNAL EXAMINATION: JAW MOVE NORMALLY?

YES

ND

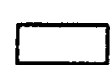

\begin{tabular}{|l|l|l|l|l|}
\cline { 2 - 5 } \multicolumn{1}{c|}{} & WOUND & SWELLING & ELEED ING & INFECTION \\
\hline CHEEK & & & & \\
\hline LIFS & & & & \\
\hline EUCAL GINGIVA & & & & \\
\hline LINGUAL GINGIVA & & & & \\
\hline PALLET & & & & \\
\hline TONGUE & & & & \\
\hline
\end{tabular}

DIAGNOSIS:

DRESSING WIGHI ........................... DATE

EXTRACTION, .............................. DATE

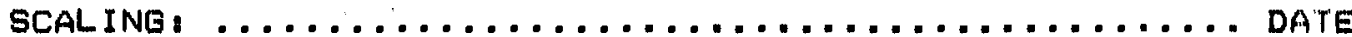

FILLING: $\ldots \ldots \ldots \ldots \ldots \ldots \ldots \ldots \ldots \ldots \ldots \ldots \ldots \ldots \ldots \ldots$ DATE

ANY OTHER TREATMENT: $\ldots \ldots \ldots \ldots \ldots \ldots \ldots \ldots \ldots \ldots \ldots \ldots$. . . . . . . . .

CODE:
\begin{tabular}{l|l|}
\hline$F-F i l i$ Ing & $E-$ Extraction \\
$D-$ Dregsing & $F-$ Pulpitis \\
$C-$ Caries & $N-$ Necromis
\end{tabular}

\begin{tabular}{llllllll|llllllll}
8 & 7 & 6 & 5 & 4 & 3 & 2 & 1 & 1 & 2 & 3 & 4 & 5 & 6 & 7 & 8 \\
\hline 8 & 7 & 6 & 5 & 4 & 5 & 2 & 1 & 1 & 2 & 3 & 4 & 5 & 6 & 7 & 8
\end{tabular}




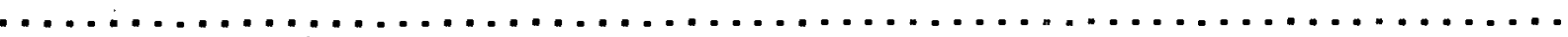

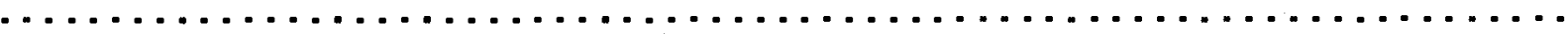

FOLLOW UP:

DATE OF NEXT VISIT: $\ldots \ldots \ldots \ldots \ldots \ldots \ldots \ldots \ldots \ldots \ldots \ldots \ldots \ldots \ldots \ldots \ldots \ldots \ldots$

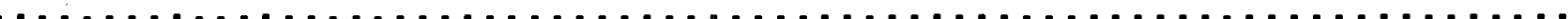

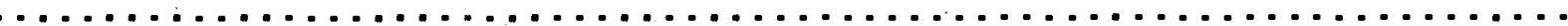
REMARKS :

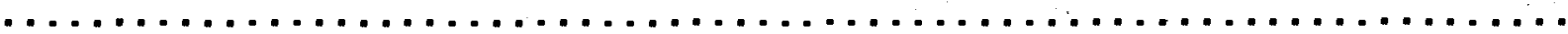

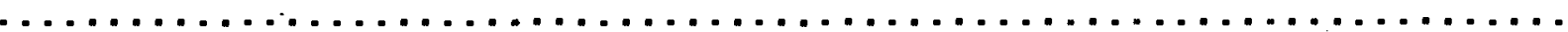

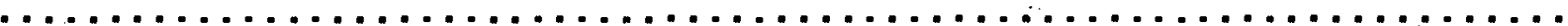

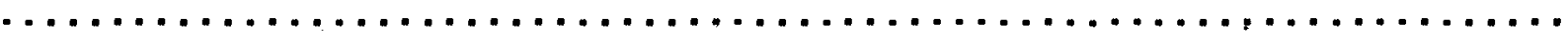
NAME OF HEALTH WORKER:

SIGNATUFE: 
1. Clinical Examination

a. Know normal teeth anatomy.

b. Recognize normal structures in the mouth.

c. Detect abnormal dental signs.

2. Dental Plaque

a. Recognize and advise on oral hygiene.

3. Dental Calculus

a. Recognize and treat dental calculus.

4. Scaling

a. Know proper scaling methods.

b. Know how to use the scaling intruments properly.

c. Give instructions to patient after scaling.

d. Advise on how to brush teeth properly.

e. Advise on how to clean teeth with meswak properly.

f. Know how to floss teeth properly.

5. Dressing for Toothache

a. Prepare cavity for dressing.

b. Know when to put dressing.

c. Know proper aressing of painful tooth with clove oil.

d. After first aid, refer to high level dental worker.

6. First Aid

a. Give first aid treatment for painful tooth and dental abscess. Refer to high level dental worker if necessary.

b. Recognize and give first aid for broken bone (i.e. cheek bone, upper jaw bone and lower jaw bone) and refer to high level dental health worker.

c. Recognize and give first aid for dislocated jaw and refer to high level dental health worker, if necessary. 
7. Sterilization

a. Know the chemical method of sterilization i.e. formol tablet method.

8. Public Health

Motivation: motivate people about oral hygiene and taking care of teeth.

Health Education: teach people

a. about cleaning and proper use of brush and meswak

b. oral hygiene and how to take care of teeth.

Sanitation: should know

a. protection of water sources

b. waste disposal (i.e. garbage and clinic waste)

c. vector control

9. Administration

a. Reporting.

b. Record keeping.

IX. CURRICULUM TOPICS FOR BASIC DENTAL WORKERS/DENTAL FIRST AIDERS

1. Health education/motivation: oral hygiene, prevention of oral diseases, how to brush teeth properly.

2. Scaling.

3. Emergency treatment - for toothache, abcess, sweliling.

4. Dressing for pain using clove oil.

5. Immobilization of fractured jaw.

6. Teach how to give drugs, what to use for what analgesics and antiblotics. (It was agreed to use only one or two drugs - paracetamol as analgesic and ampicillin or erythromycin in cases of allergy.)

7. Where, when and how to refer (to include signs and symptoms).

8. Chemical sterilization only by using formul tablets. 
X. ITST OF BOUTPYANT, MPDTCINE AND STATIONPRY FOR BASTC DENTAL MORTRR

Equipment (initial supply)

Dental bag

Cotton container

1

Dental mirror

Dental sound and excavator

Dental tweezers

each

Torch

Ivory C-1 scaler

Water syringe

Kidney tray

Brush for cleaning of instrument

Metal bowl

Hand washing jug

Plastic glass

Medicine (6-month supply)

The six-month medicine supply recommended for basic dental workers is based on 2 patients per day. There are at present no statistics available but the Dental clinic reported that their experience indicates this to be an average number. The amounts of medicine would be changed if later statistics show 2 patients per day to be unrealistic. It was also agreed that these workers should be supplied on a 6-month basis.

Ampicillin:

- capsules - $250 \mathrm{mg}$

- syrup

Erythromycin $500 \mathrm{mg}$

Aspirin $300 \mathrm{mg}$

Paracotamol:

- tablets

- syrup

Gontian violat solution - $20 \mathrm{ml}$

Hydrogen peroxide - $50 \mathrm{ml}$

Eugenol (clove oil)

Formol tablets (sterilization of cotton, gauze) 36 tablet:

Stationery (6-month supply)

Register book (green book)

Referral forms

Pons

900 capsules

20 bottles

900 tablet:

300 tablet:

Posters (if avallable)

500 tablets

20 bottles

12 bottles

24 botties

2 bottles 


\section{Miscellaneous}

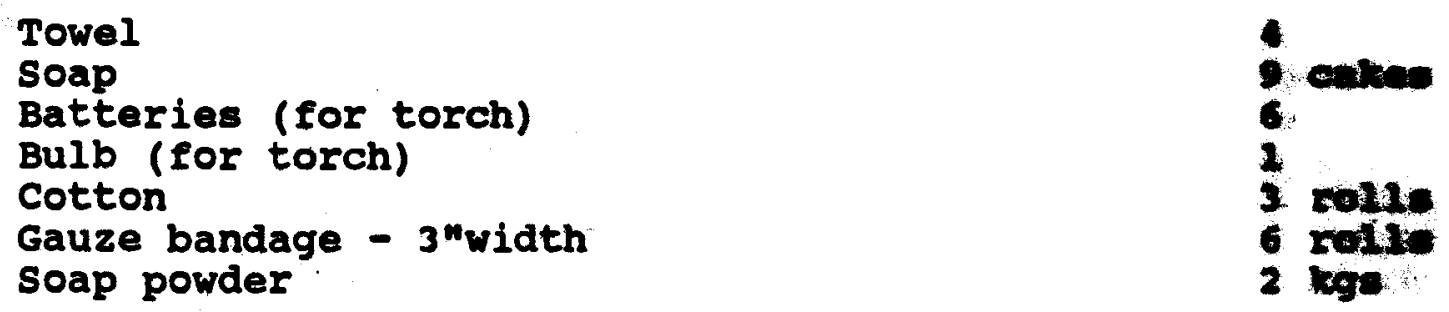

XI. REFERRAL FORY FOR BASIC DENTAI HEAITH WORKER OR FTPEY NAI:

$$
\text { s/No }
$$

DATE

NAME. • . . . . F/MAME .

AGE . . . . SEX . . . ADDRESS

H/O PRESENT ILLNESS

PAST HISTORY

\section{FINDING}

DIAGNOSIS

TREATMENT GIVEN *

NAME OF HEALTH WORKER REASON FOR REFERRAL 
APPENDIX

\section{RESOURCEs}

In Dari and Pashtu:

Bad teeth are dangerous for health [Dari] / Sher Aga Baluch. Dental Clinic for Afghanistan Refugees, 1990 (1369). 62 p.

Care of our teeth [Pashtu] / zobida sultana. Peshawar: SERVE, 1988. 56 p.: ill.

Maswak: doing maswak is sunnah [Dari] / Abdul Ahmad Amozgar. Peshawar: IRC Health Education Resource Center, 1990. 36 p.

Where there is no dentist [Dari]. Peshawar: IRC Health Education Resource Center, 1990. 346 p.: ill.

Where there is no dentist [Pashtu] / translated by Abdul Aziz Wajeed \& Ahmad Zia. Peshawar: IRC Health Education Resource Center, 1987. 260 p.: ill. 


\section{PAKISTAN}

In many refugee camps the use of pit latrines is well established and families have constructed and are using latrines. It would be regretful if this major change in attitude was neglected in the future and sanitation ignored.

\section{Problems encountered}

A. It is usual for one agency to be involved in water supply and another in latrine construction and health education. Coordination between such agencies tends to be poor and water supply can take some time to be established.

B. The ventilated improved pit (VIP) latrine has been found to ie effective and economic. However, it can only be used where a pit can be dug. In areas where there is a high water table, a double vault composting (DVC) latrine is needed but the cost is almost four times that of a VIP latrine; it is therefore difficult to ensure funding and consequently some camps cannot be included in the pit latrine construction programs.

c. Maintenance and follow-up depend on availability of funding to ensure sufficient trained personnel and materials. Refugees cannot afford these materials but are expected to dig new pits when needed.

\section{AFGHANISTAN}

Before the war in rural Afghanistan, open defecation was the norm. Of the few latrines used, the unsanitary raised open 'Kabuli' or 'kinarab' type latrine is most common, with the excreta often used as compost. This type of latrine is also used in urban areas along with nightsoil collection.

\section{Problems to be anticipated}

A. Political, cultural or religious obstacles.

B. Availability of skilled labor.

c. Maintenance responsibilities.

D. Motivating the population to build, use and maintain latrines. 
E. VIP and DVC latrines - availability of concrete materials for slab, availability of vent pipe material, inappropriate technology.

F. Garbage disposal, in particular the disposal of medical supplies.

\section{RECOMMENDATIONS}

A. Sanitation and water supply must be a coordinated effort and it is better if they are implemented by the same organization in order to maximize the health benefits for the population (as recommended by UNICEF, WHO and other international organizations).

B. Water supplies and sanitation projects should be built by the users themselves, to promote a sense of ownership among the consumers, thus facilitating maintenance.

c. Urban sanitation needs should have priority over rural needs; the danger of epidemic(s) is more acute in urban areas.

D. Latrine technology must be compatible with local custom and practices; the applied technology must be a decision of the populace.

E. The VIP latrine is suitable where a pit can be dug. The DVC latrine is suitable for areas with a high.water table or rock face or where excreta is used as compost.

F. For the refugees in Pakistan, the VIP latrine has been found to be effective and economic. However, in Afghanistan it might not be so successful, as many inhabitants use excreta as fertilizer and would not therefore want to place it in a deep pit. A better sanitary, solution might be a double vault composting latrine, with each vault filled and then emptied every. other six months. This type of latrine has already been successfully used by Afghan refugees in Pakistan but, being made of concrete, it is not really a cheap sanitation alternative. ARC (Austrian Relief Committee) experience is that a mud version built with a wooden slab and mud pipe, although relatively inexpensive, is not successful and can be dangerous. In urban areas, where water is used for anal cleansing, pour-flush latrines might also be viable. However, at present these are an expensive alternative. In Pakistan they can be built more cheaply but this is only possible when all materials are available and there is community input. In Afghanistan the availability of materials and community input will probably vary from area to area. 
G. In rural areas, the construction of water supply schemes can be used as the 'back door' to introducing health education and sanitation, so any training of health workers, ccmmunity health workers, etc., should stress this relationship between water supply, sanitation and disease.

H. The Health Eduction Messages produced by UNHCR and HERC should be promoted by all health workers (see chapter 1, page 5).

I. Public Health courses must emphasize preventive health measures, educating the people as to the reasons for illness and how it can be prevented.

J. If possible, all water quality should be in accordance with the wHO recommended absolute minimum standards (1971), with a recommended minimum supply of 25 liters per capita per day.

K. Simple rules, such as the minimum distance between a well and a latrine is 20 meters, and that a well should be uphill from the latrine, must be followed. 


\section{APPENDIX 1}

organizations involved in Sanitation and water supply projects

organizations involved in sanitation projects in refugee camps in pakistan

Austrian Relief Committee

International Rescue committee

Pakistan Red Crescent

C.R.S. - Punjab/Baluchistan

organizations involved in water supply projects in refugee camps in Pakistan

DACAAR 
APPENDIX 2

\section{RESOURCES}

The following are available from HERC (The Health Education Resource center of IRC):

1. Community Participation in Water and Sanitation, Dr. Alastair White.

2. Environmental Sanitation and Integrated Health Delivery Pro., Pineo, S., Schnare, S. and Miller, G.W.

3. Evaluation Methods for Community Rural Water supply and Sanitation Project Development, water and Sanitation for Health Project

4. Women's Issues in water and Sanitation, International Development Research Center

5. Women's Roles in Water Supply and Sanitation in Developing Countries, Alice J. Smith

6. Evaluation Methods for Community Rural Water Supply and Sanitation, water and Sanitation for Health Project

7. Pretesting and revising instructional materials for water sanitation, J. Lamzarr Cox, Ralph Wileman and Raymond

8. Participation of Women in Water Supply and Sanitation, UDP

9. Appropriate Sanitation Alternatives: A Planning and Design Manual, John Kalbermatten and D. Duncan Mara

10. Appropriate Sanitation Alternatives: A Technical and Economic Appraisal, John Kalbermatten and Charles Gunnerson

11. Appropriate Technology for the Treatment of Wastewaters for Small Rural Communities, W.H.O.

12. Clean Water and Good Health, SERVE

13. Control of Domestic Flies, Busvine, J.

14. Dirty Water, Dridwell, K. Nd Dewards.

15. Handbook for District Sanitation Coordinators, Basaako, $\mathrm{K}$. Parkway, waller and Nison

16. Information and Training Materials for low-cost Water Supply and Sanitation, World Bank

17. Integrated Resource Recovery, Peter Edwards

18. Intensive Session on Water, Sanitation and Health Education, Raymond B. Isely

19. Planning and Evaluation for Community water supply and Sanitation, International Reference Center

20. Rural Sanitation: Planning and Appraisal, Pacey, A.

21. Sanitation in Developing Countries, Pacey, A.

22. Septic Tanks and Aquaprivies from Ferrocement, Watt, s.B.

23. Sewage Treatment in Hot Climates, Duncan, M.

24. Small Excreta Disposal systems, Peache and Cairncross

25. The Ventilated Improved Pit Latrine, UNICEF Quetta

26. Water and Sanitation in Rural Baluchistan, Pamela Hunte

27. Water, Sanitation and Health for All?, Agarwal, Kamondo and Tinker

28. Environmental Health Engineering in the Tropics, Sandy Cairncross and Richard S. Peachem 
29. Environmental Sanitation and Integrated Health Delivery Program, Charles S. Pines

30. BID/UNICEF Sociocultural Research Report:3 Water and Sanitation, Pamela A. Hunte

31. Facilitation of Community organization, Raymond B. Isely

32. Cleanliness Brings Health

33. Guidelines for Environmental Health Services for Afghan Refugees in Pakistan, UNHCR 
CHAPTER 11 - ESSENTIAL MEDICINES

I. PHYSICIAN LEVEL LIST (adopted 20 June 1991)

Type of Medicine

Analgesics

Paracetamol : syrup

Paracetamol $500 \mathrm{mg}$. tab

Acetylsalicyclic acid $300 \mathrm{mg}$. tab (for adults only)

Indomethacin $25 \mathrm{mg}$. tab (comes in can 1000)

Pentazocine $25 \mathrm{mg}$. tab

Pentazocine inj. (comes in box of 5)

IF NO PENTAZOCINE, SUBSTITUTE TEMGESIC

Antiallergics \& URI

Chlorpheniramine $4 \mathrm{mg}$. tab or equivalent

Pulmonary

Aminophylline $100 \mathrm{mg}$. tab (bottle of 1000)

Aminophylline injection $250 \mathrm{mg}$. in $10 \mathrm{ml}$

Salbutamol (Ventolin) $2 \mathrm{mg}$. or $4 \mathrm{mg}$. tab

Epinephrine (adrenaline) 1:1000 (1 mg/cc)

Hydrocortisone sodium succinate $200 \mathrm{mg} / \mathrm{ml}$ injection

\section{Cardiac}

Dyazide caps (combination hydrochlorthiazide and triampterine)

Methyldopa $250 \mathrm{mg}$. tab

Furosemide $20 \mathrm{mg} / 2 \mathrm{ml}$ injection

Digoxin 0.125 or $0.25 \mathrm{mg}$. tab

Potassium chloride $500 \mathrm{mg}$. tab

Propanalol

Eye and Ear

Tetracycline ophthalmic ointment $1 \% 4 \mathrm{gm}$. tube (packets of 12 or 60)

Chloramphenicol eye drops

Glycerine (also emollient for derm) (comes in $60 \mathrm{cc}$ plastic)

Zinc boric drops (for dry eyes)

Acetazolamide (diamox)

Miotic (pilocarpine) (acute glaucoma only - open, not closed)

Flourescein sodium 1\% eye drops or strip

Local eye anaesthetic (tetracaine)

Psychiatric

Diazepam $5 \mathrm{mg}$. tabs (tin of $1000 \mathrm{tab}$ )

Diazepam injection $10 \mathrm{mg} / \mathrm{vial}$

Phenobarbitone $30 \mathrm{mg}$. tab (as anti-epileptic only)

Dilantine $100 \mathrm{mg}$. cap (to be used with Phenobarbitone)

Chlorpromazine $25 \mathrm{mg}$. tab 
Vitamins and Minerals

Multivitamin tabs

Multivitamin drops

Ferrous sulfate/folic acid tab

Vitamin A capsules $(200,000 \mathrm{IU})$ (glass bottle of 30 )

Folic acid $5 \mathrm{mg}$. tab

Vitamin C $100 \mathrm{mg}$. tab

Pyridoxine (vitamin B6) $20 \mathrm{mg}$. tab (for TB patients on INH)

Antibiotics

Ampicillin tabs. $250 \mathrm{mg}$.

Ampicillin injection $500 \mathrm{mg} / \mathrm{vial}$

Ampicillin susp $125 \mathrm{mg} / 5 \mathrm{ml}$

Erythromycin tabs $250 \mathrm{mg}$. (use in penicillin sensitive cases only)

Tetracycline tabs $250 \mathrm{mg}$

Penicillin V tabs $250 \mathrm{mg}$. (12 in a box)

Benzathine Penicillin 1.2 mu inj.

Procaine Penicillin $400,000 \mathrm{u}$. inj.

Trimethoprim-sulfa tabs $400-80 \mathrm{mg}$.

Trimethoprim-sulfa syrup 200-40 mg. (450 cc bottles)

Chloramphenicol tabs $250 \mathrm{mg}$.

Chloramphenicol syrup $125 \mathrm{mg} / 5 \mathrm{cc}$ (450 ccc bottle)( 2 bottles of 400 or $450 \mathrm{cc}$ )

Chloramphenicol inj. $1 \mathrm{gm} / \mathrm{vial}$

Metronidazole $250 \mathrm{mg}$ tabs (1000 tabs per box)

Metronidazole syrup $60 \mathrm{ml}$

Mebendazole $100 \mathrm{mg}$. tab or levamisole (Ketrax) $100 \mathrm{mg}$. tab

Piperazine

Niclosamide

Griseofulvin $500 \mathrm{mg}$. tab

Griseofulvin $125 \mathrm{mg}$. tab

Nalidixic acid $500 \mathrm{mg}$ tab (only to be used as second line in dysentery cases resistant to first line antibiotics)

Anti-tuberculosis medications

For supply to occur there must be a system which allows for case finding, sputum diagnosis, follow-up care and complete course of medication in monitored situation. This is possible in refugee circumstances, and in cross-border facilities which meet the requirements described in the "Guidelines for TB control Activities in Afghanistan". The medications approved include:

Short course regimen (sputum positive patient)

Intensive phase:

(2 months)

Maintenance phase: Thiacetazone + Isoniazid

Streptomycin

Rifampicin + Isoniazid

Pyrazinamide

(6 months) 

Standard regimen (sputum negative + extrapulm.)
Intensive phase: streptomycin
(2 months) Thiacetazone + Isoniazid
Maintenance phase: Thiạcetazone + Isoniazid
(10 months)

Anti-leprosy

Dapsone and all anti-leprosy medications removed from refugee supply list. There are currently referral centers in both Pakistan and Afghanistan that should be utilized.

Antimalarial drugs

(See Chapter 6 - Malaria Control)

Chloroquine tablets $250 \mathrm{mg}$. (250 per box)

Chloroquine syrup $50 \mathrm{mg}$. base/cc (1 bottle $=400$ to $450 \mathrm{cc}$ or $60 \mathrm{ml}$ )

Sulfadoxine + pyrimethamine tablets $500 \mathrm{mg}$ (only for falciparum resistant cases)

Quinine dehydrochloride inj. $600 \mathrm{mg} / 2 \mathrm{mls}$ (for cerebral malaria)

Dermatologic

Benzyl benzoate 60 cc bottles $25 \%$

Hydrocortisone cream $1 \% 5 \mathrm{gm}$ tube

Soap bars

Mycostatin vaginal suppositories

Petroleum jelly

Gentian violet crystals ( 1 jar)

Furacin or antibacterial cream

Glycerin

Savion concentrate

Cetrimide + chlorhexidine 3 soln.

Mycostatin cream

Gastrointestinal

ORS 1 liter packets - citrate based

Magnesium Trisilicate or aluminium hydroxide tabs $500 \mathrm{mg}$.

Hyoscine tab $250 \mathrm{mg}$. (simple or compound as available)

IIgnocaine compound $30 \mathrm{gm}$. tube

Promethazine inf.

Bisacodyl $5 \mathrm{mg}$. tab.

Anesthesia

Ketamine $50 \mathrm{mg} / \mathrm{cc}$ multidose $10 \mathrm{cc}$ vial

Atropine $1 \mathrm{mg} / \mathrm{cc}$ inj.

Lidocaine (IIgnocaine) $2850 \mathrm{cc}$ bottle

Iignocaine gel (currently not avaliable)

25\% dextrose (for severe head trauma where oadema is cuapected) 
Immunologicals

BCG vaccine (dried)

Diptheria-pertussis-tetanus inj.

Measles

Poliomyelitis (live attenuated)

Tetanus inj.

DPTP is added to list for cross-border supply only. circumstances define the type of vaccination campaign and appropriate protocols (see Chapter 5 - Immunizations).

oxytocics and womens care

Methergine $0.125 \mathrm{mg}$. tab

Norethisterone tab $5 \mathrm{mg}$.

The following drugs are reserved for referral to experts and centers where there are workers with special training. This is generally only in refugee circumstances at present. Ethinyl estradiol + levonorgestrol combination tablets. Depomedroxy progesterone acetate injection $150 \mathrm{mg}$. in $3 \mathrm{ml}$ vial.

oxytocine inj. $10 \mathrm{IU}$

Miscellaneous

Wintogen tubes (menthylated cream) for cross border

Intravenous Fluids

Normal saline $1000 \mathrm{cc}$ bags

Ringers lactate $1000 \mathrm{cc}$ bags (for diarrhoea fluid replacement only)

Water for injection (100 per small box)

II. MIDLEVEL HEALTH WORKER LIST (CMC/ACBAR/WHO)

Type of Medicine

Quantity per $1 / 3$ month

Analqesics

Paracetamol syrup

Paracetamol $500 \mathrm{mg}$. tab

Acetylsalicylic acid $300 \mathrm{mg}$. tab

Indomethacin $25 \mathrm{mg}$. tab

(comes in can 1000)

Pentazocine $25 \mathrm{mg}$ tab

Pentazocine inj.

(comes in box of 5 )

$20 / 60$

$3000 / 9000$

$4000 / 12000$

IF NO PENTAZOCINE PLEASE SEND TEMGESIC

Antiallergics \& URI

Chlorpheniramine $4 \mathrm{mg}$ tab

$333 / 1000$

$35 / 100$

or equivalent

$600 / 2000$ 
Pulmonary

Aminophyline $100 \mathrm{mg}$. tab

(bottle of 1000)

$350 / 1000$

Ventolin 2 or $4 \mathrm{mg}$. tab

Epinephrine (adrenaline) 1:1000

(1 $\mathrm{mg} / \mathrm{cc}$ )

$400 / 1000$

$5 / 15$

Cardiac

Dyazide caps

$170 / 500$

Eye and Ear

Tetracycline ophthalmic oint.

$1 \% 4 \mathrm{gm}$. tube (packets of 12 or 60 ) $50 / 140$

Chloramphenicol eye drops

$25 / 70$

Glycerine (also emollient for derm)

$300 / 600 \mathrm{cc}$

(comes in $60 \mathrm{cc}$ or $300 \mathrm{cc}$ plastic)

zinc boric drops

Flourescein sodium 1\% eye drops or

strip

$30 / 100$

1 bottle

Psychiatric

Diazepam 5mg.tabs (tin of $1000 \mathrm{tab}$ ) 160/500

Diazepam inj. $10 \mathrm{mg} / \mathrm{vial}$

$5 / 15$

Vitamins and Minerals

Multivitamin tabs

Multivitamin drops

Ferrous sulfate/folic acid tab

Vitamin A capsules $(200,000$ IU)

(glass bottle of 30)

Vitamin C $100 \mathrm{mg} \mathrm{tab}$

$5000 / 15000$

$20 / 50$

$3000 / 9000$

$100 / 300$

$350 / 1000$

Antibiotics

Ampicillin tabs. $250 \mathrm{mg}$.

Ampicillin injection $500 \mathrm{mg} / \mathrm{vial}$

Ampicillin susp $125 \mathrm{mg} / 5 \mathrm{ml}$

Erythromycin tabs $250 \mathrm{mg}$.

Tetracycline tabs $250 \mathrm{mg}$.

Penicillin V tabs $250 \mathrm{mg}$.

(12 in a box)

Benzathine Penicillin $1.2 \mathrm{mu}$ inj.

Procaine Penicillin 400,000 u inj.

Trimethoprim-sulfa tabs $400-80 \mathrm{mg}$.

Trimethoprim-sulfa syrup $200-40 \mathrm{mg}$.

(450 cc bottles)

Chloramphenicol tabs $250 \mathrm{mg}$.

Chloramphenicol syrup $125 \mathrm{mg} / 5 \mathrm{cc}$

(450 cc btl)

or 7 bottles $/ 20$ bottles

$2000 / 6000$

$30 / 90$

$20 / 60$

$350 / 1000$

$1000 / 3000$

2 bottles of 400 or $450 \mathrm{cc}$

Chloramphenicol inj. $1 \mathrm{gm} . / \mathrm{vial}$

Chloroquine tablets $250 \mathrm{mg}$.

$996 / 2988$

$10 / 30$

$15 / 45$

$5000 / 15000$

$3000 / 9000 \mathrm{cc}$

$700 / 2000$

$400 / 1200 \mathrm{CC}$

(250 per box)

$13 / 39$

$500 / 1500$ 
Chloroquine syrup $50 \mathrm{mg}$. base/cc

( 1 bottle $=400$ to $450 \mathrm{cc}$ or $60 \mathrm{ml}$ )

Metronidazole $250 \mathrm{mg}$ tabs

(1000 tab per box)

Metronidazole syrup $60 \mathrm{ml}$

Levamisol (Ketrax) 100mg tab

or Mebendazole depending on price

Niclosamide

Griseofulvin $500 \mathrm{mg}$. tab

Dermatologic

Benzyl Benzoate 60 cc bottles 25\% 350m//1000ml

Hydrocortisone cream $185 \mathrm{gm}$ tube

soap bars

Mycostatin vaginal suppositories

Petroleum jeliy

Gentian violet crystals ( 1 jar)

Furacin or antibacterial cream

glycerin - see ENT

Savion concentrate

Cetrimide + chlorhexidine $3 \%$ soln.

Potassium Permanganate

Gastrointestinal

Magnesium Trisilicate tabs $500 \mathrm{mg}$

Bisacodyl (or ducolax) 5mg tab

Hyoscine tab $250 \mathrm{mg}$.

(simple or compound as available)

Lignocaine compound $30 \mathrm{gm}$ tube

Promethazine tab $25 \mathrm{mg}$.

Promethazine inj.
$1000 / 3000 \mathrm{cc}$

$1000 / 3000$

$480 / 1440 \mathrm{CC}$

$250 / 750$

$40 / 120$

$20 / 60$
$50 / 180$

112

$50 / 150$

$400 / 1200 \mathrm{gm}$

$400 / 1200 \mathrm{gm}$

$20 / 60$

2 liter/mo
$3000 / 9000$

$20 / 60$

$100 / 300$

$5 / 15$

$170 / 500$

$20 / 60$

\section{Anesthesia}

Ketamine 50mg/cc multidose $10 \mathrm{cc}$ vial $2 / 6$

Atroplne $1 \mathrm{mg} / \mathrm{cc}$ inf.

Ildocaine (IIgnocalne) 2850 cc bottle $3 / 9$

Ilgnocalne gel (currently not available)

Oxytocics and Womens care

Methargine $0.125 \mathrm{mg}$ tab

inj. oxytoxin (female midlevel workers)

? availability

grams

\section{Miscellanous}

ORs 1 liter packets

Algipan tubes

(menthylated cream)

Dental ZEO with clove oll

Intravenous Flutds

Normal saline 1000cc bags

Ringers lactate 1000 cc bags

Water for injection

(100 per small box)

$30 / 100$ 
Supplies

IV tubing (comes with fluid)

Butterfly needles 22 gauge

IV cannula 18 gauge

IV cannula 20 gauge

Disposable syringes $1 \mathrm{cc}$

Disposable syringes $5 \mathrm{cc}$

Disposable syringes $10 \mathrm{cC}$

Needles 18 gauge

Needles 23 gauge $11 / 2$ "

Needles 25 gauge (long dental)

Suture silk 0

Suture: 3-0 monofilament nylon

on FS-2 needle

Suture: 2-0 monofilament nylon

on FS-1 needle

(ethilon =nonabsorbable)

Suture:2-0 vicryl on FS-2

(or chromic absorbable)

Methyl alcohol $400 \mathrm{ml}$ bottles

Scalpel blade \#10 (individual packs)

Formaldehyde tabs $500 \mathrm{mg}$

Sofratulle gauze (10 units/pack)

Adhesive tape rolls (2 inch)

Bandaid packages (100 per package)

Cotton rolls

Gauze $20 \mathrm{mX1m}$

Crepe bandages medium ( 4 inch)

Non-sterile gloves medium-large (pair)

Scrub brush

Razor blades packs of 5

Green books

Batteries D (flashlight)

Batteries C (otoscope)

Medicine packets

Plastic bottles $100 \mathrm{CC}$

Urine dipsticks (WBC, RBC, Protein)

Plastic teaspoons

Plaster of paris $2.7 \mathrm{~m}$ by 15

Otoscope replacement bulbs

NG tube \#18

NG tube \#12

Urihary catheter \#14 with balloon

Urinary catheter $\$ 18$ with balioon

Urinary drainage bag

Plastic bags

Triangular bandages

DDT powder

Umbilical cord tape

Formalin tablet.

$15 / 45$

$4 / 12$

$5 / 15$

$5 / 15$

$7 / 21$

$20 / 60$

$10 / 30$

$30 / 90$

$30 / 100$

$20 / 50$

$5 / 10$

$5 / 15$

$3 / 10$

$2 / 5$

$1 / 3$

$10 / 30$

$10 / 100$

$2 / 5$

$5 / 15$

1/3 packg

$1 / 10$

$3 / 10$

$8 / 24$

$20 / 50$

$2 / 6$

$2 / 5$ packs

$1 / 3$

$5 / 8$

$5 / 8$

$1000 / 3000$

$40 / 100$

1 jar

$50 / 150$

$8 / 24$

$1 / 3$

$2 / 6$

$1 / 3$

$2 / 6$

$2 / 6$

$3 / 9$

$10 / 30$

$1 / 3$

$1 / 3$ box

11 roll 
III. Basic Health Workers (CMC/ACBAR/WHO)

Type of Kedicine

Quantity per $1 / 3$ month

Analgesics

Paracetamol syrup $120 \mathrm{mg} / \mathrm{ml}$

Paracetamol $500 \mathrm{mg}$ tablet

Acetylsalicylic acid tab $300 \mathrm{mg}$

$20 / 60$

$1000 / 3000$

$1500 / 4500$

Dermatologic

Glycerin (emollient for derm)

$60 \mathrm{ml}$.plastic

Methyl Alcohol (1 liter)

Soap

Antiseptic solution - savion

$180 \mathrm{cc} / 540 \mathrm{cc}$

$1 / 3$

$4 / 12$

concentrate or ( $3 \%$ solution)

chlorhexidrine

Algipan or methylated cream (tubes)

DDT powder (1 Box)

Benzyl beneoate 60cc 25\%

Gentian violet crystals

(4.5gm/500ml-18 solution)

Vaseline

Antibacterial cream (polyfax)

or Furacin

Potassium Permanganate

Gastrointestinal

Magnesium trisilicate $500 \mathrm{mg}$ tab

Levamisol (ketrax) or Mebendazole

ORS 1 liter packages

(20 packets per box)

$1 / 3$

$10 / 30$

$1 / 3$

$350 \mathrm{ml} / 1000 \mathrm{ml}$

$9 \mathrm{mg} / 27 \mathrm{mg}$

$400 \mathrm{mg} / 1200 \mathrm{mg}$

$9 \mathrm{mg} / 27 \mathrm{mg}$

$1500 / 4500$

$30 / 90$

$1 / 3$ boxes

Vitamins

Multivitamins tablets

Multivitamins drops

Ferrous sulfate/folic acid

combination tablets

$1500 / 4500$

$20 / 60$

$1000 / 3000$

Antibiotics

Trimethoprim/sulfa tablets

(400-80mg)

Trimethoprim/sulfa syrup $50 \mathrm{ml}$

bottle (200-40mg)

Tetracycline eye ointment

Chloramphenicol eye drops

$+/-$ CHLOROQUINE tablets

$+/$ - CHLOROQUINE syrup $60 \mathrm{ml}$

$2500 / 7500$

$1500 \mathrm{cc} / 4500 \mathrm{cc}$

$10 / 30$

$10 / 30$

$250 / 750$

$500 / 1500 \mathrm{cc}$ 
Supplies

Disposable supplies

Adhesive tape rolls

$2 / 6$

cotton roll

Crepe bandage medium ( 4 inch)

$1 / 3$

Gauze than (20 meters)

Gauze bandage rolls $(15 \mathrm{~cm} \times 5 \mathrm{~cm})$

912 rolls/package

Plastic bags

Pockets for medicines

Bandaid packages (100 per package)

Triangular bandages

Green Book

$4 / 12$

$1 / 3$

$2 / 6$

$10 / 30$

$1000 / 3000$

$1 / 3 \mathrm{pkg}$

$1 / 3$

$1 / 3$

Permanent Equipment (Initial Supply)

General Medical

Thermometers

Arm circumference tapes

2

2

Surgical

Bandage

Surgical scissors (suture)

Forceps without teeth

Curved kelly

Dressing drum

Pressure cooker

Kidney basin, metal

Stainless steel bowl $14^{\prime \prime}$

sterilization box ( $50 \mathrm{ml}$ metal box)

1

2

2

2

2

1

2

1

2

\section{Miscellaneous}

1/2 liter plastic bottle

Teaching aids (posters)

Measuring cup

Safety pins

Triangle bandage

MCH medicines and equipment

* Teaching aids on selected topics

(This will be determined by UNHCR and community recommendations)

- ORS mixture

- Dehydration

- Breast feeding

- Immunization

- Health education

- Nutrition

- Environmental health 
Please note: This appendix was appendix $A 2$ in the first edition of the ACBAR Health standards and Guidelines and was prepared by Dr. Sharon McDonnell. It has been used with some adaptations to give a background to the rationale behind the initial mid-level health worker medicine 1 ist and numbers for supply. Numbers given do not always correspond exactly to those of the present mid-level health worker medicine list.

ESTIMATION OF IUMBERS FOR SUPPLY OF MID LEVEL HEALTH WORKERS IN CROSS-BORDER MEDICAL PROGRAMS

This is an explanation of the numbers for in-country supply of medications. It accompanies the standard medication list which has been finalized by community consensus. There have been many attempts to make the amounts of medications provided a rational decision process. For many reasons this is difficult. The following decisions were made in order to consider the amounts:

1. The average number of patients seen per clinic with 2 midlevel or physician practitioners in place was estimated at 1,000 (range stated as 800-1,500 per month.

2. The in-country statistics from IMC, CMC and MSF were used for percentages of diseases or health problems. There is a reassuring consistency between these sources in terms of percentages.

3. Using the treatment protocol standards for training, a standard list of essential medications is presented.

4. The health problems were sorted into groups based on the standard treatments. Thus, a total percentage was obtained for each medication. From this a monthly supply number was derived and extrapolated into larger quantities for longer supply periods, i.e. 3 and 6 months.

5. The numbers for standard treatments were based on adult dosages for the most part due to difficulty extricating numbers of chlldren per health problem. This admittedly could result in a larger supply volume but is considered acceptabla.

6. Syrups are supplied for children under the age of three. The amounts are calculated based on community data available for this age group cross border, as well as refugee experiences. The decision is to use where possible rational percentages but to err on the side of under supply. This accompanies a group effort in the training programs to teach medication administration biased toward use of tablets and capisules. The recognition, of cultural preference for syrups and injectable forins is well recognized. This reality is calculated in with the transportation and safety variables. 
7. There has been expansion of the data of the greenbook (patient log book) by CMC. A report published in October 1990 gives information on 15,000 entries and 27,000 entries have been reached by June 1991. Different data can be extracted on request to CMC, such as prevalence of disease, patient profile (age and sex), gross report of drug usage, etc.

An initial disclaimer for the information which follows must be stated. The retrieval of data from Afghanistan is problematic. The issues regarding the relevance and reliability of the data that is collected is obvious to those who have been working with crossborder training. We have relied here on green book data as well as exit interviews with returning medics.

Gastro-intestinal

1. Hyperacidity - mean percentage $=7 \%$. Results in 70 courses per month. This is considered to be generally over-diagnosed. Course is 5-10 days with approximately 40 tablets dispensed. Results in 2800-4000/month as reasonable. Magnesium trisilicate is first choice. Our supply of $3000 /$ month led to an even division of either overstock or understock comments on exit interview. CMC treatment protocol states 1 tab qid for 1-2 weeks. Will use one week as standard.

2. Abdominal parasites (worms) - mean percentage $=10 \%$. Thus, 100 cases per month. $100 \%$ are given Mebendazole as first line resulting in 100 doses ( 6 tabs each). thus need 500 tab/month. This number accounts for pediatric doses and is more reasonable package number. $10 \%$ were to be treated with Niclosamide based on protocols in drug estimation model. Thus 10 doses/month ( 4 tabs per dose) equals 40 tab/month. Due to cost of Niclosamide (7500 rupees per 1000 tablets) and the considered low incidence of taenia/H. Nana it was at first decided not to include this medicine on standard list. Mebendazole is effective at higher doses (approximately three times) against taenia. Returning patients with suspicion of segmented worms will receive higher dose of mebendazole.

3. Diarrhoea and other causes of dehydration: average of 8-10z reported. Results in 100 cases per month. Standard of 2 packages per patient. 400 packages per month of ORS (would rather err on high side).

\section{Antibiotics}

4. Metronidazole - includes gynecologic infections as well as amebiasis, giardiasis. Approximately $5 \%$ average for diarrhoea $=50$ patients per month. of those with diarrhoea have considered $40 \%$ in this category and requiring antibiotic treatment. Dosages very different for metronidazole for the 2 diagnoses in most of the teaching programs. No way to 
document the actual diagnosis. Use of pre-war epidemiology results in wide variation (German geo-medical survey). Have followed whO guidelines and considered the treatment of both as 3 tab tid times 5 days. This results in an average patient dose of 45 tablets. For the $2 \%$ (or 20 patients) that would be treated with this regimen the result is 900 tablets per month. clearly this does not separate children. The entire category of OB/GYN is less or equal to $1 \%$ in all groups considered and not divided into infectious vs other problems. For trichomonal infections the protocol is to treat as a couple. Projection to 2 cases per month (results in 4 patients if trichomonas) at 10 tabs per patient $=80$ tabs. this allows adequate coverage of Gardnerella also. this is used for vaginal infections which are unresponsive to mycostatin, gentian violet or are historically suggestive. Recommend 1000/month.

5. Malaria. Pre-war German survey showed an incidence of $1 \%$ which decreased to $0.4 \%$ after malaria eradication efforts. However, malaria prevalence is thought to be increasing. Of note:

A. When possible to supply according to area and time of year the relevant issues include a seasonal variation which is higher in October and November. Generally there is no malaria above 6000 feet.

B. Incidence vs prevalence. Demonstrated in papers from pre-war and in refugee camps.

c. The war has virtually stopped malaria control in Afghanistan. There may be an increase in the number of cases resulting from this.

D. There has long been the belief that this is overdiagnosed because of community insistence on the dispensing of chloroquine for many fevers. Most instances the diagnosis is not confirmed with blood smear. The decision was made to consider $4 \%$ of 1000 patients/month. This results in 40 patients total. Anticipate treat $3 / 4$ as adults and $1 / 4$ as children. An even smaller percentage in 1-4 yr range to calculate syrup. 40 adults with 10 pills/course $=400$ pills (some children may result in error on oversupply). 2 children (using the 1-4 age range as standard for dose) per month calculated that will require syrup. Need 5 teaspoons per patient per month (10 mg/kg initial followed by $5 \mathrm{mg} / \mathrm{kg}$ ) $=10$ teaspoons per month for 2 patients $=50 \mathrm{ml}$. Recommend supply of $160 \mathrm{ml}$ bottle per month. Include $2 \cdot$ plastic bottles for dispensing.

6. Chloramphenicol. Diagnoses for which this is recommended are all uncommon. Altogether with meningitis, severe soft tissue infections and intra-abdominal infections, puerperal sepsis, pneumonia and typhoid estimate $10 \%$ of all cases per 1000 patients per month. Many of these diagnoses are mentioned in 
other medicine protocols as first or second line. Will estimate for 5 cases per month dividing into 2 soft tissue infections per month, 1 severe pneumonia, 1 typhoid, and 1 other severe infection. All represent 10 day courses except typhoid. We split the forms available based on those patients quite likely to require injectable form for at least 2 doses $=20$ ampules. The changing to oral forms (either syrup or tablets id divided equaliy. Present supply is $7: 0$ tabs per month and $400 \mathrm{cc}$ of syrup.

7. Griseofulvin - for the treatment of tinea capitus. Reported from $0.58-25$ all cases. For those appropriate to receive this medication we used $0.2 \%$ for average. Results in 2 cases per month. Treatment protocol allows for either single dose (24 grams) or more conservative longer course for 4 to 6 weeks (10 mg/kg divided qd to qid). This is primarily a disease of children.

8. Tetracycline - indicated for:

Bronchitis in men - 30 cases/month $(1 / 2$ of all bronchitis in adults) times 10 day course results in 1200 tablets/month.

Trachoma - have calculated first line as Sulphamethoxazole/Trimethoprim with all cases treated. This is second line.

Cholera - no cases calculated.

Urethritis - Infectious urethritis is markedly over-diagnosed ( 1 out of 22 cases of male dysuria had discharge). The actual impact of tetracycline usage from urethritis will be 0 .

Total of 1000 tablets per month.

9. Erythromycin - good drug but restricted because of cost. Used in penicillin allergic patients. Estimate use for approximately $0.1 \%$ resulting in patients per month at average of 7 day course $=28$ tablets per month.

10. Benzathine Penicillin - indication is strep pharyngitis in rheumatic fever prophylaxis. Have used average of $3 \%$. The percentage of patients that would fit criteria for this regimen estimated as $1 \%$ upper 1 imit $=10$ cases per month $=10$ vials.

11. Procaine Penicillin - injectable form indicated for severe pneumonia and severe skin infections (cellulitis) first line foliowed by chloramphenicol as needed for either. This may be used as the initial form of Penicillin before changing po.

12. Penicillin $\mathrm{V}$ tablets - indications:

Impetigo - will use as mean $2.5 \%$ resulting in 25 cases/month for 5 day course. For average child need $125 \mathrm{mg}$ ( $1 / 2$ of 250 $\mathrm{mg}$ tab) qid $=10$ tablets per patient $=250 \mathrm{tab} / \mathrm{month}$.

This is also second line treatment for pharyngitis (will consider 4 patients per month). Course of 40 tablets $=160$. 
First line for adult ear infections - 18 of all cases or $1 \mathrm{C}$ patients per month: Course is $500 \mathrm{mg}$ (250 $\mathrm{mg}$ tabs) qid times 1 week $=56$ tablets.

Tooth abscess and severe gingivitis may be treated oral penicillin. Data shows approximately 5 patients per month. course is $500 \mathrm{mg}$ ( 2 tabs) qid times 3 days (tooth extraction also indicated which shortens treatment course). Total is 100 tabs per: month.

Total $560+160+100=820$, will round to 100 tabs. (Current supply is 996 tablets due to packaging - 12 in a box.)

13. Epinephrine - indicated for anaphylaxis. Fleetingly small numbers reported by all. Will go with very mall supply for emergencies.

Gastro-intestinal

See page 208 for initial discussion of this section.

14. Hyoscine compound tabs $(10 \mathrm{mg})$ : indicated for renal colic, colicky abdominal pain. These numbers are difficult to extract. For all groups we found 0.1 as average for the two diagnoses. This medication is also used for abdominal cramping associated with various complaints. course is variable with tid dose for 3 days. This medication is popular with the population and local providers. This estimate may appear conservative (previous supply much higher) because of lack of evidence for efficacy.

15. Promethazine - the sole diagnosis of vomiting is rare. The data is hidden in other diagnoses which cause nausea and vomiting and difficult to quantify. The group has decided to include two forms oral and injectable. The division into the two forms is currently arbitrary.

\section{Analgesics and Anti-pyretics}

16. Aspirin (for adults only) - indications: pharyngitis, URI, headache, otitis, tooth pain, acute joint pain and a percentage of chronic joint pain, fever of many causes (pelvic infections, measles, malaria, chickenpox, typhoid, hepatitis), other musculo-skeletal pain (sprains and strains), pain associated with minor procedures (I\&D, debridement). Tutal of $22 \%$ after review of all. data. The difference in course based on indication is significant when comparing antiinflammatory versus anti-pyretic or analgesics with the latter two being significantly shorter. For anti-inflammatory or significant musculo-skeletal pain the course is $40 \mathrm{tab}$. This is used in 8\% of all presentations. $11 \%$ of patients will present with problems that require the combined (analgesic, anti-inflammatory, anti-pyretic) effects of ASA for a 2- day course. The remaining $3 \%$ of patients who need a mild 